\title{
An integrated computer-based timber cruising system for Appalachian hardwoods
}

Jingxin Wang

West Virginia University

Follow this and additional works at: https://researchrepository.wvu.edu/etd

\section{Recommended Citation}

Wang, Jingxin, "An integrated computer-based timber cruising system for Appalachian hardwoods" (2005). Graduate Theses, Dissertations, and Problem Reports. 3222.

https://researchrepository.wvu.edu/etd/3222

This Thesis is protected by copyright and/or related rights. It has been brought to you by the The Research Repository @ WVU with permission from the rights-holder(s). You are free to use this Thesis in any way that is permitted by the copyright and related rights legislation that applies to your use. For other uses you must obtain permission from the rights-holder(s) directly, unless additional rights are indicated by a Creative Commons license in the record and/ or on the work itself. This Thesis has been accepted for inclusion in WVU Graduate Theses, Dissertations, and Problem Reports collection by an authorized administrator of The Research Repository @ WVU. For more information, please contact researchrepository@mail.wvu.edu. 


\title{
An Integrated Computer-Based Timber Cruising System for Appalachian Hardwoods
}

\author{
Jingxin Wang \\ Thesis submitted to the \\ College of Engineering and Mineral Resources \\ at West Virginia University \\ in partial fulfillment of the requirements \\ for the degree of \\ Master of Science \\ in \\ Computer Science
}

Bojan Cukic, Ph.D., Chair

Elaine Eschen, Ph.D.

Powsiri Klinkhachorn, Ph.D.

Lane Department of Computer Science and Electrical Engineering

Morgantown, West Virginia

2005

Keywords: Timber Cruise, Forest Inventory, Computer Modeling, Database Design, Appalachian Hardwoods, Forest Management. 


\begin{abstract}
An Integrated Computer-Based Timber Cruising System for Appalachian Hardwoods
\end{abstract}

Jingxin Wang

In order to facilitate resource data collection and processing, an integrated computer-based timber cruising system was modeled and developed based on Microsoft Component Object Model (COM) and Objected-Oriented Programming (OOP) techniques. The system consists of three components - handheld data collection system, data transfer, and data analysis, all of which are stand-alone objects. The handheld system, which is Windows CE based, was used to collect overstory and understory tree data in the field. Data transfer and analysis components reside on a desktop PC and were used to synchronize cruising data from handheld PCs, analyze data and generate reports. A relational data model was implemented via MS Access to store cruising data in the system. All components have been successfully tested and used in the large-scale inventory of West Virginia's state and West Virginia University research forests, and could be adapted for use in related forest inventory projects. 


\section{DEDICATIONS}

I would like to dedicate this thesis to my wife, son, and late parents for their love and endless and unselfish support throughout my life and career. 


\section{ACKNOWLEDGEMENTS}

I would like to thank my advisory committee: Drs. Bojan Cukic, Elaine Eschen, and Powsiri Klinkhachorn for sharing their time, perspective suggestions, and wisdom throughout my graduate study. Special thank goes to Dr. Bojan Cukic for taking on the duty of being my major professor. I enjoyed working with them and have learnt a lot in computer science, which will be definitely beneficial to my academic career.

I am grateful to my colleagues: Dr. Joe McNeel, Mr. Shawn Grushecky, Dr. John Brooks, and others in the Division of Forestry at West Virginia University. I thank them for the friendship, cooperation, and impressive discussions.

The last but not the least, I would like to pay my greatest appreciation to my wife, Xiaoming, and son, Jerry Shida, for their support, patience, and sacrifice. 


\section{TABLE OF CONTENTS}

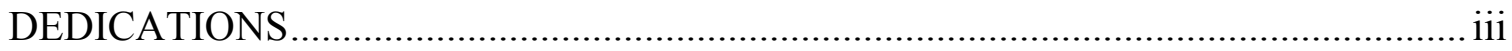

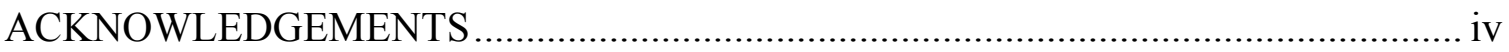

LIST OF FIGURES ………………………….................................................... vii

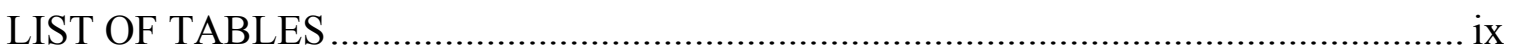

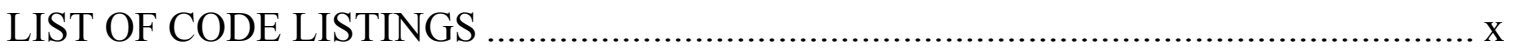

LIST OF SYMBOLS/NOMENCLATURE ...............................................................

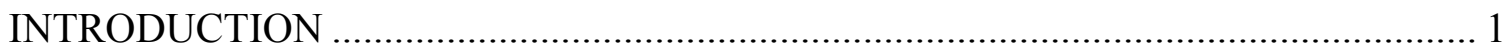

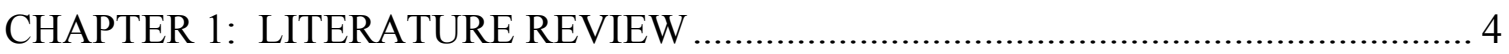

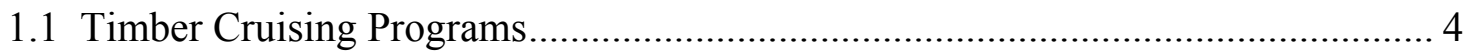

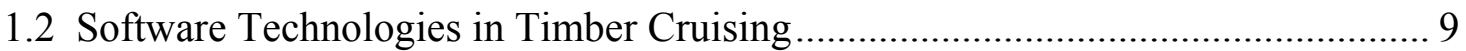

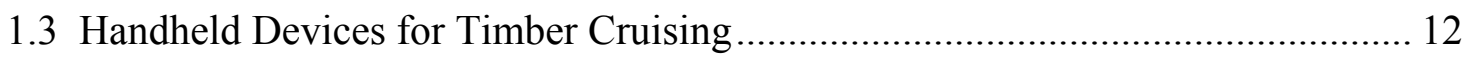

CHAPTER 2: TIMBER CRUISING DESIGN AND SYSTEM STRUCTURE.............. 17

2.1 Requirements of Timber Cruising .................................................................. 17

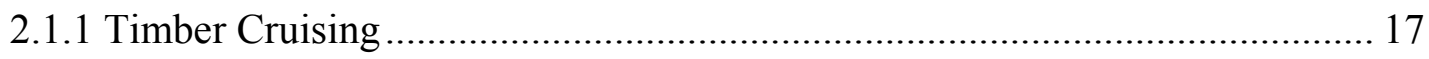

2.1.2 Cruising Statistics ………………………………................................. 20

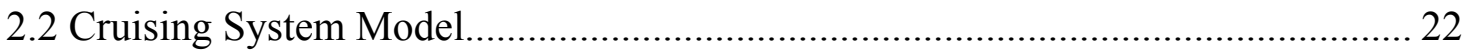

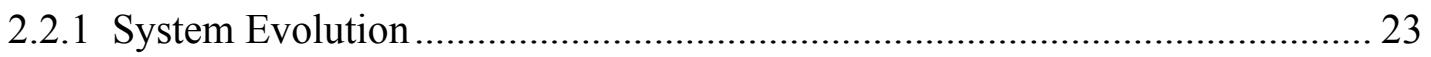

2.2.2 Functional Requirements ........................................................................ 23

2.3 Cruising System Design............................................................................... 25

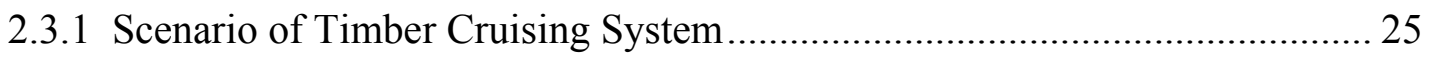

2.3.2 Event Flow and State Diagrams................................................................ 26

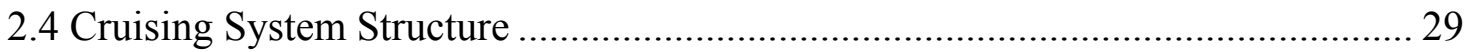

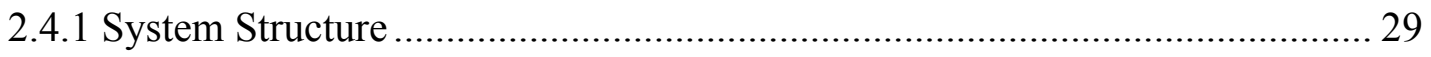

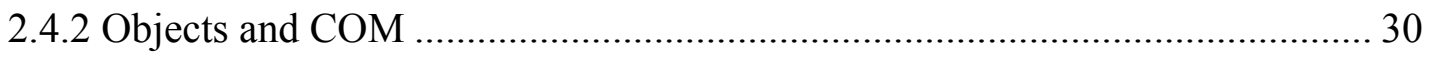

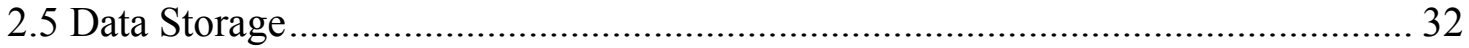

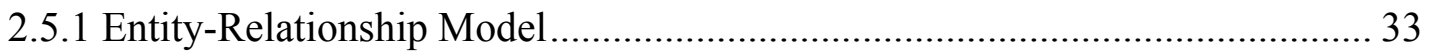

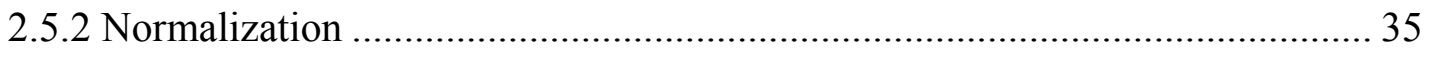

CHAPTER 3: CRUISING SYSTEM IMPLEMENTATION .......................................... 40

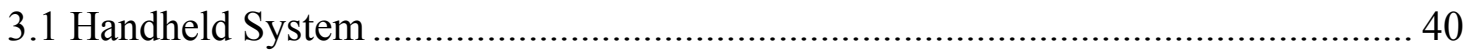


3.1.1 Handheld System Implementation ...................................................................... 40

3.1.2 Algorithm for Calculating Cull Percent.......................................................... 41

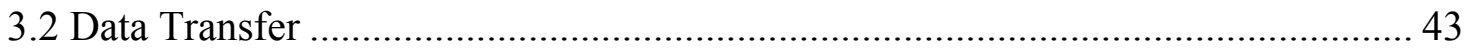

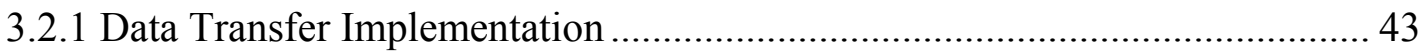

3.2.2. Algorithm for Transferring Cruising Data..................................................... 45

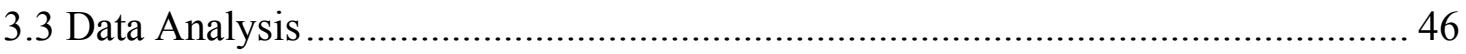

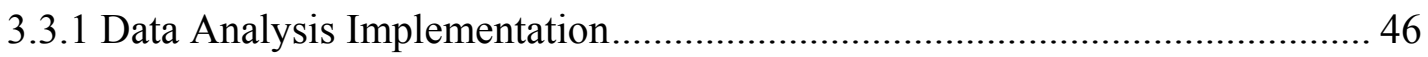

3.3.2 Algorithms for Volume Summary ……………............................................. 48

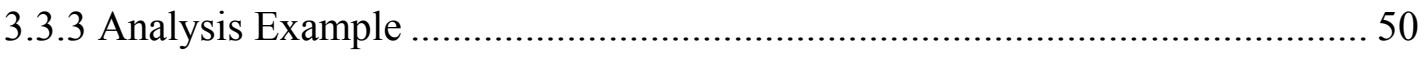

CHAPTER 4: CONCLUSIONS AND DISCUSSION ............................................... 52

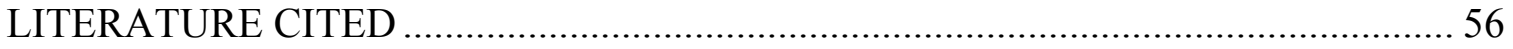

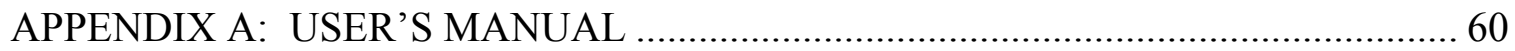

APPENDIX B: CODE LISTINGS OF SOME MAJOR FUNCTIONS ……………….... 73 


\section{LIST OF FIGURES}

Figure 2.1. Typical layouts of plots in a systematic line-plot and a sampling point.....17

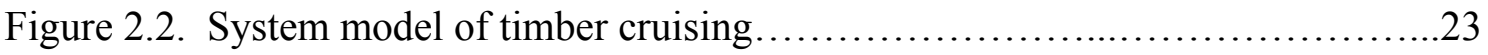

Figure 2.3. Event trace for a scenario of timber cruising .........................27

Figure 2.4. Event flow diagram of the integrated timber cruising system .............28

Figure 2.5. State diagram for interface of the integrated timber cruising system........28

Figure 2.6. State diagram for application in the integrated timber cruising system......29

Figure 2.7. State diagram for data store in the integrated timber cruising system ......29

Figure 2.8. Structure of the integrated timber cruising system...................... 30

Figure 2.9. COM model of timber cruising system .............................. 32

Figure 2.10. ER data model of the integrated timber cruising system..................34

Figure 2.11. Data items and FDs for the timber cruising database ...................36

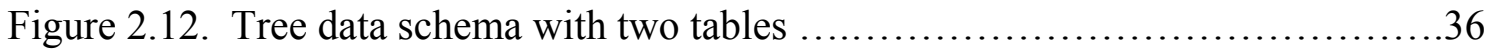

Figure 3.1. Architecture of the integrated timber cruising system....................42

Figure A.1. Field data collection.......................................60

Figure A.2. Transect data collection.........................................61

Figure A.3. Edit trees......................................................61

Figure A.4. Data transfer dialog box......................................62

Figure A.5. Edit plot, trees, and transects..................................62

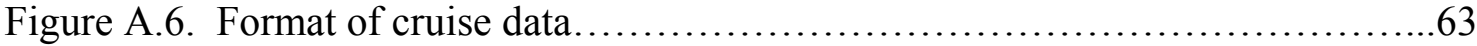

Figure A.7. Define a data range associated with data object......................64

Figure A.8. Menu and tool bars of WVU Cruise...............................64

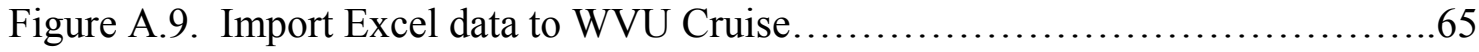

Figure A.10. Load cruise data for analysis.................................65

Figure A.11. Cruise design window.......................................66

Figure A.12. Edit Girard form class by species................................66

Figure A.13. Volume summary on both per acre basis and tract basis...............67

Figure A.14. Report of merchantable volume summary.........................68

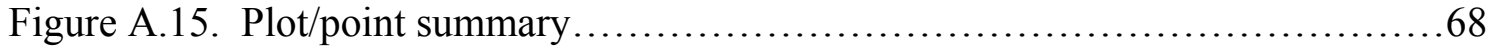

Figure A.16. Report of plot summary .....................................69 
Figure A.17. Cruise statistics summary..................................69

Figure A.18. Report of cruise statistics.................................... 70

Figure A.19. Cruise design window..................................... 70

Figure A.20. Stand and stock table......................................... 71

Figure A.21. Report of stand and stock table................................... 71

Figure A.22. Report of stand and stock table by species and DBH.................72 


\section{LIST OF TABLES}

Table 3.1 Merchantable volume summary per acre for a tract of 80 acres on the WVU Research Forest....................................................50

Table 3.2. Timber cruising statistics on per acre basis for a tract of 80 acres on the WVU Research Forest......................................................51 


\section{LIST OF CODE LISTINGS}

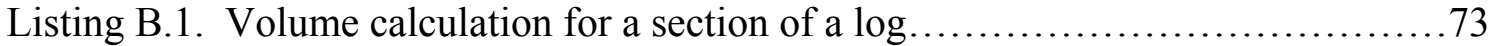

Listing B.2. Cull percent calculation........................................ 74

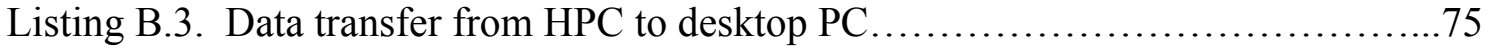

Listing B.4. Transfer plot data from HPC to desktop PC............................ 76

Listing B.5. Volume calculation for individual tree............................. 77

Listing B.6. Volume summary in the format of stand and stock table..................78

Listing B.7. Cruise statistics for a volume estimator............................ 79 


\section{LIST OF SYMBOLS/NOMENCLATURE}

1. ADO ActiveX Data Object

2. BA basal area in cubic feet

3. CFV cubic foot volume of trees

4. COM component object model

5. DAO Data Access Object

6. DBFV Doyle board foot volume of trees

7. DBH diameter at breast height in inches

8. DCOM distributed COM

9. ER entity-relationship

10. FD functional dependency

11. GFC Girard form class

12. GUI graphical user interface

13. HPC handheld PC

14. IBFV International $1 / 4$ " board foot volume of trees

15. MHT merchantable height of a tree in the number of 16 -foot logs

16. $\mathrm{O}(\mathrm{n}) \quad$ O-notation represents asymptotic upper bound

17. OOP object-oriented programming

18. OMT object-oriented modeling technique

19. QMD quadratic mean diameter

20. SQL structured query language

21. THT total height of a tree in feet

22. TPA trees per acre

23. VB Microsoft Visual Basic

24. VRP variable radius plot or point sampling plot 


\section{INTRODUCTION}

Timber cruising is the process of measuring and estimating volumes of standing timbers on a fixed area of forestland, which involves the establishment of sample plots in a forest and accurately assessing the quantity and quality of the trees within the plots. The analysis and report of the detailed data collected during timber cruising process is referred to as a forest inventory. There are three major methods that can be used to design the cruises: $100 \%$ tally, fixed area plots, and point sampling. In most cases, measuring each and every tree within a forest with $100 \%$ tally would be an overwhelming task, if not outright possible (Ben Meadows Company 2003). For this reason, most foresters would prefer to use sampling methods. Fixed area plot refers to sampling an area of a predetermined size that can vary depending on the forester's requirements. On the other hand, point sampling, rather than using a plot of defined size, the forester measures all trees that can be seen in a $360^{\circ}$ circle around the point where the forester is standing.

Traditionally, timber cruising was done manually by a one- or two-person crew with tally sheets and pencils for recording cruising tree data in the field. The use of computer programs in the forest industry can reduce costs, save time, and aid extensively in the practice of processing timber inventory data (Rennie 1991). Timber cruising and forest inventory are two very important aspects of forestry, and using a computer program to determine timber cruise and forest inventory design and plot layout can minimize time in the field and result in considerable savings in time and money (Wiant and Gambill 1985). 
During the winter of 2002, we began a cooperative project with the West Virginia Division of Forestry that included the re-inventory of the forest resources on state forests in West Virginia, USA. This was a rather large undertaking, with approximately 70,000 acres needing to be inventoried. Because of the magnitude of data to be collected, we wanted to make certain that the data handling aspects of the project would be especially efficient. We were looking for a robust system that would allow for easy field data collection, but also incorporate a powerful backend system for data storage, retrieval and analysis.

Although there were many systems that could have been used for this project, we did not feel that any of the options fit our situation. Due to the specific requirements and the sheer size of the inventory, the development of an integrated timber cruising system for the state forests in West Virginia was necessary. This study discusses the modeling process and development of the timber cruising system with reference to object-oriented design and entity-relationship (ER) data modeling techniques.

Specifically, the objectives of this study were to:

(1) model an integrated timber cruising system using Component Object Modeling (COM) and Object Oriented Programming (OOP) techniques,

(2) develop a handheld system with MS Windows CE based graphical user interface (GUI) for timber cruising in the field,

(3) adapt a relational data model to hold cruising data on both handheld and desktop PC, 
(4) implement data transfer component on desktop PC to copy or synchronize cruising data using ActiveX Data Object (ADO), and

(5) provide a data analysis component to summarize cruising data and generate cruising reports. 


\section{CHAPTER 1: LITERATURE REVIEW}

\subsection{Timber Cruising Programs}

Computer programs have been developed for many applications in forestry from the development of species-specific optimal thinning schedules to stand generation and harvesting simulations. Farrar (1981) developed an in situ stand generator for use in harvesting machine simulators. He validated the model by comparing characteristics of trees created by the generator to those of the trees in the parent forest model. OAKSIM, an individual-tree growth and yield simulator, was developed for managed, even-aged, upland oak stands in the early of 1980s' (Hilt 1985). OAKSIM was written in FORTRAN and especially designed to evaluate stand management alternatives on a mainframe computer. A program called YPOP was developed for evaluating thinning alternatives in natural stands of yellow-poplar (Brooks and Vodak 1986). The YPOP was written in Applesoft BASIC, which makes both the physical and economic data for thinning accessible to the forest manager and landowner for investment analysis. Rose and Chen (1995) developed a computer program REDPTHIN for scheduling red pine plantation in Lake States. It used a dynamic programming algorithm to derive optimal thinning schedules while maximizing total volume production for any initial stand condition of age, site, and basal area stocking. Based on 20 -year records from a permanent-plot regional growth study, Farrar and Matney (1994) developed a stand growth simulator for even-aged stands of longleaf pine in the South's east gulf region. Their system consists of two parts: (1) a three-parameter, Weibull-recovery system to simulate stand development up to the first thinning and (2) a parameter-free, least-squares 
adjustment, dbh-distribution recovery system to simulate stand development after thinning.

Computer simulation has proven to be sufficiently comprehensive to handle the various types of problems envisioned in forest operations and has been used for linking the variable components into production and cost analysis (Goulet et al. 1979, Stuart 1981). Simulation also provides an accepted method of evaluating a wide range of system configurations, operating environments, and timber utilizations. Reisinger et al. (1988) compared three computer-based programs for analyzing harvesting operations: Auburn Harvesting Analyzer, Harvesting System Analyzer, and Harvesting System Simulator. They indicated that the three programs produced comparable results using realistic system data, even though there seems to be some inconsistency in the way harvesting costs and productivity are computed. These three programs should help forest engineers and logging contractors make better business decisions, reduce costs, and improve operating efficiency through more detailed analysis of harvesting operations. More recently, an interactive simulation program that includes a stand generator was used to evaluate the relationships among stands, equipment, and harvest prescriptions that are typical of USDA Forest Service timber sales (Wang and Greene 1999). Earlier, Wang et al. (1998) used interactive simulation to examine the interactions of a variety of stand, harvest, and machine features. They found that this method was labor intensive, particularly for simulating skidding and forwarding. Simulating chain saw felling on a 0.16-ha plot took 10 to 35 minutes depending on stand density and harvest method, while simulated skidding on a 7.84-ha tract took 40-90 minutes depending on stand, harvest, and machine factors. It seems essential to model harvesting numerically, especially for 
skidding or forwarding with uniform patterns. Accordingly, Wang and LeDoux (2003) develop a numerical ground-based timber harvesting simulation model, validate the model using field study data, and perform an intensive experiment for evaluating the interaction of stand and machine types, harvest treatments, and extraction patterns on production, cost, and traffic intensity.

A computer-based timber cruising and forest inventory system could help landowners and resource managers protect forest resources and might assist in the management of timberlands (Blinn and Vandenberg-Daves 1993). Several programs have been developed in the area of timber cruising and forest inventory from the simple calculator-assisted procedures for marking stands and rapid sawtimber/pulpwood estimates to relatively complicated handheld- or PC-based programs for yield curve design and cruising data collection and analysis (Wiant 1990). Wiant and Gambill (1985) developed a program to minimize timber cruise field time by determining the optimal basal area factor or plot size. This package was written in BASIC and run under the DOS environment. The program requires that the user indicate whether board foot or pulpwood volume is desired on plots or points and other information needs to be entered including the tract size, the average time spent on each plot or point, walking speed, and sampling error.

Moser and Raney (1990) developed the marking procedures of uneven-aged stands for the Hewlett-Packard 41C handheld calculator. This calculator program consists of a main module and three utility modules. The main module allows the forester to set dbh range of trees for marking and set the cut probability for each dbh class. The three utility modules provide status and summary information. 
Rennie (1991) showed new uses of $\mathrm{SAS}^{\odot}$ for processing timber inventory data. $\mathrm{The} \mathrm{SAS}^{\odot}$ routines allow the forester to write a program that enables the efficient design of a forest inventory to meet specified objectives. It is extremely versatile in input and output and very powerful in data manipulation. There are two steps needed for processing of forest inventory data with SAS. One is for data input, merging, subsetting, transforming, while the second step conducts data manipulation and statistical calculations.

The Private Lands Information System (PLIS) was developed to provide field foresters with access to a map-based inventory of nonindustrial private forest landowners' timberlands in Minnesota (Blinn and Vandenberg-Daves 1993). The PLIS includes three basic components - a database, software, and hardware. The database holds not only data for individual timber stands, but also spatial data for stand or property boundaries.

The forester's yield curve designer (FYCD) was developed with Visual Basic and it runs under the Windows environment with a graphical user interface (GUI) (MacLean and Porter 1998). FYCD addressed two separate uses related to yield curve: (1) the development of volume yield curves from stand growth model output and plot data and (2) the access, use, and validation of the complex yield curve data sets used in management plans.

Reports need to be generated once cruising/inventory data are processed. Using a database management system, such as dBASE, could fulfill the need of generating forest inventory reports (Belli et al. 1987). Belli et al. (1987) stored tabular data such as site descriptions, plot-level data and tree-level data in a database. Reports generated by the 
database management system included stand/stock tables, land use summaries and recalculation of individual tree volume estimates from specified input file (Belli et al. 1987).

Information on timber cruising programs is also available on the Internet. The USDA Forest Service provides four Window-based generic programs - Check Cruise, Cruise Design, Timber Theft/Local Volume Table, and Traverse. (http://www.fs.fed.us/fmsc/measure/cruising/othersoftware.php). The Check Cruise program is used to compare measurements and volumes between an original cruise and a check cruise, while the Cruise Design program was developed to help cruisers design timber cruises and meet predetermined sampling errors. The Timber Theft/Local Volume program is not only used to determine the volume of a tree using regression techniques, but also to estimate the removed volume in a theft case or create local volume tables based on cruise information. The Traverse program uses distances and compass bearing to construct maps and determine the acreage within the traversed area. Canal Forest Resources has developed Cypress ${ }^{\mathrm{TM}}$, an advanced timberland inventory and investment management system (http://www.canalforest.com/software.htm). It offers silvicultural, land management and investment information to timberland investors through secure, web-based technology.

A forest inventory software program named TwoDog has been developed and provided by Foresters Incorporated (http://foresters-inc.com/). It is a comprehensive forest inventory application for field and desktop computers. Office Dog runs on the PC and provides method setup, comprehensive data analysis, and report generation, while Field Dog runs on the highest-quality field computers, to provide fast, reliable data entry 
and up-to-the-minute calculations in any environment, incurring productive and reliable data collection Sampling options are also provided in the package.

Timber Cruise (T-Cruise) is a cruising program with heuristic solutions (www.forsonline.org/tcruise.htm). The program accepts data plot, point, double point, or segmented trip cruises of stratified, or non-stratified tracts, and prepares reports. Cruise data can be entered from tally sheets using T-Cruise built-in spreadsheet interface.

\subsection{Software Technologies in Timber Cruising}

The earlier timber cruising programs were developed with BASIC or FOTRAN under DOS environment. Both BASIC and FORTRAN are so-called traditional, procedural programming languages, which execution always starts with the first line of code and follows a predefined path through the application, calling procedures as needed. A version of HotPaw ${ }^{\mathrm{TM}}$ Basic was later used to develop the cruising program for Palm Pilots on the Palm OS handheld (www.geocities.com/harryvwiant/). A timber cruise and forest inventory program named CRUISE was especially developed to process cruise data into meaningful cruise statistics in the field. These earlier versions of timber cruising programs used either a command line or a menu driven interface for input. Output could be an ASCII file or a screen display.

Visual Basic (VB) is currently a popular language to program the timber cruising and inventory. Unlike procedural programming languages, Visual Basic is an eventdriven programming language (Microsoft Corporation 1998). In an event-driven application, the code does not follow a predetermined path and it executes different code sections in response to events that can be triggered by the user's actions, messages from the system, or event from the application itself. The built-in controls, functions and 
libraries in Visual Basic provide a complete set of tools to simplify the application development.

Since the early days of Windows CE, development languages for mobile devices have largely been limited to $\mathrm{C}++$ and assembly (Tacke and Bassett 2002). Although this allowed for great access to low-level functions, it meant that rapid application development was difficult. After Windows CE 2.0 was released, the Visual Basic for Windows CE (VBCE) Toolkit was released. The VBCE Toolkit is Microsoft's answer to simplifying the process of creating applications for handheld computers (Roof 1998). By augmenting their popular Visual Basic product with the VBCE add-in, Microsoft has provided a tool that enables anyone experienced with Visual Basic to immediately begin to develop handheld applications. VBCE is a new programming language. However, it does share a common core language with VB and has many differences from VB. Major differences include that (1) VB and VBCE use different ActiveX controls, (2) there is a single data type in VBCE, and (3) VBCE is limited to a single .bas module.

In April 2000, Microsoft released eMbedded Visual Tools 3.0 (eVT), a standalone tool suite that allows you to develop applications for Windows CE based Pocket PC, Palm-size PC, and Handheld PCs (Mitchell 2001). This was a boon for programmers since eVT encompasses all the tools required for Windows CE application development. This refresh of the eMbedded Visual Tools 3.0 contains Microsoft eMbedded Visual C++® 3.0; Microsoft eMbedded Visual Basic 3.0®, and now includes the Software Development Kits (SDKs) for Pocket PC 2002 and Smartphone 2002. This download does not contain the SDKs for Palm Size PC or Handheld PC. eMbedded Visual Basic (eVB) offers the easiest path to developing Pocket PC applications and system 
components for Windows ${ }^{\circledR}$ Powered devices, including the Pocket PC and Smartphone. However, $\mathrm{eVB}$ is an interpreted language, which means the eVB program is executed by the runtime environment.

Recent development of internet technologies allow us to develop web-based timber cruising programs. The Cypress ${ }^{\mathrm{TM}}$ system developed by Canal Forest Resources (http://www.canalforest.com/software.htm) allow users to access the system via secure, web-based application and can simultaneously utilize timber inventory and spatial data, and perform timber growth simulations and other economic analyses. Appalachian Hardwood Center in the Division of Forestry at West Virginia University has developed a web-based timber cruising system for landowners or others in West Virginia (http://www.ahc.caf.wvu.edu/cruiser/). The web-based program can perform field data entry, cruising data manipulation, and cruising data reports. Active Server pages (ASP) is a powerful server-based technology from Microsoft, designed to create dynamic and interactive HTML pages (Buser et al. 1999), which has been popularly used in forestry applications including timber cruising. ASP can integrate with the latest versions of new technologies such as ActiveX Data Objects and Components Object Model (COM).

Microsoft COM (Component Object Model) technology in the Microsoft Windows-family of Operating Systems enables software components to communicate (Lewis 1999, www.microsoft.com/com/default.mspx). COM is used by developers to create re-usable software components, link components together to build applications, and take advantage of Windows services. The family of COM technologies includes COM+, Distributed COM (DCOM) and ActiveX ${ }^{\circledR}$ Controls. Traditional operating systems only dealt with application binaries and not components. Components developed 
using Microsoft's COM provide a way by which two objects in different object spaces or networks, could talk together by calling each other's methods.

COM is used in applications such as the Microsoft Office Family of products. For example COM OLE technology allows Word documents to dynamically link to data in Excel spreadsheets and COM Automation allows users to build scripts in their applications to perform repetitive tasks or control one application from another. Application of COM in forestry-related software appears to be lack and needs to be studied.

Windows CE 4.1 or later is considered as Windows CE .NET, which can run MS Visual Studio .NET software applications. The core programming interface is the .NET framework on desktop and the .NET compact framework on mobile devices such as pocket PCs and handheld PCs. The .NET compact framework brings the technologies of the .NET framework to the mobile and embedded world of Windows CE (Yao and Durant 2004). The .NET compact framework supports Visual Basic .NET is a much better alternative for mobile device application development and will eventually replace the eVB (Yao and Durant 2004).

\subsection{Handheld Devices for Timber Cruising}

There are many types of handheld devices or personal digital assistants (PDAs) available for timber cruising program. Pocket PC refers to a device that fits in the palm of your hand and runs the latest Windows CE operation system. The programs preinstalled include Pocket Word, Pocket Excel, Pocket Access, and others. Palm-size 
PC (PPC) is the first and second generation keyboard less PDA and is not normally used to describe a Pocket PC. Handheld PC (HPC) refers to a Windows CE PDA with a 640x240 or larger display and built-in keyboard (www.cewindows.net/wce/gettingstarted.htm) while HPC Pro and HPC 2000 are the $3^{\text {rd }}$ and $4^{\text {th }}$ generation of HPC.

Several major characteristics that should be considered when selecting a HPC for application include size/weight, input methods, features, uses, application programs. Specifically, for forestry applications, HPCs are being used in the field. The devices should be rugged, water resistant, and durable under extreme weather conditions. A previous study indicated that a HP Jornada 720 HPC can easily run out $60 \%$ of its power after few hours in the field (Wang et al. 2003). They also noticed that viewing the HPC screen in direct sunlight was difficult. Any handheld devices that support Pocket Access could be desirable for timber cruising programs. Handheld devices of reasonable prices are commonly used in forest and land management companies, such as HP iPaq equipped with a rugged case.

Specifically-designed field PCs such as Allegro by Juniper Systems and fex21 by ITRONIX are best suited to rugged forest applications. However, they are about 5 to 10 times more expensive than a regular HPC. The Allegro $\mathrm{CX}^{\mathrm{TM}}$ is the most current HPC version introduced by Juniper Systems. Like their Allegro CE/DOS, the Allegro CX is becoming a field computing standard in natural resource and agriculture fields (Juniper Systems 2003). The Allegro field PC features a rugged, waterproof, field-ergonomic design and long battery life. The clarity of the display and non-glare touch-screen make information easy to read and enter outdoors. A color display option and the fast 
processor of Allegro CX make field data collection even more productive (www.junipersys.com). However, the Allegro does not provide a pre-installed MS Pocket Access that is used to hold field data by many field applications. In order to use data objects on Allegro, a piece of software called Visual CE needs to be installed (www.syware.com).

The fex 21 field PC by ITRONIX ${ }^{\circledR}$ is designed with the latest integrated wireless technologies, combining powerful processing, simplified applications development and enhanced Internet connectivity for rugged use in harsh field environments (www.itronix.com). The ITRONIX ${ }^{\circledR}$ fex21 is a rugged Handheld PC running Windows $\mathrm{CE}$ and is rated to military standards for impact and water resistance, and designed to meet the needs of highly mobile workforces. The fex21 features a 6.5" Half VGA $640 \mathrm{x}$ 240 pixel touch screen, visible across high and low light environments, specifically works well in the forest. This handheld device also provides MS Pocket Access.

Another type of handheld device that has been used in forestry applications is the GeoExplorer ${ }^{\circledR}$ CE series by Trimble. The GeoExplorer ${ }^{\circledR}$ CE series of GPS CE handhelds is a CE device with a unique combination of GPS and the Windows CE operating system (www.trimble.com). This device is rugged, portable, and reliable. It can not only provide accurate and reliable GPS data, but also allow installing customized programs for field applications. With a third-party component as a bridge between Windows CE and the GPS receiver, the handheld device could incorporate real-time GPS data into the cruising component and be used to spatially map stands during the timber cruising process. 
A significant difference between Windows CE and the desktop version of Windows is that the operating system must support multiple processor architecture (Tacke and Bassett 2002). The systems running Windows CE are most likely not using an Intel x86-compatible microprocessor. Instead, Windows CE runs on four different CPU families - SHx, MIPx, ARM, and x86 (Boling 2003). A number of potential processors available for mobile devices include SH3, SH4, MIPS, ARM, and others. The .NET compact framework takes the notion of portability one step further by supporting binary portability between different processor platforms (Yao and Durant 2004). A built .NET compact framework program (.exe) could run on the above processors.

Handheld devices can be connected to host computers through a serial port, USB, infrared port, or a network connection. The devices running Windows CE synchronize data on desktop PCs using Microsoft ActiveSync. There are many versions of ActiveSync. The ActiveSync 3.8 is the latest version of synchronization software for Windows Mobile-based pocket or handheld PCs. ActiveSync 3.8 contains a set of security enhancements that provide a more secure syncing experience with a Windows PC (www.microsoft.com/windowsmobile/downloads/activesync38.mspx). ActiveSync 3.8 supports Windows 98 (including Second Edition), Windows NT Workstation 4.0 SP 6, Windows 2000 Professional Edition, and Windows XP. ActiveSync 3.5 also supports Office 97, Office 2000, and Office XP, including Outlook 98, Outlook 2000, and Outlook XP and Outlook 2003.

After Microsoft ActiveSync is installed on a desktop PC, a partnership between handheld device and host computer should be established that can enable the host computer to recognize the handheld device when transferring files or synchronizing data. 
The handheld device can not only transfer the files of application data, but also automatically synchronize Microsoft Office files like Access, Inbox, Task, and others. 


\section{CHAPTER 2: TIMBER CRUISING DESIGN AND SYSTEM STRUCTURE}

\subsection{Requirements of Timber Cruising}

\subsubsection{Timber Cruising}

Timber cruising and inventory are the two major aspects of forest management.

Data collected in the field includes forest, plot, tree, transect, and elemental times, which are later analyzed to generate reports and prepare a long-term forest management or scheduling plan. Sampling methods can be point sampling, fixed area plot, or $100 \%$ tally (Figure 2.1). At each plot or point, however, species, dbh, merchantable height, total height, product, and cull percent need to be measured for each individual tree in a plot. Information at each transect measured includes understory and overstory vegetation.
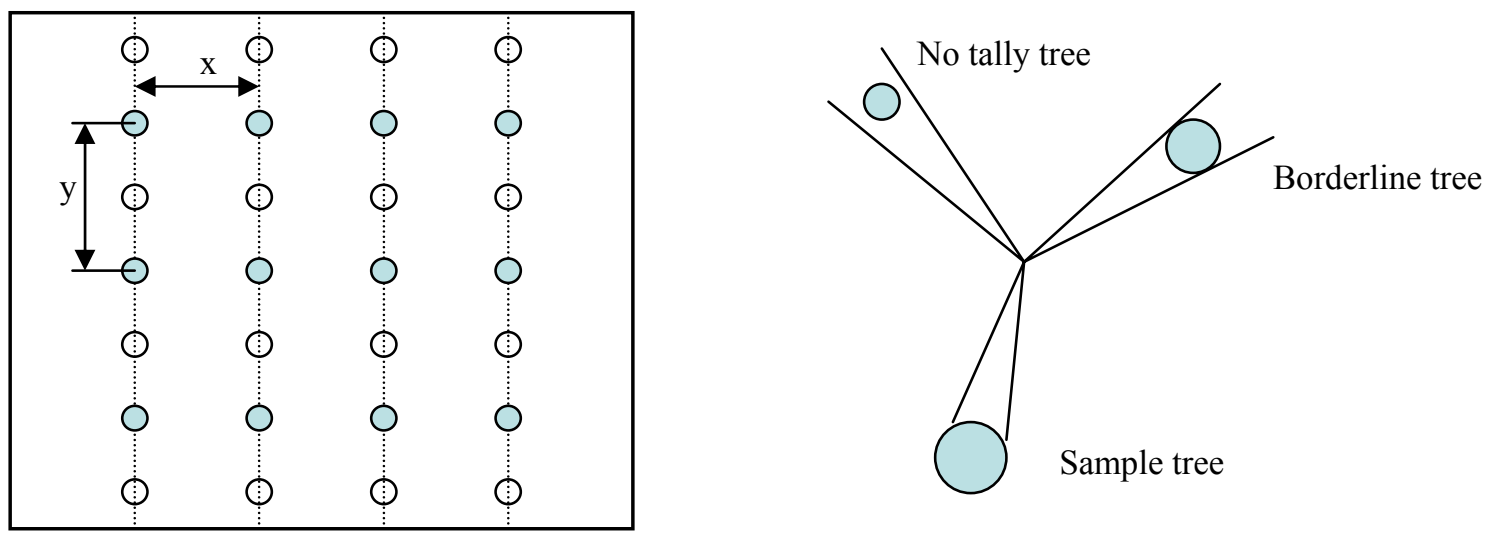

Figure 2.1. Typical layouts of plots in a systematic line-plot and a sampling point. (Source: Shiver and Borders 1996)

The Mesavage and Girard board foot volume equations/tables remain one of the most commonly used ones in the eastern and southern United States (Clutter et al. 1983, Brooks and Goerlich 2002). Local volume equations that were fitted on Girard form class (GFC) of 78 were used to compute the volumes of individual trees based on tree dimensions and species (Wiant 1977, Wiant 1986, Rennie 1996). However, a fixed 
percent is usually incorporated into the function to adjust the form class of 78 for different species and dbh classes. GFC was defined as the ratio between stem diameter, inside bark, at the height of $17.3 \mathrm{ft}$ and dbh, outside bark (Avery and Burkhart 1994). For example, a tree with a diameter $16 \mathrm{in}$. at the height of $17.3 \mathrm{ft}$. and a dbh $20 \mathrm{in}$. has a GFC of $16 / 20=0.80$ or 80 percent. Volume can be in cubic foot or board foot that is computed with either Doyle or International $1 / 4 \log$ rule.

Tree volume in board foot (International $1 / 4 \log$ rule):

$$
\begin{aligned}
V= & A F \times\left[\left(1.52968 L^{2}+9.58615 L-13.35212\right)+\right. \\
& \left(1.7962-0.27465 L^{2}-2.59995 L\right) D+ \\
& \left.\left(0.04482-0.00961 L^{2}+0.45997 L\right) D^{2}\right]
\end{aligned}
$$

Where AF is adjusted factor based GFC and species, D is the diameter at breast height, and L stands for the number of 16-foot logs. The AF can be expressed as:

$$
A F=1+(G F C-78) \times A P T
$$

Where APT is a fixed percent of adjustment for the form class of 78. The most commonly cited adjustment of this factor is 3\% per form class (Avery and Burkhart 1994) although variation exists among species and dbh classes (Brooks and Goerlich 2002).

Tree volume in board foot (Doyle scale):

$$
\begin{aligned}
V= & A F \times\left[\left(0.55743 L^{2}+41.51275 L-29.37337\right)+\right. \\
& \left(2.78043-0.04516 L^{2}-8.77272 L\right) D+ \\
& \left.\left(0.04177-0.01578 L^{2}+0.59042 L\right) D^{2}\right]
\end{aligned}
$$


Tree volume in cubic foot (for trees with 5 more logs):

$$
\begin{aligned}
V= & A F\left(2.5984-0.32222 D+0.01383 D^{2}+\right. \\
& 0.05906 D^{2} L+0.0001061 D^{3} L- \\
& \left.0.003333 D L^{3}-0.005602 D^{2} L^{2}+0.00042 D^{2} L^{3}\right)
\end{aligned}
$$

Tree volume in cubic foot (for trees with 5 logs or less):

$$
\begin{aligned}
V= & A F(-4.5465+0.3102 D+2.427 L+ \\
& 0.0478 D^{2} L+0.0004282 D^{3} L- \\
& 0.07632 D L^{2}+0.0001858 D^{2} L^{3}- \\
& \left.0.0001197 D^{3} L^{2}-0.00000658 D^{3} L^{3}\right)
\end{aligned}
$$

Pulpwood volume in cubic foot:

$$
V=\left(-0.017+0.00105 D^{2.2}\right) \times 128
$$

The individual tree volumes could be converted to the volumes on a per acre basis by using the expansion factor. The expansion can be stated as:

$$
E F= \begin{cases}1 & \text { for } 100 \% \text { tally } \\ \frac{1}{\text { Plot size }} & \text { for fixed area plot } \\ \frac{B A F}{B A} & \text { for point sampling }\end{cases}
$$

Where $\mathrm{EF}=$ expansion factor,

Plot size $=$ the size of a fixed area plot, for example, 1/10 acre,

$\mathrm{BAF}=$ basal factor that is a constant for all trees regardless of size, 
$\mathrm{BA}=$ basal area of a tree, which is equal to $0.005454154 \mathrm{dbh}^{2}(\mathrm{dbh}$ in inches).

\subsubsection{Cruising Statistics}

Cruise data are summarized in the format of stand and stock table by dbh class, species, grade, or their combinations. The cruise data can also be analyzed statistically among plots or points including the following statistics:

(1) Mean

$A V P=\frac{T V O L}{N P}$

Where AVP = mean of the volume per plot or point,

$\mathrm{TVOL}=$ total volume for all plots or points,

$\mathrm{NP}=$ number of plots or points.

(2) Variance

$V V P \frac{\sum_{i=1}^{N P}\left(T V O L_{i}\right)^{2}-\left[\frac{\left(\sum_{i=1}^{N P} T V O L_{i}\right)^{2}}{N P}\right]}{N P-1}$

Where VVP = variance of the volume per plot or point,

$\mathrm{TVOL}_{\mathrm{i}}=$ the volume of $\mathrm{i}^{\text {th }}$ plot or point.

(3) Standard deviation 


$$
S D V P=\sqrt{V V P}
$$

(4) Standard error

$S E V P=\sqrt{\frac{V V P}{N P}}$

(5) Coefficient of variation

$C V V P=\frac{S D V P}{A V P} \times 100$

(6) Confidence interval of $95 \%$

$C I V P=1.96 \times S E V P$

(7) Cruising percent error

$P E V P=\frac{C I V P}{A V P} \times 100$

(8) Sample size

$S Z=\frac{4 C V V P^{2}}{A E^{2}}$

Where $\mathrm{AE}=$ allowable error (5 to 10 percent). 


\subsection{Cruising System Model}

Component Object Model (COM) with object-oriented modeling techniques (OMT) is employed in the system design. A hierarchical structure among different components or modules in the system could be useful while modifying the program. A schematic hierarchy of the integrated timber cruising system contains the following major layers (Figure 2.2):

(1) Component layer. This layer is composed of three components of timber cruising applications that deal with GUI support of different modules or functions like collecting field data, transferring data, performing operations, analyzing, viewing, and reproducing outputs. This layer talks to the underlying module layer following the system hierarchy.

(2) Module layer. This is the major part of the system. Objects, controls, and object-oriented data models are implemented here. The modules contain form, class, and standard modules.

(3) Data store/function layer. Module layer talked to this layer to obtain the persistent functional and data support. 


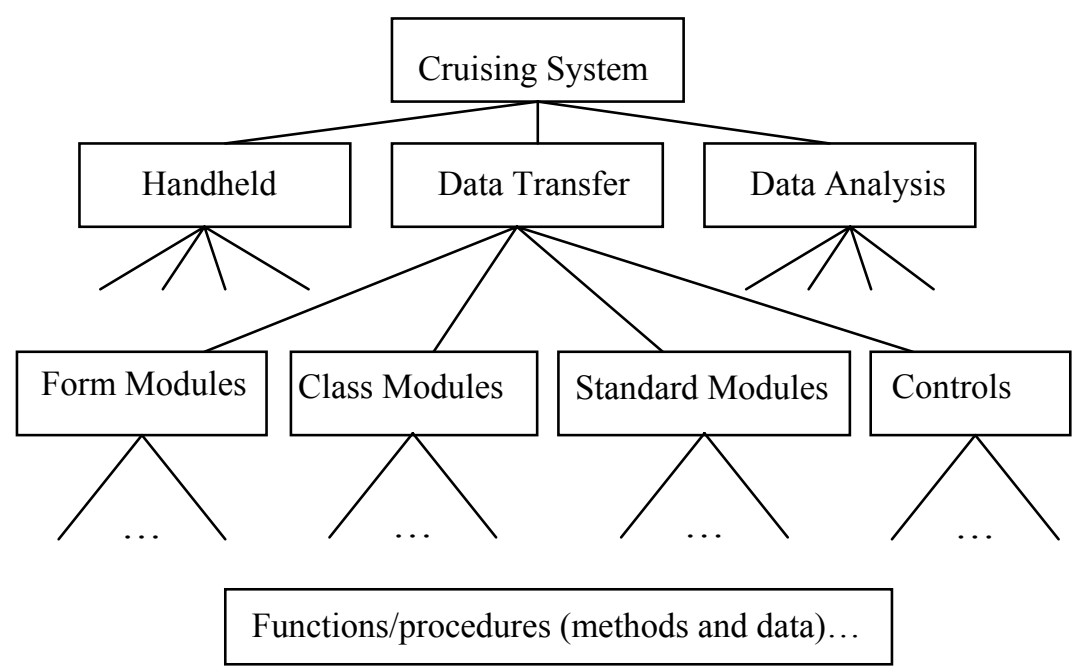

Figure 2.2. System model of timber cruising.

\subsubsection{System Evolution}

With rapid advances of hardware and software technology and proliferation of Internet and its related applications, I envision major advances of this cruising system in the near future. Our current hardware resources allow us to develop the relatively limited-size and PC-based application supporting limited users. I would be able to scale up the system to support more demanding environment. Active X and DCOM (Distributed Component Object Model) technology would be incorporated into the system that would be a major boost of the system in terms of the capability to accommodate more diverse and demanding performance requirements.

\subsubsection{Functional Requirements}

The integrated timber cruising system built here is a more convenient and costeffective way to perform timber cruising or forest inventory in the fields. This system 
allows you to make applications that make full use of the graphical user interface (GUI). The functional requirements of the system are as follows:

- Design a cruise

- $\quad$ Collect field data with handheld

- $\quad$ Edit field data

- $\quad$ Transfer data

- $\quad$ Manipulate and analyze cruise data

- $\quad$ Report

Through GUI, the user can collect and edit cruise data in the field with a handheld device, transfer data from handheld to desktop PC, and analyze and report cruise data. The following is a list of the major functions or event procedures in the system: Collect() - to collect field data;

EditHPC( $)$ - to edit tree and transect data of a plot on handheld;

Transfer() - to perform data transfer between handheld device and desktop PC;

EditPC () - to manipulate tree and transect data associated with a specific plot on desktop PC;

CullPct() - to calculate cull percent for a tree;

TreeVolume - to compute tree volume in three different log rules based on tree dimension and form class;

VolumeSummary() - to summarize volume of trees on per acre basis by species, DBH, and grade;

Analysis() - to analyze the cruise statistically;

Report() - to produce the summary reports of cruising data; 


\subsection{Cruising System Design}

Based on OMT, the application scenario was analyzed and modeled as a system of interrelated objects. The result is presented using an object diagram complemented with a more textual detailed description. Objects are central to the system design. For example, with Visual Basic programming, forms and controls are objects, and database and tables are data objects. These objects have properties, methods, and events. User accesses the system through GUI. The GUI is not treated as an independent object, but like an implementation issue that acts between user and the system. The GUI is implemented in the form modules. The communications and data exchange among form modules are carried out by the standard module object.

\subsubsection{Scenario of Timber Cruising System}

The following scenario shows the major interactions among three components, such as the interactions among user, system, external displays, and information exchanges (Figure 2.3):

The user selects an operation, for example, collect cruising data with handheld in the field.

The user will be prompted to enter cruising data including forest, plots, trees, and transects.

The user enters cruising data.

The system verifies the validity of data and saves the data into data storage.

The user performs data transfer and check the consistency of data tables on desktop PC. The cruising data are appended to corresponding tables on desktop PC. 
The user selects to an operation to analyze cruise data. The system summarizes the data including volume, basal area, trees per acre, and other statistics and then summary data are saved into the system.

The user selects to report the cruise. The reports are generated by species, plot or point, grade, or in the format of stand and stock table depending on the user's choice.

The system asks the user to select an operation provided by interface.

\subsubsection{Event Flow and State Diagrams}

The timber cruising system can be also viewed as a system of the interrelated interface, application, and data storage (Figure 2.3). An event trace for a system scenario of timber cruising was presented in Figure 2.3. If more than one object of the same class participates in the scenario, assign a separate column to each object. By scanning a particular column in the trace, you can see the events that directly affect a particular object, which can appear in the state diagram for the object.

An event flow diagram shows the events among a group of classes or modules (Figure 2.4). This diagram summarizes events between classes without regard for sequence including events from all scenarios and error events. The event flow diagram is a dynamic counterpart to an object diagram. Paths in the object diagram show possible information flows and paths in the event flow diagram show possible control flows.

Based on the event trace diagram, the state diagrams of the integrated timber cruising system were presented for interface, application and storage respectively (Figures 2.5, 2.6, and 2.7). Operations such as collect data, edit data, transfer data, and analyze data were distinguished. Verifications for data entry validity and table 
consistency need to be conducted in these three state diagrams. Some operations were also combined in the state diagram as much as possible in order to simplify state diagram. Many states are involved in the interface, such as request an operation, display main screen, and verify (Figure 2.5). All situations can be categorized into three states for application (Figure 2.6). Add and retrieval are the two major states for storage (Figure 2.7).

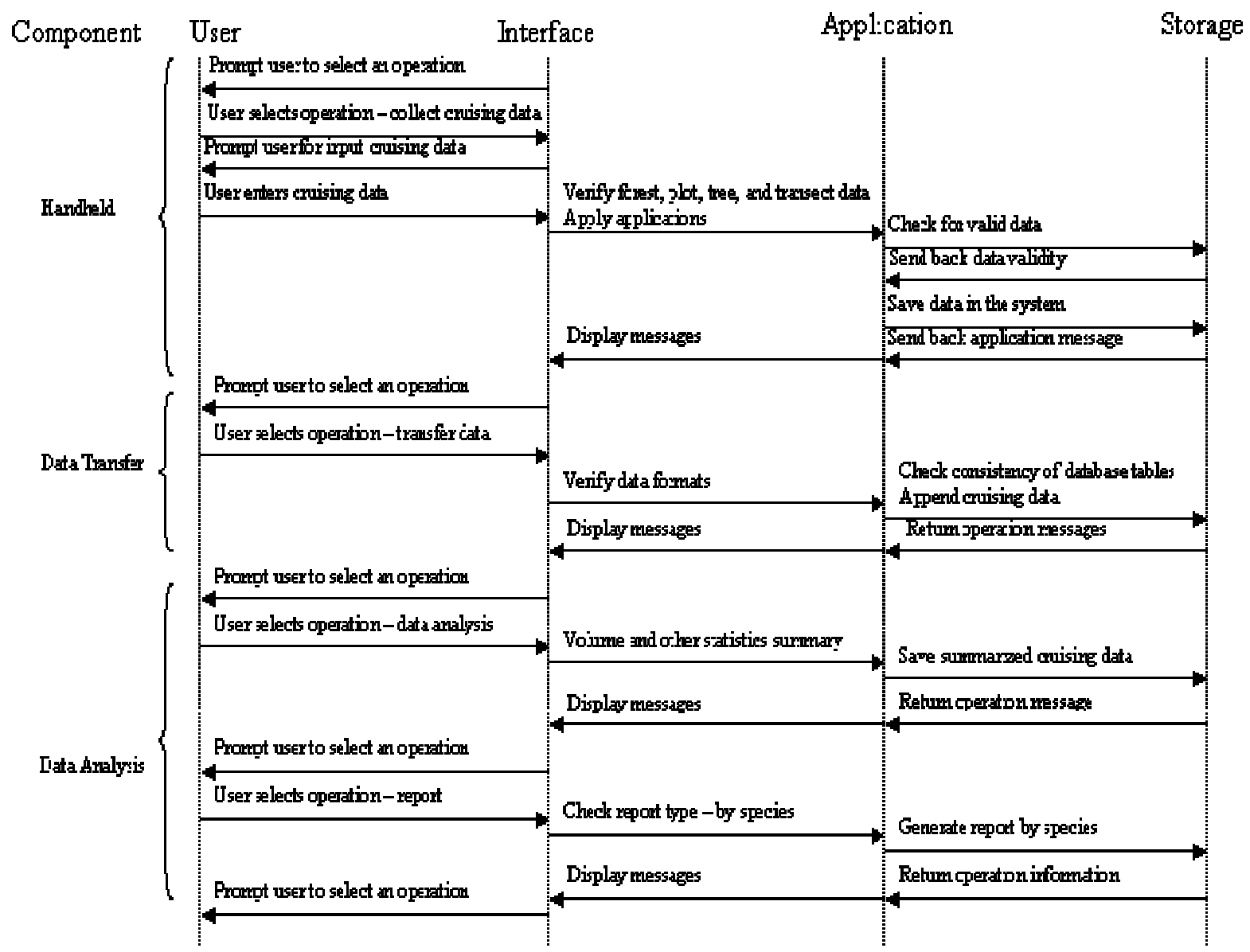

Figure 2.3. Event trace for a scenario of timber cruising. 


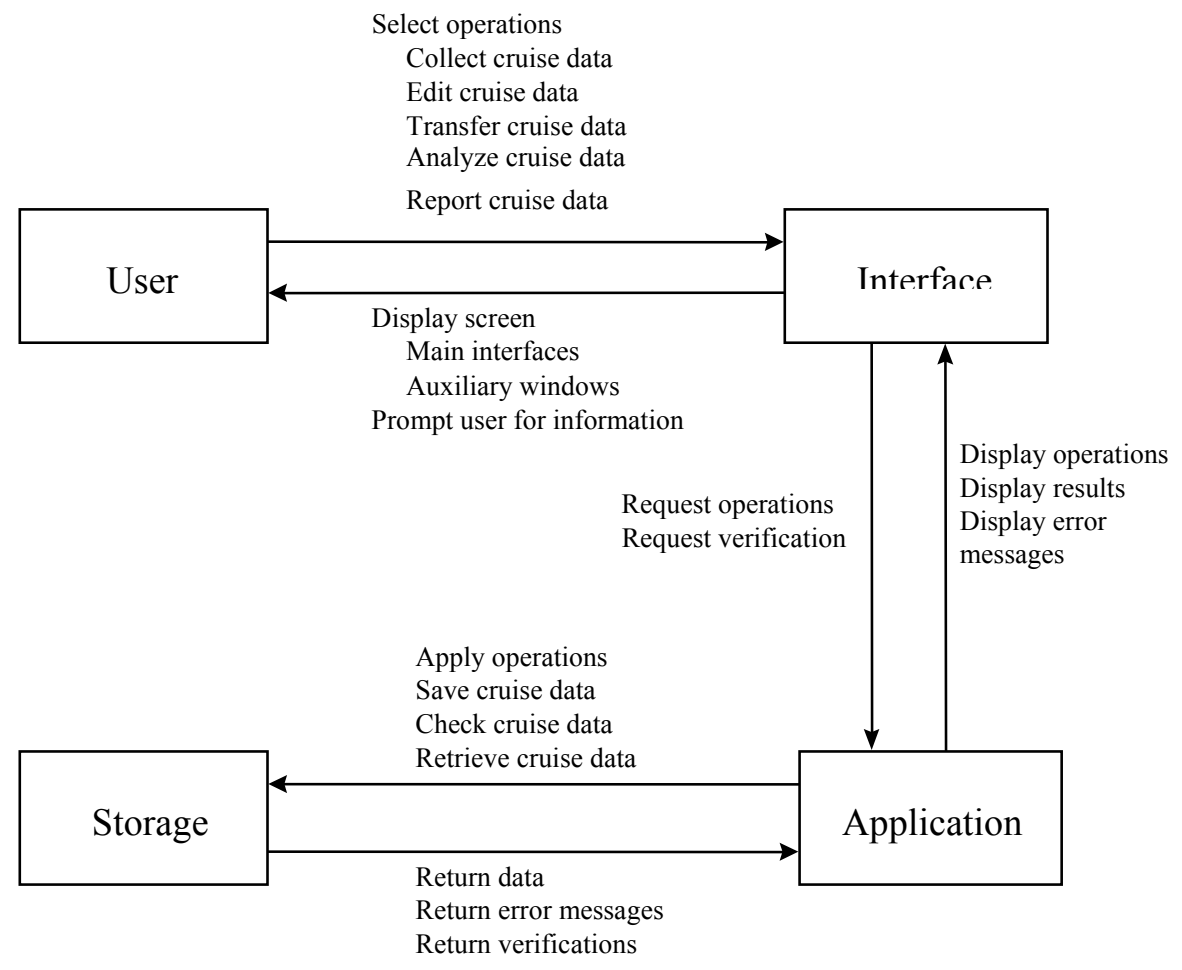

Figure 2.4. Event flow diagram of the integrated timber cruising system.

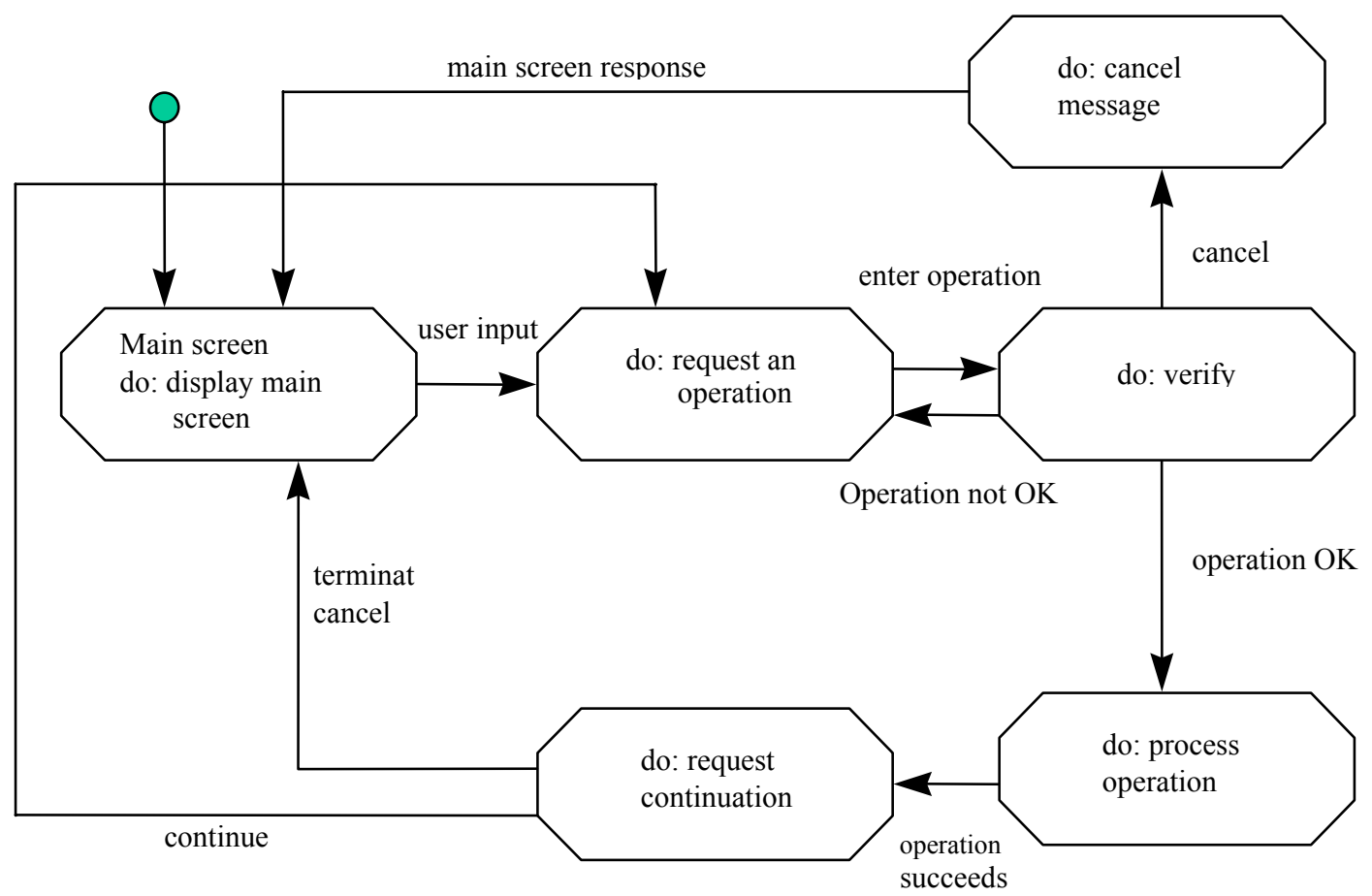

Figure 2.5. State diagram for interface of the integrated timber cruising system. 


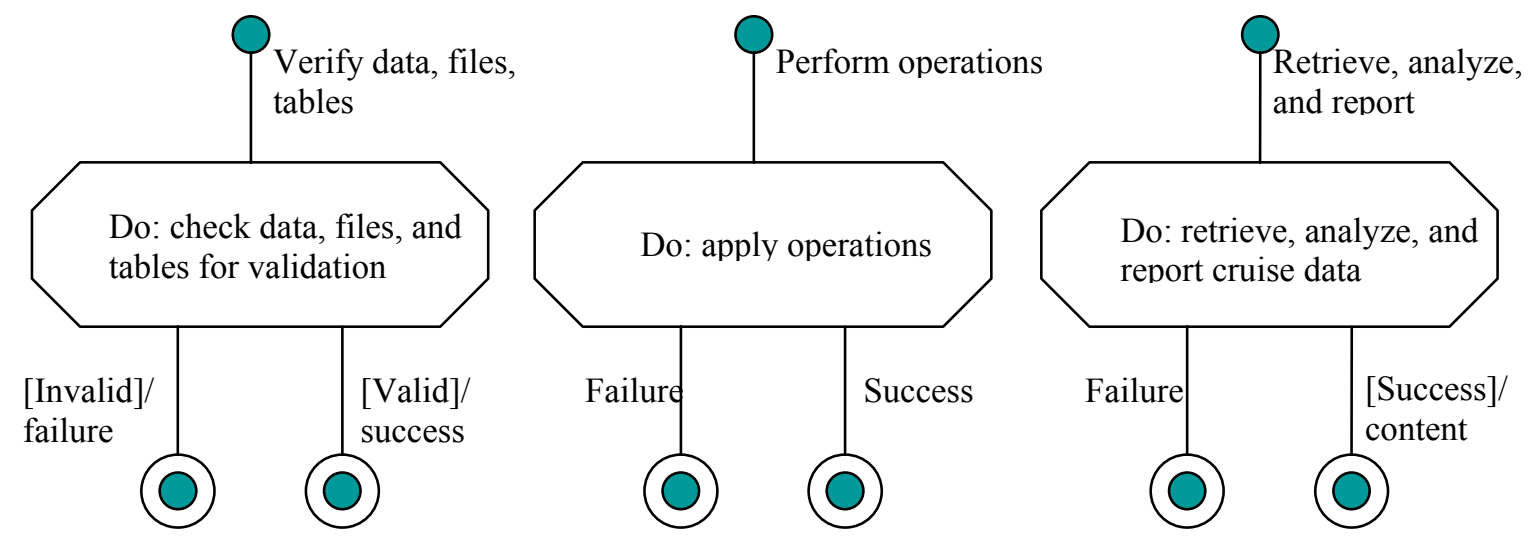

Figure 2.6. State diagram for application in the integrated timber cruising system.

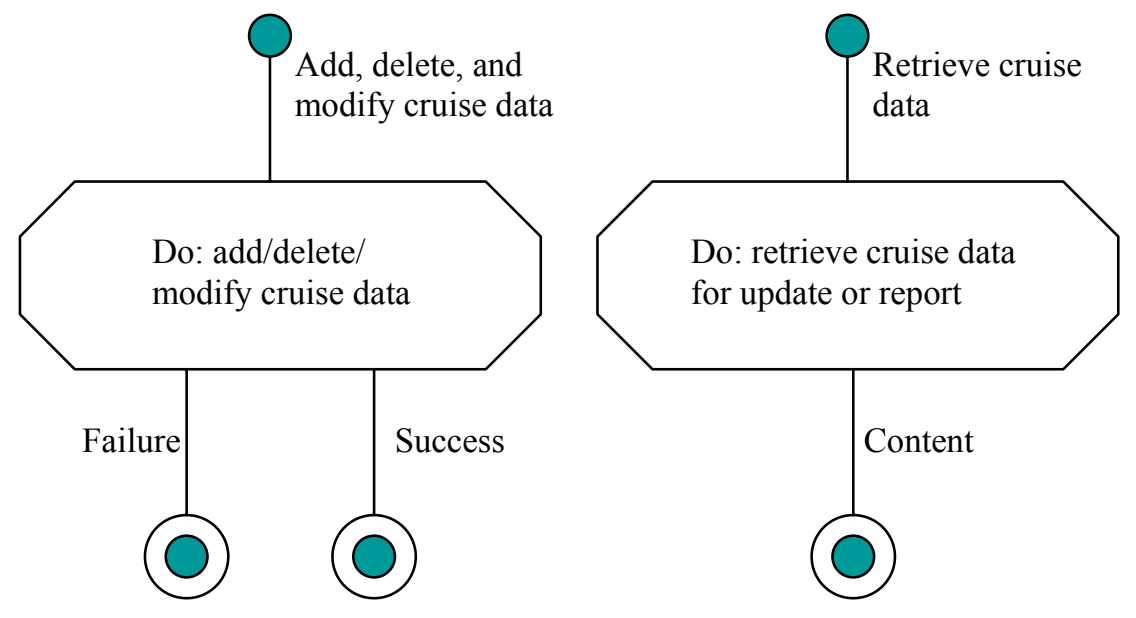

Figure 2.7. State diagram for data store in the integrated timber cruising system.

\subsection{Cruising System Structure}

\subsubsection{System Structure}

This integrated timber cruising system consists of three major components: a handheld data collection system, data transfer, and data analysis components (Figure 2.8) 
(Wang et al. 2003, Wang et al. 2004). The handheld system is used to collect cruising data including forest, plot, and tree measurements. Understory vegetation and wildlife data collection (referred to as transect data) could be also gathered with the handheld system. Data transfer is an interface for communicating between handheld PC (HPC) and desktop PC, which is used to synchronize data on the desktop PC. Data analysis is a component that is used to analyze and summarize the cruise data and generate desired reports. These components can be run as an integrated system, or on a stand-alone basis.

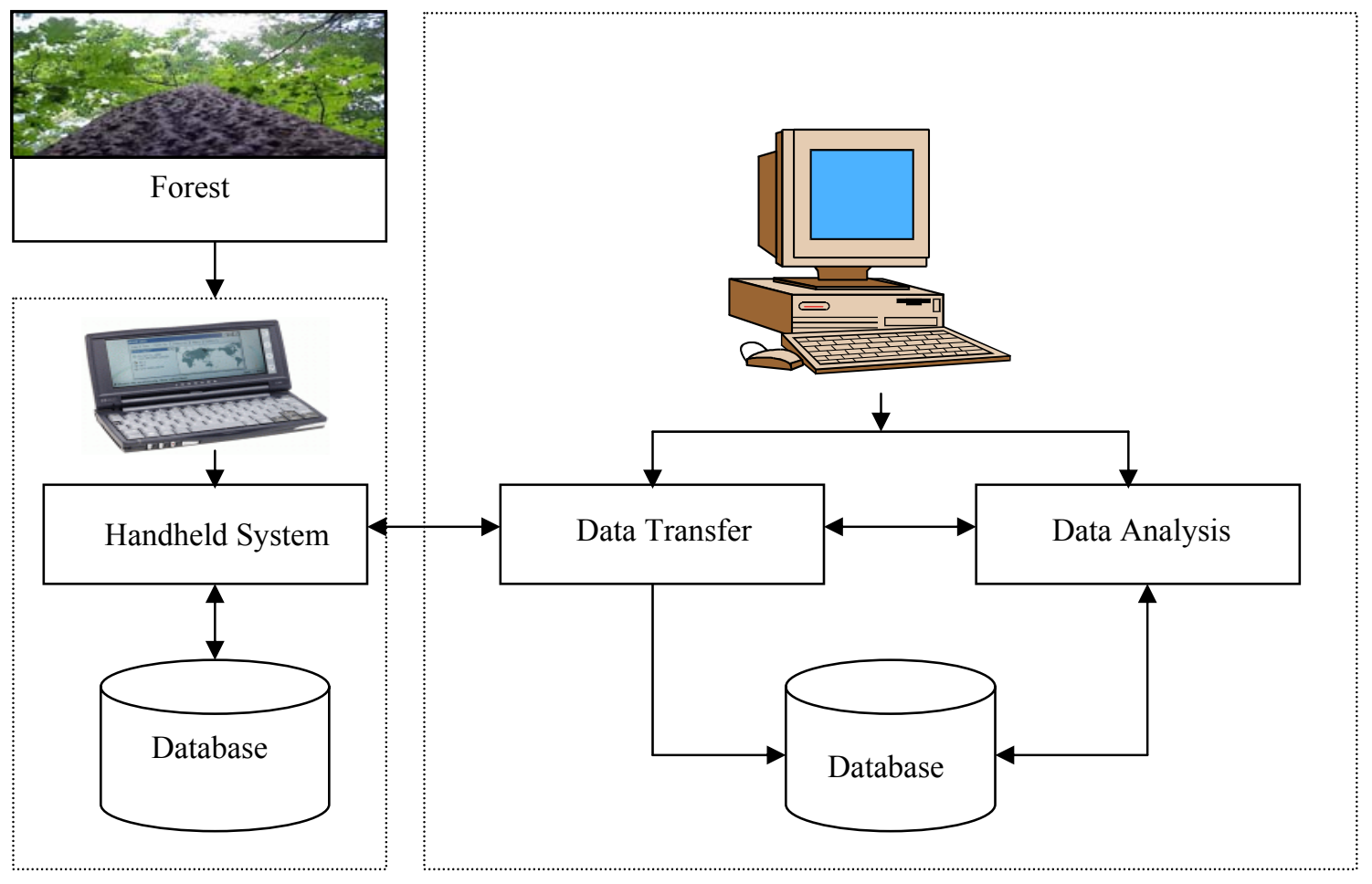

Figure 2.8. Structure of the integrated timber cruising system.

\subsubsection{Objects and COM}

The entire system is event driven as codes are executed in response to an event. Each object, e.g., form or control in the system, has a predefined set of events. When one of these events occurs, the system invokes the codes in the associated event procedure. 
Objects in the system using Visual Basic automatically recognize a predefined set of events whenever one is evoked. Usually, an event is invoked by a mouse click on a corresponding command button or item.

A component object model (COM) was employed to integrate the system, especially input to and output from the system. Components and objects are key concepts in COM that is a framework for creating and using components. Componentoriented design breaks applications down into components either in the format of dynamic-link libraries (DLLs) or executables (EXEs) (Rumbaugh et al. 1991). Each component can act as both client and server. A server is a component that exposes interfaces and therefore a list of functions that a client can use. Because COM is a language-independent standard, it is possible to build and subsequently use components with different languages such as Visual Basic, Visual $\mathrm{C}++$, and others. The COM model of this cruising system consists of three components (Figure 2.9). The COM interface includes a binary description of the layout of a block of memory containing an array of function pointers (Lewis 1999). The timber cruising users use these pointers to access the components via the interface such as ITimberCruising and then invoke the methods exposed by the objects in the model. Communication among components is conducted via other COM interfaces.

Both input and output modules in data transfer and analysis components were developed using MS Windows standard and MS VB built-in libraries, which were designed to handle the files in the formats of plain text, MS Excel, and Access. The Microsoft Data Access Object (DAO) and ActiveX Data Object (ADO) were used for the database connection and data manipulation in the system. The file system object (FSO) 
model was used to provide the functionalities to create, alter, move, and delete text files (Microsoft Corporation 1998). FSO model, which is contained in the scripting type library (scrrun.dll), supports text file creation and manipulation through TextStream object. The TextStream object especially enables the user to read and write text files. Both the Microsoft Excel object and DAO libraries were referenced and used for converting a database table into an Excel spreadsheet or retrieving information from an Excel sheet and then writing into a database table.

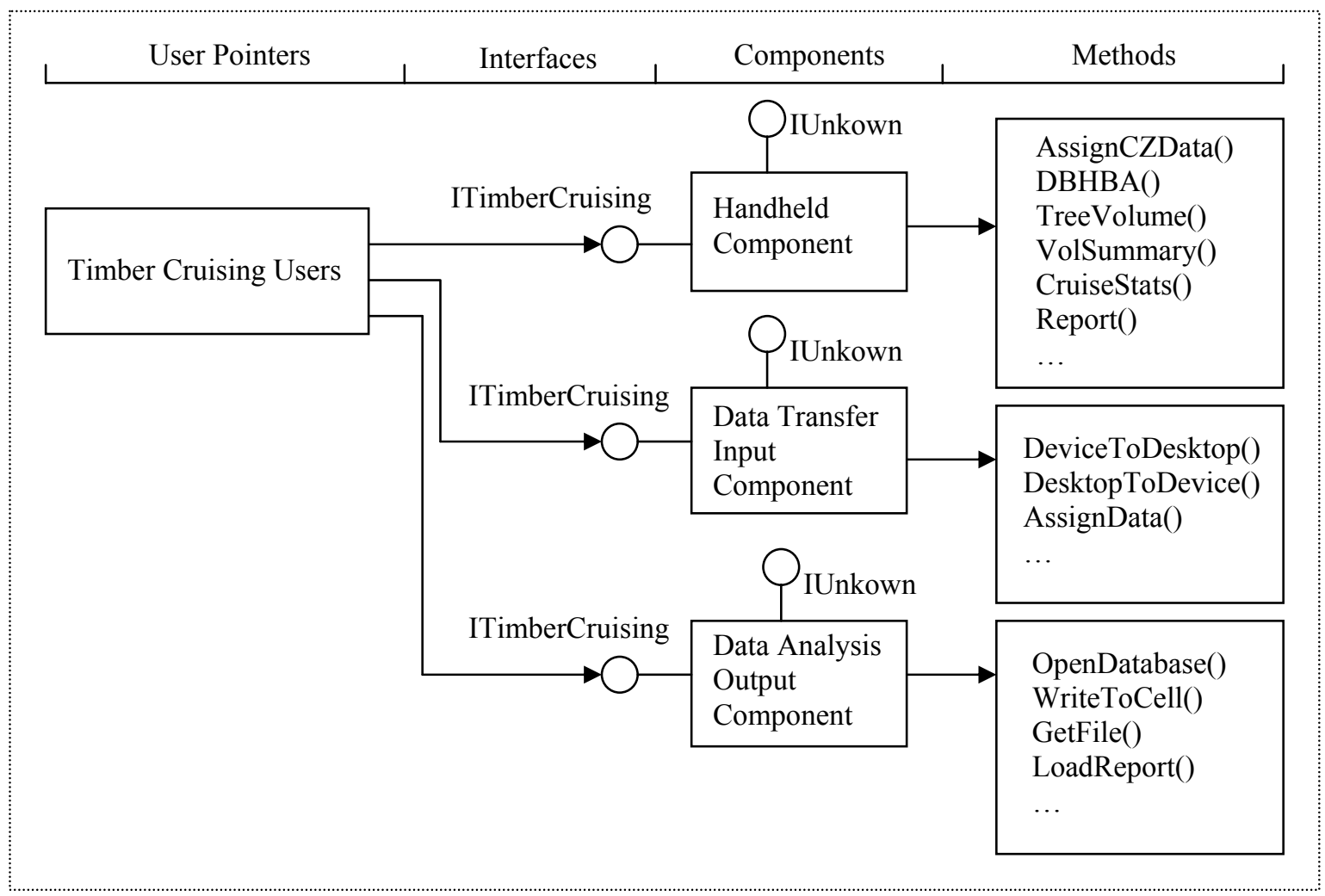

Figure 2.9. COM model of timber cruising system.

\subsection{Data Storage}

Two common techniques were used to design the database in the integrated timber cruising system: the entity-relationship (ER) approach and the normalization 
approach. The ER approach provides a taxonomy of data items to allow a database administrator (DBA) to intuitively recognize different types of data classification objects and their relationships (O’Neil and O'Neil 2001). The normalization approach, however, is less dependent on intuition. All the data items are listed and then all dependencies are identified.

\subsubsection{Entity-Relationship Model}

A relational database model was used for holding cruising data on both the handheld system and data transfer component, which was implemented based on the entity-relationship (ER) model (Figure 2.10). The relational database model presents the data as a collection of tables. Instead of modeling the relationships in the data according to the way that it is physically stored, the structure is defined by establishing relationships between data entities (Ullman and Widow 1997). An entity type represents a data table in the ER model and has attributes (fields) that are the descriptive properties of the entity type. Primary key refers to one or more fields that make a record unique in a data table.

The field or fields used to link to a primary key in another data table are known as foreign keys and a foreign key is any field(s) used in a relationship.

After creating the ER model, data objects in the integrated timber cruising system are illustrated (Figure 2.10). Based on this model, the design of these data objects were translated to relational tables and integrity constraints in the database management system. 


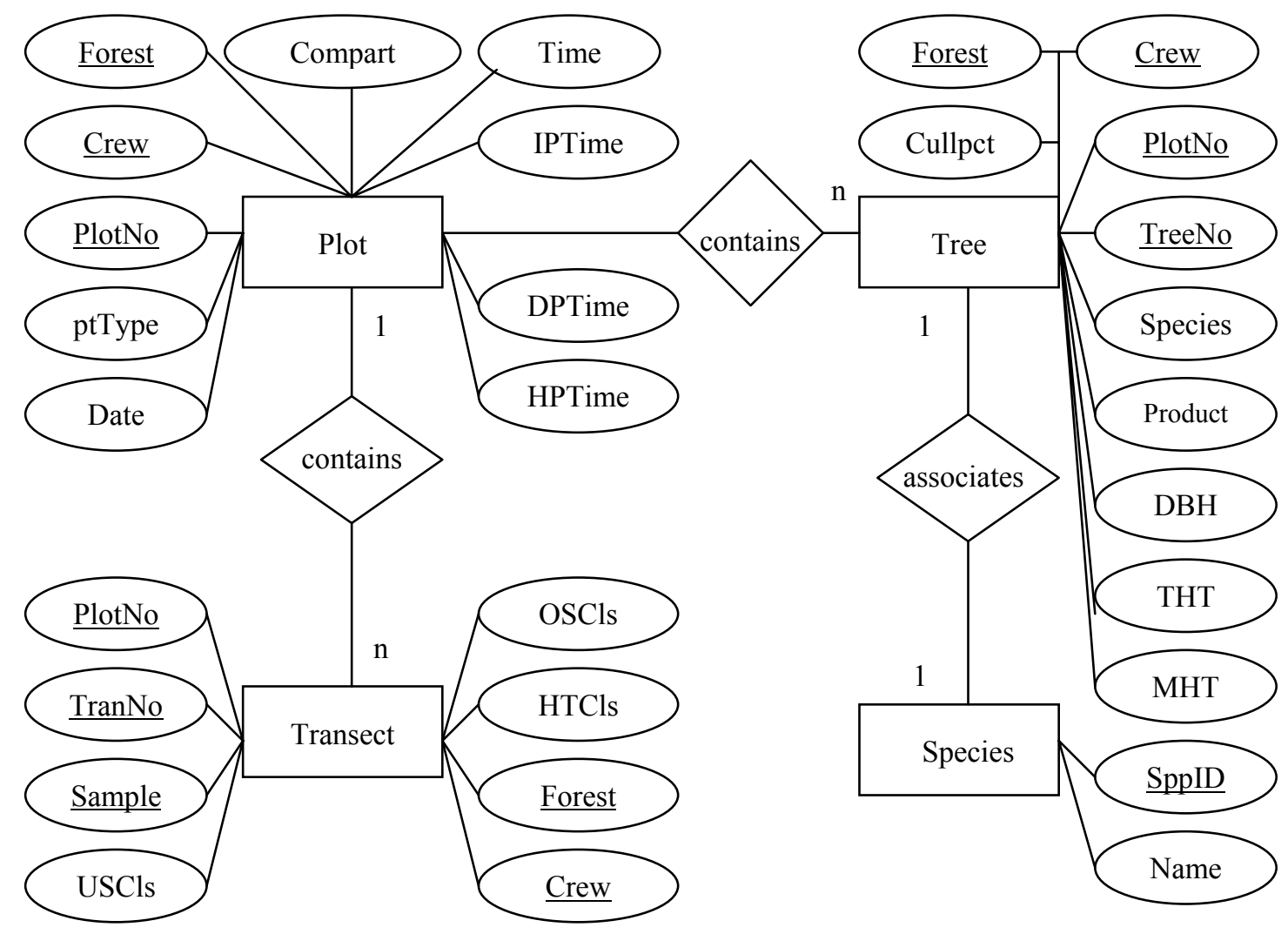

Figure 2.10. ER data model of the integrated timber cruising system.

There are four data entity types - Plot, Tree, Transect, and Species in the model. Each entity type has its own attributes. For example, the Plot entity type has forest, crew, plotNo, plotType, and other attributes. Entity types are related using relationships such as "contains," and "associates" in the model. The relationship between plot and tree or transect is one-to-many and simply means that the plot "contains" many trees or transects. One-to-one relationship is applied between tree and species entity types, which implies each tree is "associated" with a specific species. Attributes belonging to a key are underlined for an entity set. For example, forest, crew, and plotNo together is a primary key of entity type plot while forest, crew, plotNo, treeNo is a primary key of 
entity type tree. Foreign key of forest, crew, and plotNo for entity type tree and transect represented the one-to-many relationships.

\subsubsection{Normalization}

Normalization is another approach to logical design of a relational database, which seems to share little with the ER model (O'Neil and O'Neil 2001). However, it will turn out that a relational design based on normalization and a careful ER design transformed into relational form have nearly identical results, and in fact the two approaches reinforce each other (O'Neil and O'Neil 2001). There is a series of normal form definitions such as first normal form (1NF), second normal form (2NF), third normal form (3NF), Boyce-Codd normal form (BCNF), and others.

All data items and functional dependencies (FDs) in the timber cruising database need to be considered during the normalization process (Figure 2.11). The normalization process started with a first normal form table that contains all tree data items. A table in $1 \mathrm{NF}$ is simply one that has no multi-valued attributes or just has scalar or atomic attributes. Therefore, a combined tree data table of timber cruising is in 1NF. However, a number of design problems or anomalies could be noted, such as redundancy. Since no designer would like to leave a database in $2 \mathrm{NF}$, it is necessary to show all tables in this timber cruising system are in $3 \mathrm{NF}$.

One of the anomalies is if all the trees associated with a specific plot were deleted, no information about this plot would be remained in the table. Similarly, if we deleted a transect information associated with a plot or all the trees with same species, the transect and the species will be permanently lost. A solution for these anomalies is to factor the combined table into four tables of plots, trees, transect, and species (Figure 2.12). 


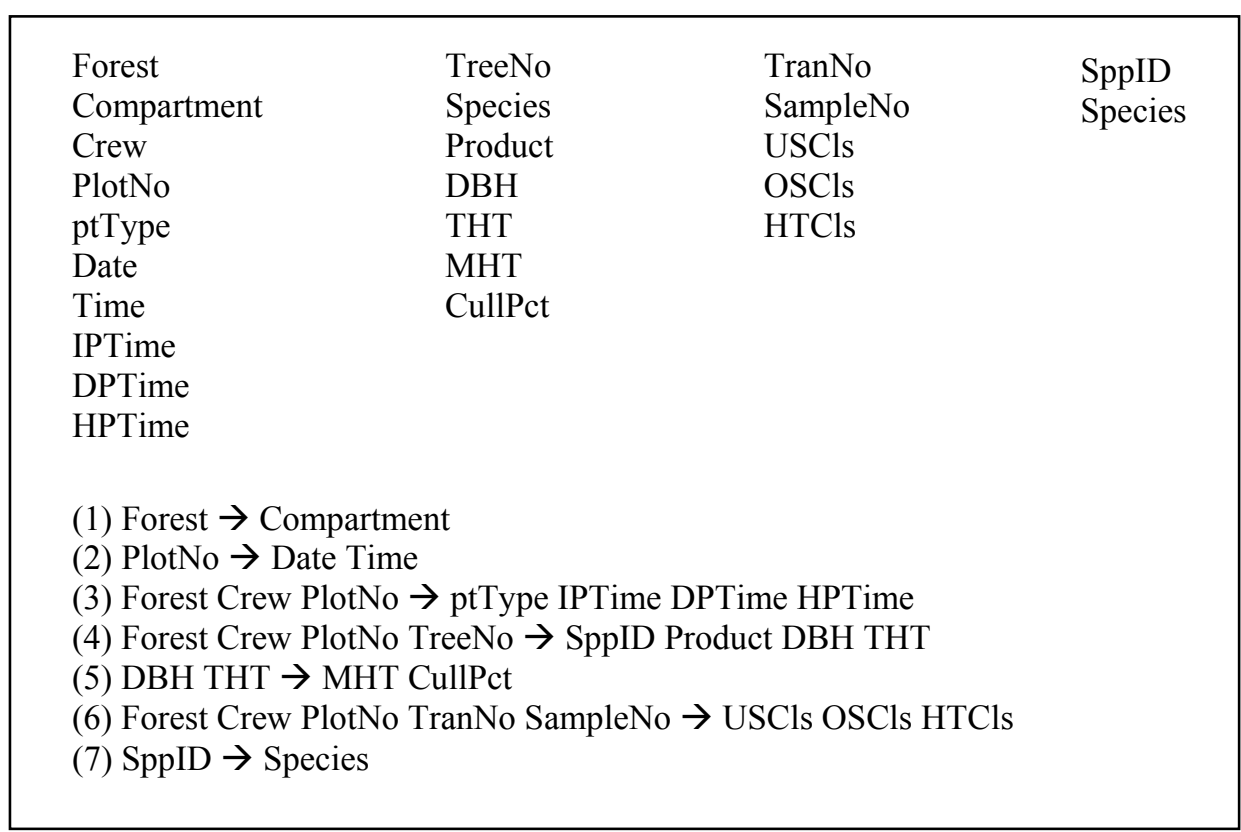

Figure 2.11. Data items and FDs for the timber cruising database.

\begin{tabular}{|c|c|c|c|}
\hline Plots & Trees & Transects & Species \\
\hline $\begin{array}{l}\text { Forest } \\
\text { Compartment } \\
\text { Crew } \\
\text { PlotNo } \\
\text { ptType } \\
\text { Date } \\
\text { Time } \\
\text { IPTime } \\
\text { DPTime } \\
\text { HPTime }\end{array}$ & $\begin{array}{l}\text { Forest } \\
\text { Crew } \\
\text { PlotNo } \\
\text { TreeNo } \\
\text { SppID } \\
\text { Product } \\
\text { DBH } \\
\text { THT } \\
\text { MHT } \\
\text { CullPct }\end{array}$ & $\begin{array}{l}\text { Forest } \\
\text { Crew } \\
\text { PlotNo } \\
\text { TranNo } \\
\text { SampleNo } \\
\text { USCls } \\
\text { OSCls } \\
\text { HTCls }\end{array}$ & $\begin{array}{l}\text { SppID } \\
\text { Species }\end{array}$ \\
\hline \multicolumn{4}{|c|}{$\begin{array}{l}\text { (1) Forest } \rightarrow \text { Compartment } \\
\text { (2) PlotNo } \rightarrow \text { Date Time } \\
\text { (3) Forest Crew PlotNo } \rightarrow \text { ptType IPTime DPTime HPTime } \\
\text { (4) Forest Crew PlotNo TreeNo } \rightarrow \text { SppID Product DBH THT } \\
\text { (5) DBH THT } \rightarrow \text { MHT CullPct } \\
\text { (6) Forest Crew PlotNo TranNo SampleNo } \rightarrow \text { USCls OSCls HTCls } \\
\text { (7) SppID } \rightarrow \text { Species }\end{array}$} \\
\hline
\end{tabular}

Figure 2.12. Tree data schema with four tables.

By definition, a superkey for a table $\mathrm{T}$ is a set of attributes $\mathrm{X} \subseteq \operatorname{Head}(\mathrm{T})$ such that $X \rightarrow \operatorname{Head}(\mathrm{T})$ (O’Neil and O’Neil 2001). We can determine the closure of X denoted $\mathrm{X}^{+}$ 
that are the FDs logically implied by the FDs in Figure 2.12. If starting with $\mathrm{X}=$ Forest Crew PlotNo and then applying FDs (3), (1), and (2), we have

$$
\begin{aligned}
& \mathrm{X}^{+}=\text {Head(Plots) } \\
& \text { Forest Crew PlotNo } \rightarrow \text { Head(Plots) }
\end{aligned}
$$

Therefore, Forest Crew PlotNo is a superkey for table plots. Similarly, we can determine the superkeys for tables trees (Equation 2-17), transects (Equation 2-18), and species (Equation 2-19).

$$
\begin{aligned}
& \text { Forest Crew PlotNo TreeNo } \rightarrow \text { Head(Trees) } \\
& \text { Forest Crew PlotNo TranNo SampleNo } \rightarrow \text { Head(Transects) } \\
& \text { SppID } \rightarrow \text { SppName }
\end{aligned}
$$

The next thing we need is to prove that the factorization of the combined timber cruising table into tables plots, trees, transects, and species is a true lossless decomposition. We know the combined table (TCruise) of timber cruising with the following attributes: Head(TCruise) = Forest Compartment Crew PlotNo ptType Date Time IPTime DPTime HPTime TreeNo SppID Product DBH THT MHT CullPct SppName. Therefore,

TCruise $\rightarrow$ \{plots, trees, transects, species

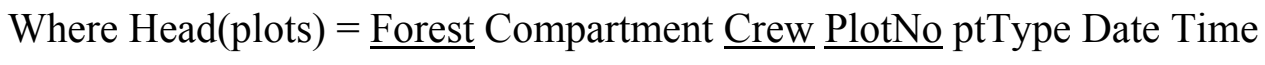
IPTime DPTime HPTime (the keys for these tables are underlined), Head(trees) $=\underline{\text { Forest }}$

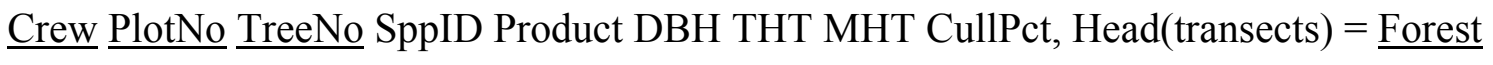

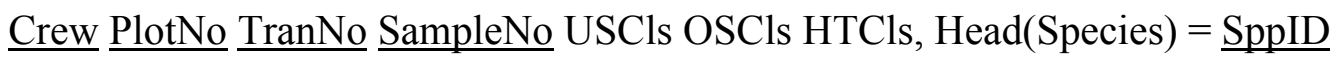
SppName.

We can easily find out that the natural join $(|x|)$ of these four sub tables is the combined table timber cruising. That is, 
$(($ trees $|\mathrm{x}|$ plots $)|\mathrm{x}|$ transects $)|\mathrm{x}|$ Species $=$ Head(TCruise $)$

Head(plots) $\cap$ Head(trees) $=$ Forest Crew PlotNo $\rightarrow$ Head(plots), because of FD (3)

Head(plots $|x|$ Trees $) \cap$ Head(Transects) $=$ Forest Crew PlotNo $\rightarrow$ Head(plots X trees), because of FD (3)

$\operatorname{Head}(($ plots $|\mathrm{x}|$ trees $)|\mathrm{x}|$ transects $) \cap \operatorname{Head}($ Species $)=$ SppID $\rightarrow$ Head(Species), because of FD (7)

By definition, the process of factorization of TCruise into plots, trees, transects, and species has been proven a lossless decomposition. A table $\mathrm{T}$ in a database schema with FD set $\mathrm{F}$ is said to be in $3 \mathrm{NF}$ if $\mathrm{X}$ is a superkey for $\mathrm{T}$ or $\mathrm{Y}$ is a prime attribute in $\mathrm{T}$ for any functional dependency $\mathrm{X} \rightarrow \mathrm{Y}$ implied by $\mathrm{F}$ that lies in $\mathrm{T}$, where $\mathrm{Y}$ is a single attribute that is not in X. Based on equations (2-16), (2-17), (2-18), and (2-19), we have proved:
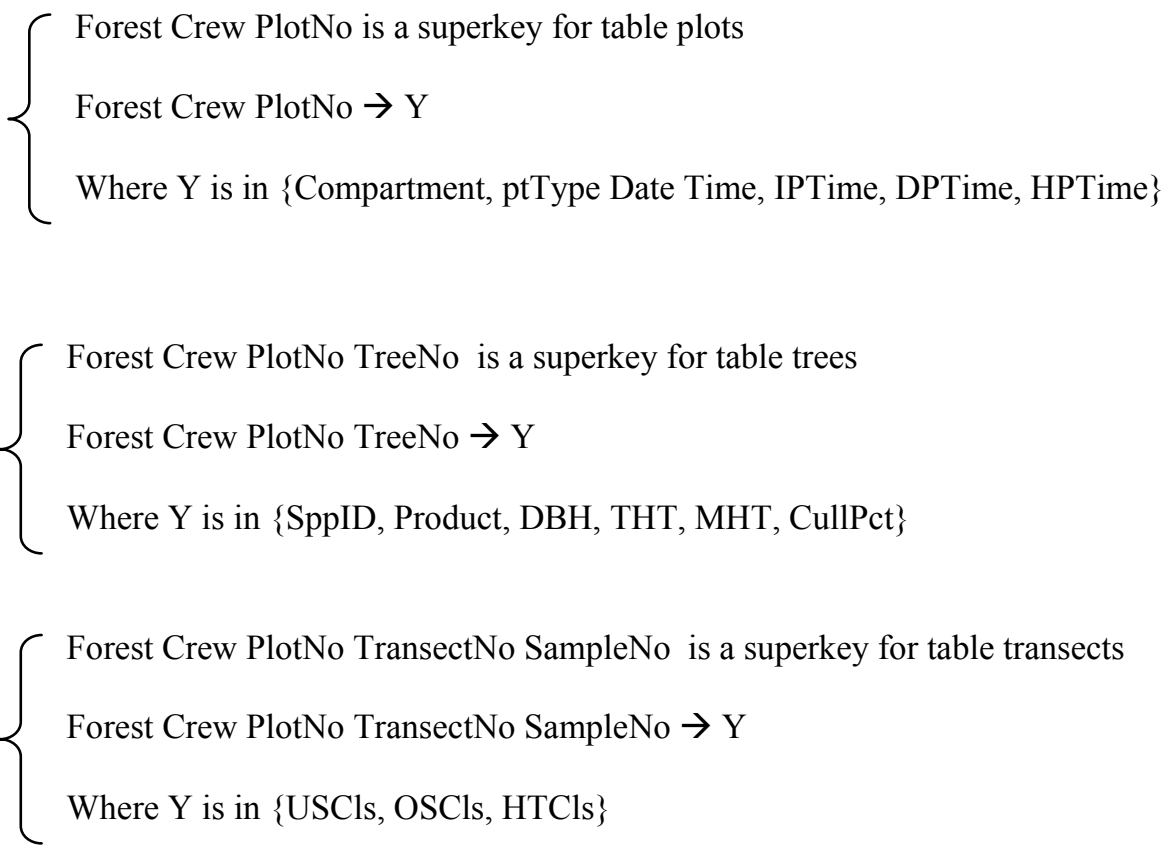


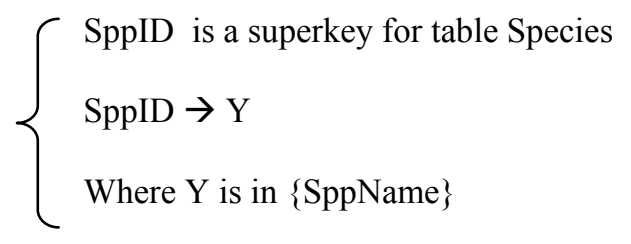

By definition, tables plots, trees, transects, and species are in $3 \mathrm{NF}$. We can also conclude that the database of timber cruising is also in $3 \mathrm{NF}$. 


\section{CHAPTER 3: CRUISING SYSTEM IMPLEMENTATION}

The whole system is event-driven. Event-driven applications execute codes in response to an event. Each object, such as form or control, in the system has a predefined set of events. If one of these events occurs, the system invokes the codes in the associated event procedure. Objects in the system using Visual Basic automatically recognize a predefined set of events.

\subsection{Handheld System}

\subsubsection{Handheld System Implementation}

The handheld system was written with Microsoft VB CE, which is run under Microsoft Windows CE environment. It contains two main modules: collect and edit (Figure 3.1). The collect module is designed to allow a user to collect plot, tree, and transect data associated with each cruise point, while the edit module is designed to permit field editing of tree data. Retrieval and storage of cruising data is accomplished with an MS Access database.

The main method of user interface with the handheld system is accomplished through the use of a "stylus". The stylus is included with the handheld systems and is used in much the same way the user would use a mouse to navigate and select objects on a desktop computer screen. The user can also use a fingertip to tap the touch screen, however, the stylus provides the greatest accuracy.

Two modules were implemented in the handheld system to collect and edit cruising data. For the West Virginia state forest inventory, there were three types of plots 
- intensive, DBH only, and DBH and merchantable height. Two functions were also implemented in the handheld system to calculate the cull percent of a tree.

\subsubsection{Algorithm for Calculating Cull Percent}

An algorithm is defined as any well-defined computational procedure that takes some value, or set of values, as input and produces some value, or set of values, as output (Cormen et al. 2001). The efficient algorithm implemented in a program can save both time and space while running it. Here is an algorithm implemented on the handheld for calculating the cull percent in a tree:

(1) Based on the total height and merchantable height, check two ratios: $\mathrm{x}=$ merchantable height/total height, $\mathrm{y}=1 /$ total height.

(2) Calculate term volume of a section of $\log$ (Listing B.1).

(3) Calculate the volume of merchantable log section.

(4) Redefine the ratios of $\mathrm{x}$ and $\mathrm{y}: \mathrm{x}=$ top height of cull section/total height, $\mathrm{y}=$ bottom height of cull section/total height.

(5) Calculate the volume of cull section.

(6) Calculate the cull percent by dividing the volume of cull section by the total volume of merchantable section (Listing B.2).

This algorithm takes a constant time to calculate the cull percent - O(1). 


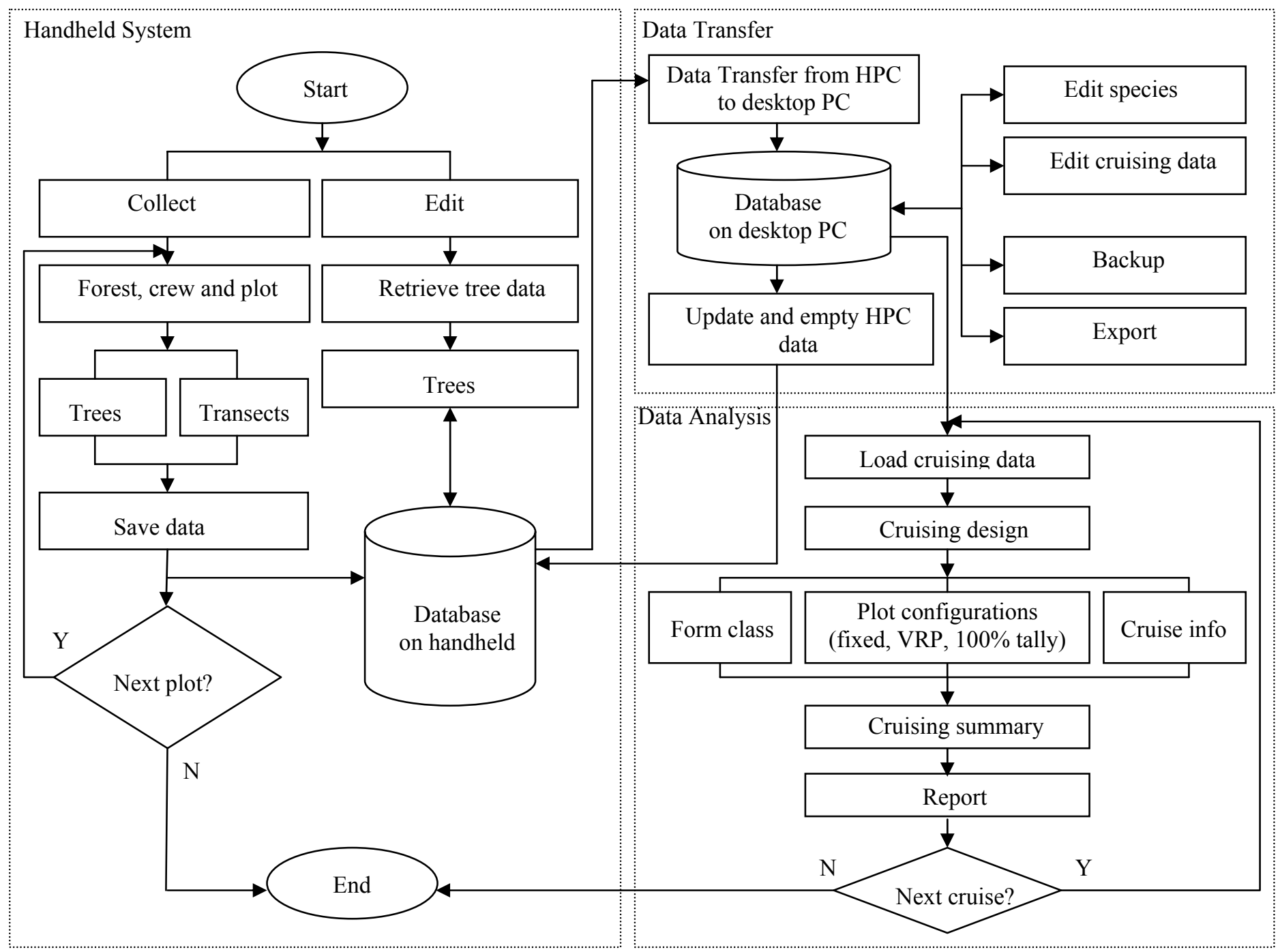

Figure 3.1. Architecture of the integrated timber cruising system. 
Three elemental times are collected at each plot, IP_Time, DP_Time and HP_Time (Figures A.1 and A.2):

- The IP_Time is the time interval from the time the "Add Plot" button is pressed to the time the "Start Transect" (understory vegetation data collection) button is pressed.

- The DP_Time is the time interval from the time the "Add Plot" button is pressed to the time the "In-Trees" box is checked.

- The HP_Time is the time element from the time the "Add Plot" is pressed to the time the "In-Logs" box is checked.

These time values can be used to examine the cruising efficiency of the field users.

\subsection{Data Transfer}

\subsubsection{Data Transfer Implementation}

Data transfer component was programmed with MS VB V6.0, which resides on a desktop PC under MS Windows environment (Figure 3.1). The data transfer provides two major functions: it allows for the transfer of cruising data from a HPC to a desktop PC, and accommodates updates of data tables on the desktop PC as well as readying the database for the next cruise transfer. The edition of species, cruise data backups, and exportation of data (into ASCII text and MS Excel) are also provided in the data transfer

component. ADO CE application programming interface (API) was employed to conduct 
data transfer via a dynamic link library (DLL) - adofiltr.dll (Roof 1998). The adofiltr.dll, a MS pocket Access file converter and synchronizer, is a part of the ADO 2.0 Solution Development Kit (SDK) for Windows CE. It allows programmatic transfer of database tables between the host desktop computer and the remote device. This DLL contains two functions, DesktopToDevice and DeviceToDesktop, which are used to transfer data or copy tables. The syntax of these two functions is as follows (Roof 1998):

$V=$ DesktopToDevice(DecktopLocn,TableList, Sync, Overwrite, DdeviceLocn) $V=$ DeviceToDesktop(DecktopLocn,TableList, Sync, Overwrite, DdeviceLocn)

Where, $V$ is a return value ( 0 is successful). DesktopLocn is the path and file name of MS Access database that contains the tables to be transferred to the desktop PC. TableList is the list of tables and fields that will be copied from or to the handheld PC. Sync is an argument for synchronization and should be always set to False. Overwrite is the argument that specifies whether to overwrite existing tables of the same names, which also has Boolean values of True or False. DeviceLocn is the path and file name and tells where the file is on handheld PC.

Data transfer runs on the desktop PC, not the handheld. The desktop initiates and controls the transfer process. The key requirement for this transfer process is the presence of the same table schemas on both desktop and handheld. The ADO CE data transfer feature has a solid set of tools for transferring data. While the manual method for copying tables does not offer the control needed by most applications, the programmatic method does. This feature allows the transfer of complete tables between devices, rather than requiring the synchronization of individual records. 
The data transfer component was implemented on the desktop PC, which provides two basic functions: the transfer of cruise data from the HPC to PC, and updating and clearing data tables on the HPC. For the sake of data security, this component was designed to run these events separately. The system is designed to first update the species table and then empties temporary tables on the HPC before the cruise data can be entered in the field. Once users collect the cruising data, the data tables on the handheld PCs are copied and synchronized to a temporary database on the desktop PC. The tables in the temporary database are then appended to the related tables in the main database. Finally, the system again needs to empty the data tables on the handheld in preparation for the next timber cruise.

The other major function provided is for editing cruising data. A VB tab strip control was used to implement three tabs for plot, tree, and transect. A VB DB gird on each tab is associated with a record set defined in the database. The plot tab is first displayed. Structured Query Language (SQL) was used for retrieving trees and transects associated with the plot the user selects. Once the user selects a record from the plot tab, they can select either the tree tab or the transect tab to continue the editing process.

\subsubsection{Algorithm for Transferring Cruising Data}

(1) Set application directory (Listing B.3).

(2) Set the DEVICETODESKTOP() function in adofiltr.dll (Listing B.3).

(3) Open database on the desktop PC.

(4) Set data objects for plot, tree, and transect.

(5) Check the return value of the transfer function.

(6) Call data transfer functions (Listings B.3 and B.4) 
The two functions (Listings B.3 and B.4) take a linear time to transfer plot, tree, or transect data from HPC to desktop $\mathrm{PC}-\mathrm{O}(\mathrm{n})$. Where, $\mathrm{n}$ is the number of trees being transferred.

\subsection{Data Analysis}

\subsubsection{Data Analysis Implementation}

The data analysis was organized in a modular way and was programmed with MS Visual Basic, in which modules were designed as independently as possible (Figure 3.1). A module, or self-contained unit of code, could be a single function or act as several functions. Data Access Object (DAO) was used to load the cruising data from the database into this component. This allows tree form class and cruise information to be edited for summaries and reports. In the cruise summary module of this component, stand/stock table, point/plot, and cruising statistics are provided by business functions built in the component. All end user reports were developed using an ActiveX component of MS Access object, which is a reusable piece of programming code and data. It allows the user to call MS Access reports directly from VB application without the use of complicated coding.

The DAO was implemented to connect the database and a VB flex grid control was used to display the data. Once the cruising data were loaded into computer memory, a cruise design window is then popped out. The user can browse the data loaded and invoke another dialog box to view species and grade codes used in the system. In this design window, the user can design and save cruising information for a report header. The user simply enters data into the required text boxes and then selects the "Save Cruise Info" button. To modify form class for a specific species, the user needs to simply click 
"Girard Form Class" button. A form is displayed using a DB grid control associated with a form class table in the database. This allows the user to modify the form class data.

Cruise type selections can also be made during the cruise design process. The user can choose fixed area, variable radius plot or point sampling (VRP), or $100 \%$ tally by checking VB radio buttons. If a plot type of fixed area is chosen, plot size must be entered while basal area factor should be given if VRP is checked. Four types of summaries are provided depending on the user's requirements. Volume summaries can be done on both per acre basis and per tract basis. Stand/stock tables are further summarized by DBH class, species and DBH, and by species, grade, and DBH. Cruise statistics are provided for volume per acre in cubic feet (CFV), International board feet (1/4) (IBFV), Doyle (DBFV), trees per acre (TPA), and basal area per acre (BA/A). Statistics include the mean, standard deviation, standard error, variance, coefficient of variance (CV), confidence interval at 95\% level, percent of error, and sample size.

Local volume equations were incorporated into the system for automating individual tree's volume calculation. These equations were based on DBH and merchantable height in the number of 16-foot logs for Girard Form Class (GFC) 78. The system can compute board-foot volume of both Doyle and International 1/4 (Wiant and Castandra 1977, Wiant 1986) and cubic-foot volume (Rennie 1996). The computed volume in board feet is then adjusted by $3 \%$ per unit of GFC for each form class value above or below 78 while it is adjusted by $2 \%$ for cubic-foot volume. However, volume equations can be easily modified for other species in other regions. 
Once the cruising data were summarized, the results are stored in the database for report generation. A total of seven reports can be generated in the data analysis component of this system.

\subsubsection{Algorithms for Volume Summary}

Three algorithms discussed in this section are used most frequently for volume summary in the system and are computationally expensive. The first one is for the volume calculation of an individual tree while the second algorithm is about the volume summary for all plots or points cruised and converts it to a per acre basis. The third algorithm deals with the cruising statistics for volume estimators, trees per acre, or basal area per acre.

(1) Calculating the volume for a tree

a. Adjust the form class for the tree

b. Check log rule used

c. Calculate the volume based on the dbh, the number of 16-foot logs, and adjusted form factor

This function is the most frequently used function in Data Analysis module (Listing B.5). It takes a constant time to compute the volume for a tree - $\mathrm{O}(1)$.

(2) Summarizing the volume

a. Check the number grades, species, dbh classes, tree 
b. Convert expansion factor for a specific plot type and prepare the volume on a per acre basis

c. Summarize the volume by dbh class

d. Summarize the volume by species

e. Summarize the volume by grade

f. Summarize the volume by the combinations of dbh, species, and grade

g. Save the summary data for generating reports.

The code for this function is listed (Listing B.6). The algorithm takes $\mathrm{O}\left(\mathrm{n}^{4}\right)$ times to summarize the volume by the combination of grade, species, and dbh class. Where, $n$ is the number of trees. As n get bigger, it will take substantial time to summarize the volume and other information for a large cruising job.

(3) Cruise Statistics

a. Summarize the volume estimator for all the plots or points

b. Summarize the square of a volume estimator for all plots or points

c. Calculate the cruising statistics for volume estimators and other measured variables, including mean, variance, standard deviation, standard error, coefficient of variation, confidence interval, percent error of cruising, and the sample size.

This function is applied to a cruising job (Listing B.7). It takes a linear time to compute all the statistics for a cruise $-\mathrm{O}(\mathrm{n})$. $\mathrm{n}$ stands for the number of sampling plots or points. 


\subsubsection{Analysis Example}

A tract of 80 acres was cruised on the West Virginia University Research Forest to demonstrate how this timber cruising system works (Wang et al. 2004). With the handheld unit, a total of 35 sample points were cruised including 204 trees. Variables recorded in the filed include plot number, species, DBH, merchantable height, total height, and grade for each individual tree. The cruise data were then transferred into a database on a desktop PC with the data transfer component. The data analysis component was used to analyze the cruise data, which provides us seven summary reports, such as volume summary per acre by species (Table 3.1) and cruising statistics (Table 3.2).

Table 3.1. Merchantable volume summary per acre for a tract of 80 acres on the WVU Research Forest.

\begin{tabular}{llllllllll}
\hline Species & QMD & IBFV & DBFV & CFV & TPA & BA & IBFV, \% & DBFV, \% & CFV,\% \\
\hline American & 7 & 0.0 & 0.0 & 16.1 & 2 & 0.6 & 0 & 0 & 1 \\
beech & & & & & & & & & \\
Basswood & 13 & 138.4 & 105.8 & 39.1 & 2 & 1.7 & 1 & 2 & 2 \\
Black cherry & 17 & 810.1 & 570.1 & 118.1 & 4 & 6.3 & 8 & 8 & 5 \\
Black locust & 13 & 43.3 & 28.3 & 93.3 & 4 & 4.0 & 0 & 0 & 4 \\
Black oak & 19 & 101.9 & 72.1 & 15.0 & 0 & 0.6 & 1 & 1 & 1 \\
Chestnut oak & 14 & 850.5 & 653.6 & 184.8 & 11 & 10.9 & 9 & 10 & 8 \\
Cucumber & 8 & 88.0 & 60.8 & 27.0 & 3 & 1.1 & 1 & 1 & 1 \\
tree & & & & & & & & & \\
Hickory & 13 & 231.7 & 150.5 & 54.4 & 3 & 2.9 & 2 & 2 & 2 \\
Red oak & 12 & 3430.2 & 2358.9 & 791.6 & 50 & 38.3 & 36 & 34 & 35 \\
Red maple & 8 & 1222.8 & 817.2 & 287.6 & 48 & 16.6 & 13 & 12 & 13 \\
Black birch & 10 & 129.2 & 84.2 & 110.9 & 11 & 6.3 & 1 & 1 & 5 \\
Sugar maple & 9 & 348.5 & 268.3 & 149.4 & 14 & 6.3 & 4 & 4 & 7 \\
Scarlet oak & 15 & 0.0 & 0.0 & 21.6 & 1 & 1.1 & 0 & 0 & 1 \\
White ash & 18 & 74.7 & 52.6 & 11.1 & 0 & 0.6 & 1 & 1 & 1 \\
Yellow birch & 17 & 60.3 & 43.5 & 33.6 & 2 & 2.9 & 1 & 1 & 1 \\
Yellow poplar & 14 & 1961.4 & 1457.9 & 310.2 & 13 & 13.1 & 20 & 21 & 14 \\
Others & 5 & 143.6 & 121.6 & 20.4 & 28 & 3.4 & 1 & 2 & 1 \\
Total & & 9634.8 & 6845.4 & 2284.1 & 196 & 116.6 & 100 & 100 & 100 \\
\hline
\end{tabular}

QMD refers to quadratic mean diameter and can be calculated by the following equation: 


$$
Q M D=\sqrt{\frac{B A A}{0.005454154}}
$$

Where $\mathrm{BAA}=$ basal area in $\mathrm{ft}^{2}$ per acre.

Table 3.2. Timber cruising statistics on per acre basis for a tract of 80 acres on the WVU Research Forest.

\begin{tabular}{llllllllll}
\hline Statistics & Mean & Sd. Dev. & Sd. Error & Variance & CV, \% & CI, 95\% & Error, \% & $\begin{array}{l}\text { Sample } \\
\text { size, } \\
95 \%\end{array}$ \\
\hline CFV & 2284.1 & 1106.2 & 187.0 & 1223742.0 & 48 & 366.5 & 16.0 & 93.8 \\
IBFV & 9634.8 & 5160.4 & 872.3 & 26629490.0 & 54 & 1709.6 & 17.7 & 114.7 \\
DBFV & 6854.4 & 3702.6 & 625.8 & 13708880.0 & 54 & 1226.7 & 17.9 & 117.0 \\
TPA & 196.0 & 217.6 & 36.8 & 47364.3 & 111 & 72.1 & 36.8 & - \\
BA/acre & 116.6 & 45.9 & 7.8 & 2105.5 & 39 & 15.2 & 13.0 & - \\
\hline
\end{tabular}

Statistics are provided for the cruising estimators such as volume per acre and trees per acre (Table 3.2). Specifically, the sample size can be determined for each of the estimators. For example, if the forester concerns Doyle board foot volume with allowable error $10 \%$, the sample size should be 117 of sampling points or plots at $95 \%$ confidence level based on equation (2-15).

$$
S Z=\frac{4 \times 54^{2}}{10^{2}}=116.6 \approx 117
$$

If the forester only concerns cubic foot volume estimator, the sample size needed is 94 for $95 \%$ confidence level. However, if all three estimators of CFV, IBFV, and DBFV are considered, a sample size of 117 points should be conducted in the field in order to meet $95 \%$ confidence level. 


\section{CHAPTER 4: CONCLUSIONS AND DISCUSSION}

Foresters have always embraced the use of computer applications that make the collection and processing of inventory data more profitable in terms of money and time. When faced with the large task of cruising 70,000 acres, which would include the measurement of approximately 115,000 trees, we developed a software solution that would facilitate the warehousing and analyses of the inventory data.

The timber cruising system has been developed with a modular design, which could be easily maintained and evolved. The three components developed as part of the inventory software solution can work separately or perform as an integrated system. This cruising package provides a user-friendly interface and very flexible functions for the collection, analysis and reporting of inventory data. Touch screen or numeric data entry on handheld computers provides an efficient means of data collection. No specific computer knowledge is required to operate this system.

This inventory system has been successfully tested in the field during the recent inventory of three state forests in West Virginia and the WVU research forest. The software solution provided fieldworkers an accurate, user-friendly data collection system. Although the HP Jornada Pocket PC was used as the development prototype for this cruising system, the system is compatible with any handheld computers that run the Microsoft Pocket-PC or CE operation system. The HP Jornada Pocket PC was used because it used both a touch screen and a keypad, as well as its modest price tag. Likewise, in the event of a critical failure, a new HP Jornada Pocket PC could be purchased immediately at a local office supply outlet. 
Under extreme weather conditions, this system may be more reliable if used with a weather-tight field handheld PC such as Juniper Allegro or Itronix fex21. Likewise, if cold temperatures are expected, extra batteries are needed to keep the Jornada PCs working for the duration of data collection. Other problems included difficulty viewing the Jornada HPC screen in direct sunlight. However, once the contrast and brightness were adjusted to appropriate levels and direct sunshine was avoided, the HPC worked well. Use of field HPC such as Itronix Husky can also overcome the viewing problem. In addition, the data collected with the system can not only be used to generate useful cruising summary reports, but also to conduct research such as time study of cruising efficiency of the field user and others.

One negative aspect of this system is that reports generated with ActiveX object of MS Access cannot be embedded within an interface form in the data analysis component, which can correspondingly cause some problems to the backend database. The MS Data Report designer with MS VB V6.0 or later can be used to overcome this problem. This VB object is a versatile data report generator that features the ability to created banded hierarchical reports. Used in conjunction with a data source, such as the data environment designer, the user has the ability to create reports from several different relational tables. The reports will then be displayed and contained seamlessly in the cruising project. In addition to creating printable reports, the user can also export the report to HTML or text files.

A few things need to be improved in the integrated timber cruising system. Algorithms, specifically the one for volume summary with $\mathrm{O}\left(\mathrm{n}^{4}\right)$ running time, should be redesigned so as to reduce the running times for a larger inventory job. The handheld 
system should be adapted to the global positioning system (GPS) with Windows CE operating system, such as Geo XT, which could allow the user to collect the tree position during the field cruising process, in addition to the species and size of a tree. An online cruising system has been developed for the landowners to analyze the field data online and generate the reports. The online system should allow the user not only to enter the cruising data manually, but also to be able to upload the data and download the cruising summary and reports. Since the handheld system also records three elemental times, the cruising efficiency could be analyzed using this system.

Historically, developers have come in two general flavors: Visual C++ and Visual Basic developers. Specifically, many forestry related applications were recently developed with Visual Basic. VB provides for rapid GUI-based application development that, time-wise, just can not be matched with $\mathrm{C}++$. Certainly, there are always applications for which $\mathrm{C}++$ is better suited.

The integrated timber cruising system should be migrated into the Microsoft .NET environment, specifically for web-based applications. Microsoft .NET provides a consistent programming model that can be used for many types of applications. Before .NET, Microsoft tools were lacking in their integration and ease-of-use for web development. While COM is a viable platform for enterprise-level Internet applications, it does have some serious limitations such as DLL Hell, lack of interoperability, and lack of built-in inheritance (Barwell et al. 2003). When the .NET initiative was announced in 2000, it heralded a replacement for both Win32 and COM (Yao and Durant 2004). The .NET Framework provides developers with a significant number of benefits including a more robust, evidence-based security model, automatic memory management and native 
Web services support. For new development, Microsoft recommends .NET as a preferred technology because of its powerful managed runtime environment and services. Like the .NET compact framework, ASP.NET mobile controls allows the user to build applications for mobile devices. However, .NET compact framework applications run on the devices as "rich client" with access to the resources of the device, while ASP.NET applications only use a web browser (Wigley and Wheelwright 2003). ASP.NET allows the user to use any programming languages based on the .NET framework, such as VB.NET or VC++.NET, to create web applications. 


\section{LITERATURE CITED}

Avery, T. and H. Burkhart. 1994. Forest Measurements (Fourth Edition). McGraw-Hill. Boston, MA. 408p.

Barwell, F., R. Case, B. Forgey, B. Hollis, and T. McCarthy. 2003. Professional VB.NET ( $2^{\text {nd }}$ Edition). Wiley Publishing, Inc. Indianapolis, IN.

Belli, K.L., A.R. Ek, M.H. Hansen and J.T. Hahn. 1987. Statewide forestry databases for microcomputers. Northern J. of Appl. For. 4: 117-118, 165.

Ben Meadows Company. 2003. Timber Cruising. TechInfo. Document No. 224 (www.benmeadows.com).

Blinn, C.R. and J. Vandenberg-Daves. 1993. Evaluation of a computerized timber inventory system for nonindustrial private landowners. Northern J. of Appl. For. 10(3): 123-127.

Boling, D. 2003. Programming Microsoft Windows CE .NET ( $3^{\text {rd }}$ Edition). Microsoft Press, Redmond, Washington, USA.

Brooks, D.G. and M.C. Vodak. 1986. YPOP: A microcomputer program for evaluating thinning alternatives in natural stands of yellow-poplar. Northern J. of Appl. For. 3: 3-5.

Brooks, J. and D. Goerlich. 2002. Review of Avery's 3\% rule for Mesavage and Girard board foot volume tables. Unpublished Paper.

Buser, D., J. Kauffman, J. Llibre, B. Francis, D. Sussman, C. Ullman, and J. Duckett. 1999. Beginning Active Server Pages 3.0. Wrox Press Ltd. Birmingham, UK.

Clutter, J.L., J.C. Fortson, L.V. Pienaar, G.H. Brister, and R.L. Bailey. 1983. Timber management: A quantitative approach. Krieger publishing Company. Malabar, Florida.

Cormen, T.H., C.E. Leiserson, R.L. Rivest, and C. Stein. 2001. Introduction to algorithms (second edition). The MIT Press. Cambridge, Massachusetts.

Farrar, K.D. 1981. In situ stand generator for use in harvesting machine simulations. M.Sc. Thesis, Virginia Polytech. and State Univ., Blacksburg. 211 p.

Farrar, R.M. and T.G. Matney. 1994. A dual growth simulator for natural even-aged stands of longleaf pine in the south's east gulf region. South. J. Appl. For. 18(4): 147155. 
Hilt, D.E. 1985. OAKSIM: An individual-tree growth and yield simulator for managed, even-aged, upland oak stands. USDA Forest Service, Northeastern Forest Experiment Station. Research Paper NE-562.

Goulet, D. V., R. H. Iff, and D. L. Sirois. 1979. Tree-to-mill forest harvesting simulation models: Where are we? Forest Products Journal. 29(10): 50-55.

Lewis, T. 1999. VB COM - A Visual Basic Programmer's Introduction to COM. Wrox Press Ltd., Birmingham, UK. 345pp.

MacLean, D.A., K.B. Porter, and J. Kerr. 1998. Forester's yield curve designer software. Northern J. of Appl. For. 15(1): 23-27.

Microsoft Corporation. 1998. Microsoft Visual Basic 6.0 - Programmer's Guide. Microsoft Press, Redmond, Washington, USA.

Mitchell, D. 2001. Developing pocket PC applications with MS eMbedded Visual Basic. PocketPC Magazine (www.PocketPCmag.com).

Moser, J.W. and J.D. Raney. 1990. A programmable calculator-assisted procedure for marking uneven aged stands. Northern J. of Appl. For. 7: 140-142.

O’Neil, P. and E. O’Neil. 2001. Database Principles, Programming, and Performance ( $2^{\text {nd }}$ Edition). Morgan Kaufmann Publishers, San Francisco, CA.

Reisinger, T., W. D. Greene, and J. F. McNeel. 1988. Microcomputer-based software for analyzing harvesting systems. Southern J. of Appl. For. 12: 37-41.

Rennie, J.C. 1991. Forest inventory processing with statistical software. Northern J. of Appl. For. 8: 41-44.

Rennie, J.C. 1996. Formulas for Mesavage's cubic-foot volume table. Northern J. of Appl. For. 13(3): 147-148.

Roof, L. 1998. Professional Visual Basic Windows CE Programming. Wrox Press Ltd., Birmingham, UK. 447 pp.

Rose, D.W. and C.M. Chen. 1995. An interactive thinning simulation for red pine stands. Northern J. of Appl. For. 12(1): 43-48.

Rumbaugh, J., M. Blaha, W. Premerlani, F. Eddy, and W. Lorensen. 1991. Objectoriented modeling and design. Prentice Hall. Englewood Cliffs, New Jersey. 
Shiver, B. and B. Borders. 1996. Sampling techniques for forest resource inventory. John Wiley \& Sons, Inc., New York. 356p.

Stuart, W. B. 1981. Harvesting analysis technique: a computer simulation system for timber harvesting. Forest Products Journal. 31(11): 45-53.

Tacke, C. and T. Bassett. 2002. eMbedded Visual Basic: Windows CE and pocket PC mobile applications. SAMS Publishing. Indianapolis, Indiana, USA.

Ullman, J. and J. Widow. 1997. A first course in database systems. Prentice Hall. Upper Saddle River, New Jersey.

Wang, J., W.D. Greene, and B.J. Stokes. 1998. Stand, harvest, and equipment interactions in simulated harvesting prescriptions. Forest Prod. J. 48(9): 81-86.

Wang, J. and W.D. Greene. 1999. An interactive simulation system for modeling stands, harvest, and machines. International J. of For. Eng. 10(1): 81-99.

Wang, J. and C. LeDoux. 2003. Estimating and validating ground-based timber harvesting production through computer simulation. For. Sci. 49(1):64-76.

Wang, J., J. McNeel, and J. Baumgras. 2003. A computer-based time study system for timber harvesting operations. Forest Prod. J. 53(3): 47-53.

Wang, J., S. Grushecky, and J. Brooks. 2004. An integrated computer-based cruising system for central Appalachian hardwoods. Computers and Electronics in Agriculture. 45(2004): 133-138.

Wang, J., C. Long, and J. McNeel. 2004. Production and cost analysis of a fellerbuncher and grapple skidder in central Appalachian hardwood forests. Forest Prod. J. 54(12): 159-167.

Wiant, H.V., Jr. and F. Castandra. 1977. Mesavage and Girard's tables formulated. Resour. Inventory Note. BLM 4:1-4.

Wiant, H.V., Jr. and C.W. Gambill. 1985. Minimize field time when cruising Appalachian hardwoods. Northern J. of Appl. For. 2: 70-71.

Wiant, H.V., Jr. 1986. Formulas for Mesavage and Girard's volume tables. Northern J. of Appl. For. 3:124.

Wiant, H.V. 1990. An inexpensive computer system for rapid sawtimber estimates. Northern J. of Appl. For. 7: 142-145.

Wigley, A. and S. Wheelwright. 2003. Microsoft .NET compact framework. Microsoft Press, Redmond, Washington, USA. 
Yao, P. and D. Durant. 2004. .NET compact framework programming with Visual Basic .NET. Addison-Wesley. Boston, MA. 


\section{APPENDIX A: USER'S MANUAL}

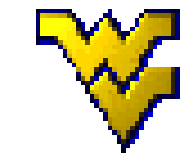

WVU Cruise V1.0.0

\section{WVU Cruise Help}

Field Data Collection

Field Data Transfer

Field Data Format

Import Data

Load Data

Cruise Deign

Analysis and Report

\section{Field Data Collection}

Forest and plot information is entered first and the user then selects the "Add Plot" button. The tree data frame is then enabled accordingly. Text boxes on the tree data frame are enabled and disabled depending on the type of plot being selected. Once trees are entered, a VB list box control is used to display the tree attributes found on a plot.

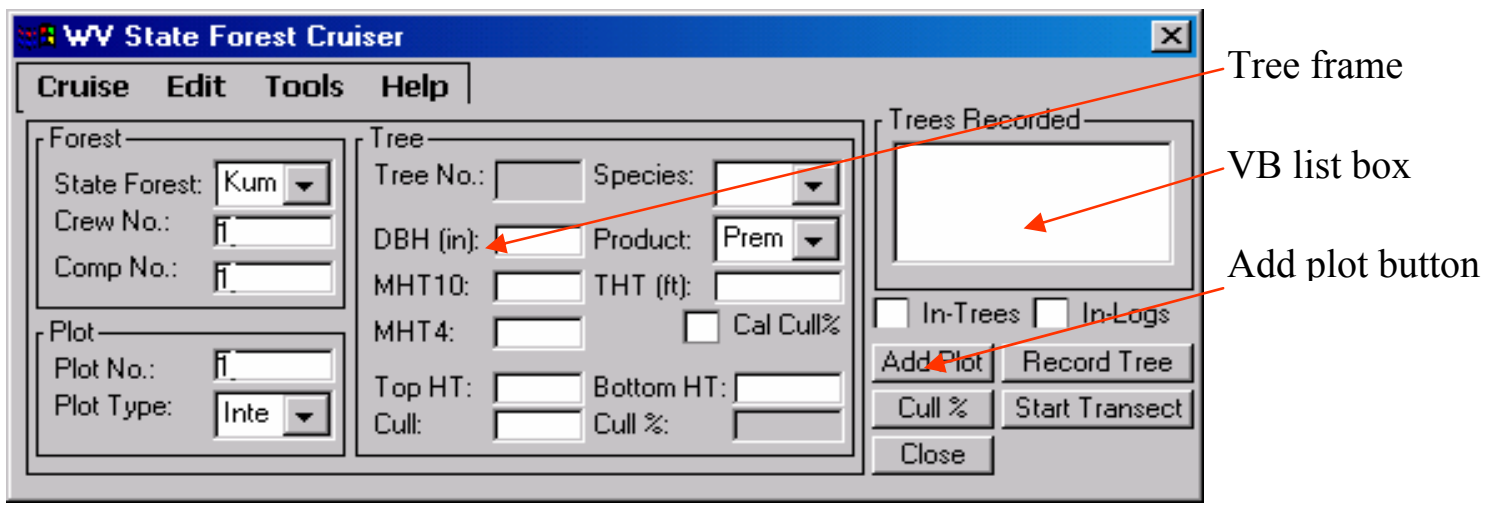

Figure A.1. Field data collection. 
A list of convenient VB list controls were implemented for adding or removing single or multiple items for transect data collection.

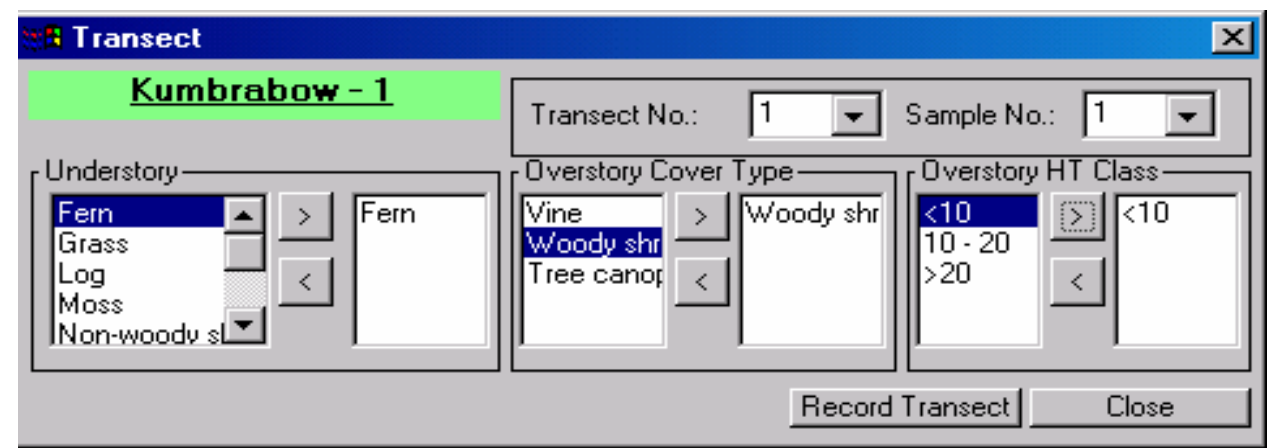

Figure A.2. Transect data collection.

Field transcription mistakes are common; therefore the handheld system provided functionality that allowed the user to edit tree data in the field. Trees sampled on a plot can be retrieved based on forest, crew number and/or plot number. Once trees are retrieved for a plot, the user can navigate the selected record set and modify the data for that tree and then move to the next tree or on to another plot.

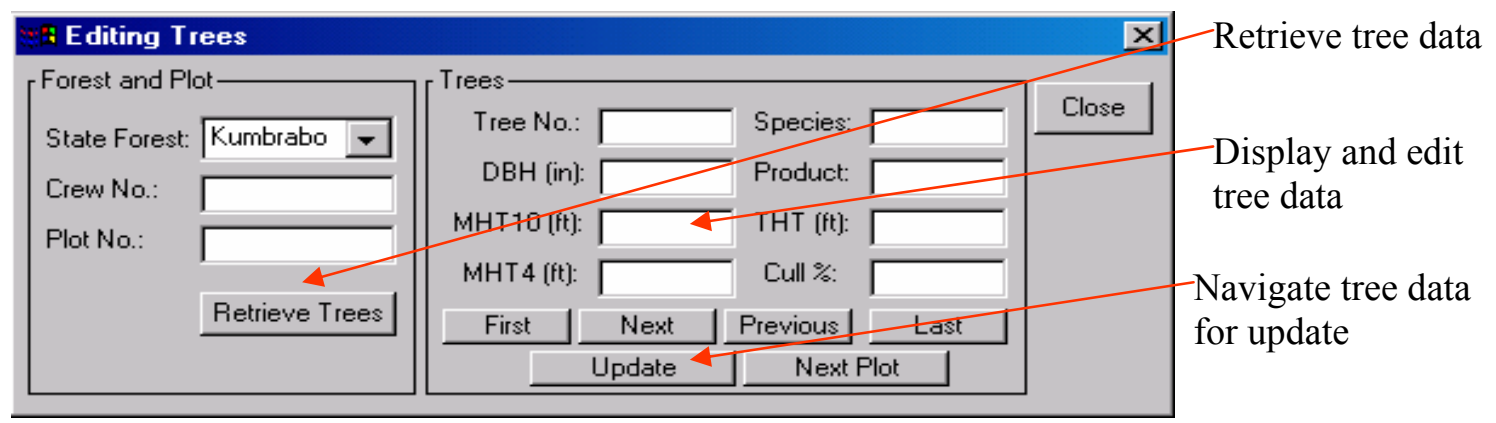

Figure A.3. Edit trees. 


\section{Field Data Transfer}

(1) Click on the "Get Data From HPC" button to transfer the field cruise data from HPC to desktop PC.

(2) Then the user can update tree species on the HPC and empty data tables on the HPC for nest cruise job.

(3) The user is prompted the transferring status and any potential errors occurred during the process.

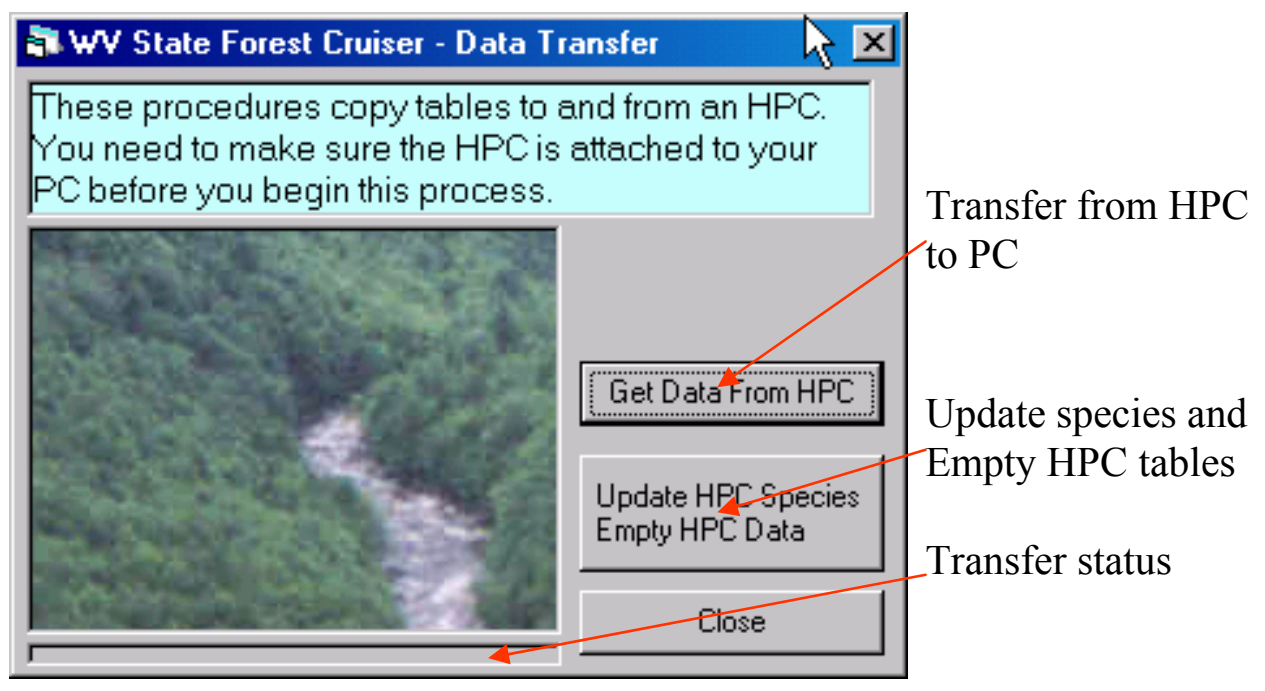

Figure A.4. Data transfer dialog box.

Once you transferred the cruise data to a desktop PC, you are allowed to edit plot, tree, or transect data. The user selects a plot first, then the user can edit the trees or transects associated with this selected plot.

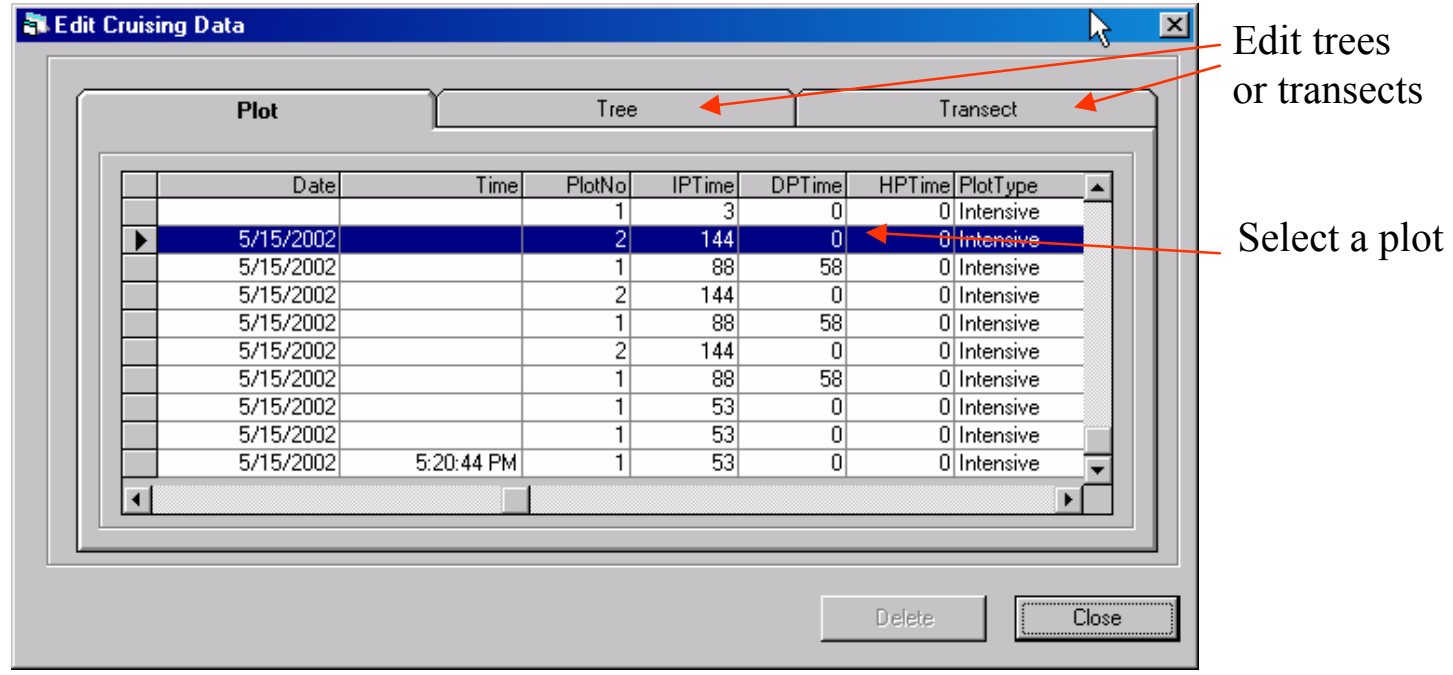

Figure A.5. Edit plot, trees, and transects. 


\section{Field Data Format}

The field cruising data should be in the format of MS Excel. In order to import the Excel data to WVU Cruise, you need to do the following things:

(1) Open the Excel file that contains the cruising data. The data must contains the fields of Plot\#, Species (Spp), DBH, merchantable height in number of logs (MHT), Pulp, Grade, and total height in feet (HGT). These fields must be in the proper order. If you have no data for one or more fields, put $0 \mathrm{~s}$ in the cells.

\begin{tabular}{|c|c|c|c|c|c|c|c|c|}
\hline \multicolumn{7}{|c|}{ 离 Charlie.xls } & \multicolumn{2}{|c|}{\begin{tabular}{l|l|l|} 
&
\end{tabular}} \\
\hline & A & B & C & $\bar{D}$ & E & $F$ & G & $\overline{1}$ \\
\hline 1 & Plot & $\overline{\text { Spp }}$ & $\overline{\text { DBH }}$ & MHTT & Pulp & Grade & HGT & $=$ \\
\hline 2 & 1 & $\mathrm{RM}$ & 34 & 1.5 & 0 & 3 & 117 & \\
\hline 3 & 1 & YB & 21 & 0 & 0 & 8 & 0 & \\
\hline 4 & 1 & YB & 13 & 0 & 0 & 10 & 0 & \\
\hline 5 & 1 & YB & 18 & 1.5 & 0 & 3 & 97 & \\
\hline 6 & 1 & $S \mathrm{M}$ & 12 & 0.5 & 0 & 3 & 83 & \\
\hline 7 & 1 & $\mathrm{OH}$ & 2 & 0 & 0 & 9 & 0 & \\
\hline 8 & 1 & SM & 19 & 3 & 0 & 3 & 102 & \\
\hline 9 & 1 & YB & 18 & 0 & 0 & 8 & 0 & \\
\hline 10 & 2 & RM & 14 & 1.5 & 0 & 3 & 0 & \\
\hline 11 & 2 & NRO & 23 & 2.5 & 0 & 3 & 0 & \\
\hline 12 & 2 & NRO & 15 & 2.5 & 0 & 3 & 0 & 에 \\
\hline \begin{tabular}{|l|}
12 \\
14
\end{tabular} & |7| & $\mathrm{ns} / \mathrm{s}$ & ${ }^{\circ} /$ & $\begin{array}{c}n \\
\text { CRE }\end{array}$ & & & & \\
\hline
\end{tabular}

Figure A.6. Format of cruise data.

(2) Create a Named Range, DataRange, in your Excel spreadsheet

a. Highlight the row(s) and column(s) area where your data resides.

b. On the Insert menu, point to Name, and click define.

c. Enter the name DataRange for the Named Range name.

d. Click OK. 


\section{区 Microsoft Excel}

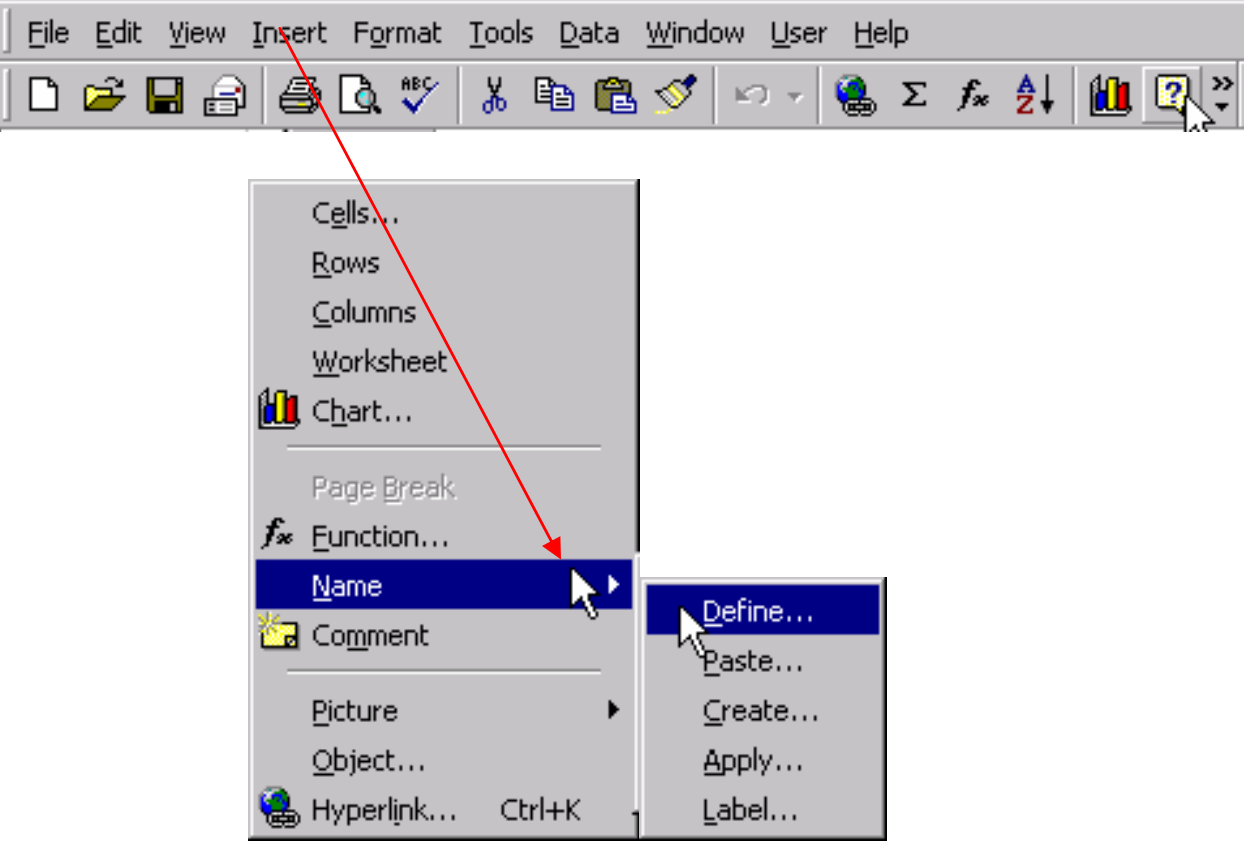

Figure A.7. Define a data range associated with data object.

(3) Now, start WVU Cruise program, the main MDI form is displayed first. On the menu bar, there are File, Report, Tools, and Help menus.

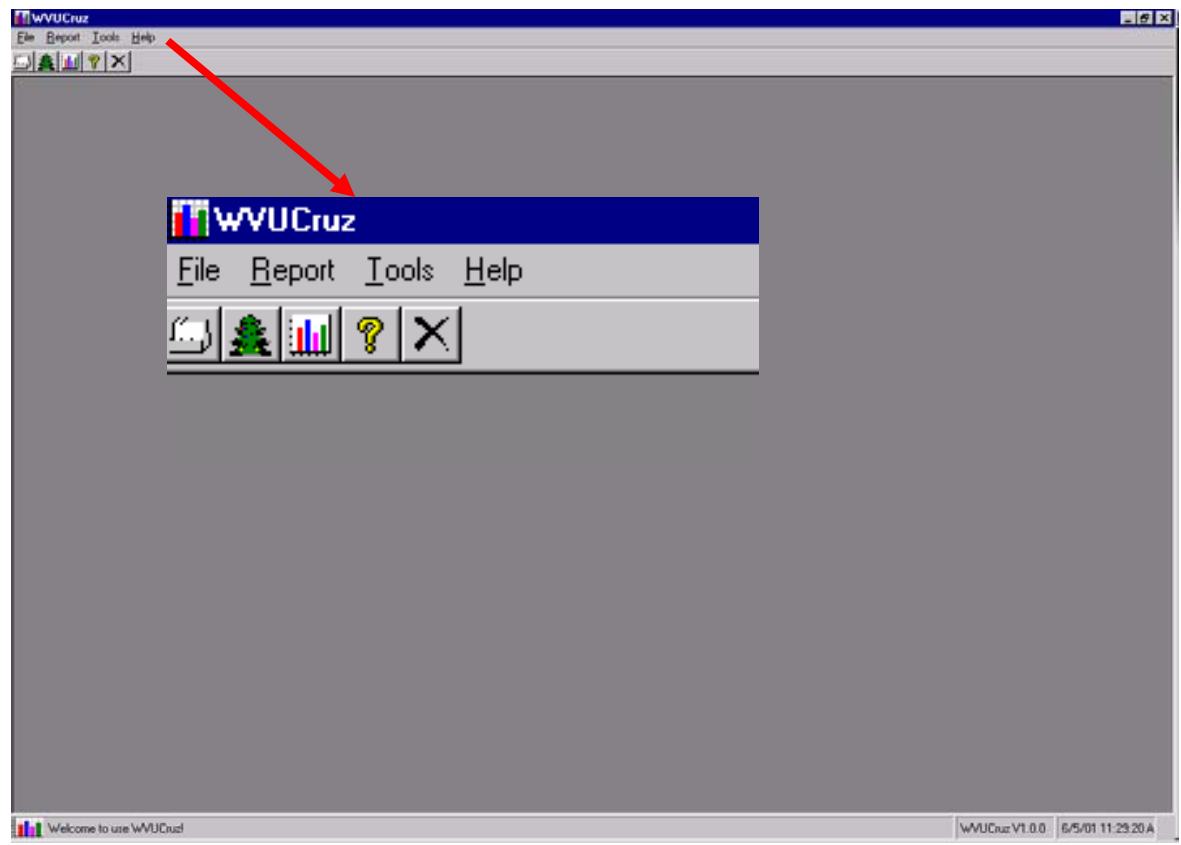

Figure A.8. Menu and tool bars of WVU Cruise. 


\section{Import Data}

(1) In the Tools menu, click Import, a dialog window is popped up for importing Excel data into the cruising program. Once the file is selected, click OK.
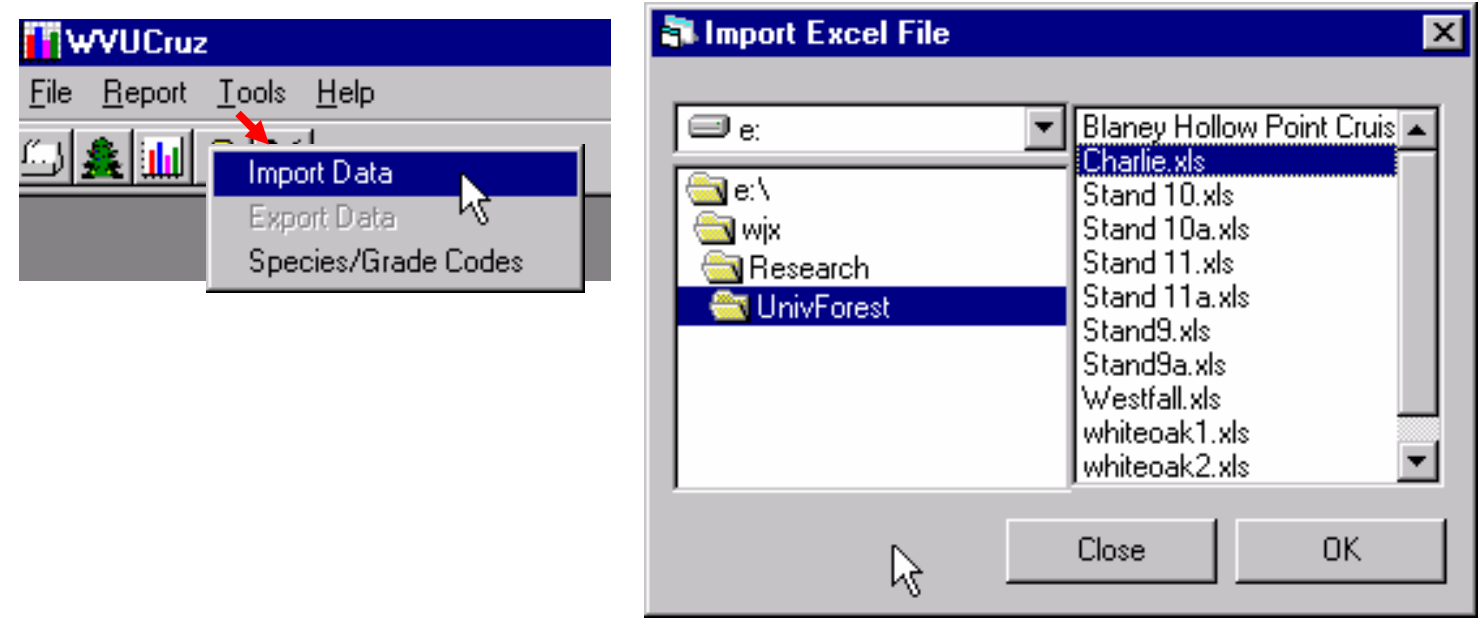

Figure A.9. Import Excel data to WVU Cruise.

\section{Load Data}

(1) Now you can load the cruising data in the program. In the File menu, click Open, the cruising data will be loaded for analyses.

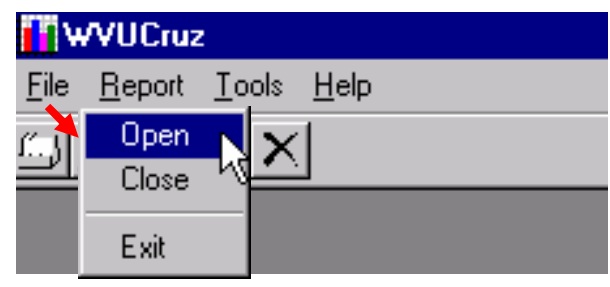

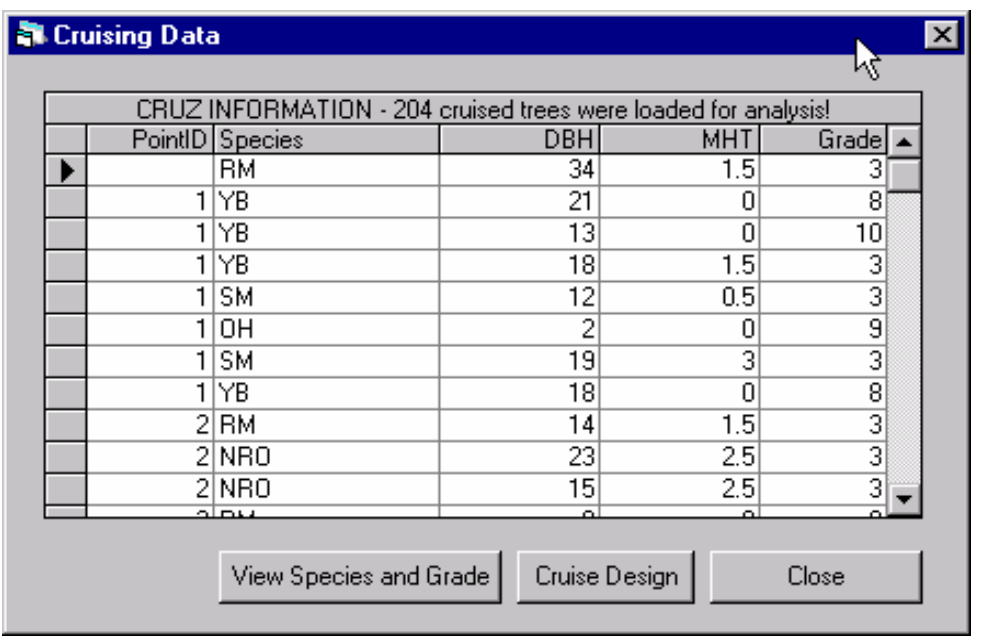

Figure A.10. Load cruise data for analysis. 
(2) You can browse the data loaded. You should notice there are "View Species and Grade" and "Cruise Design" buttons on the form.

\section{Cruise Design}

If the user clicks the "Cruise Design" button, a design form will be popped up.

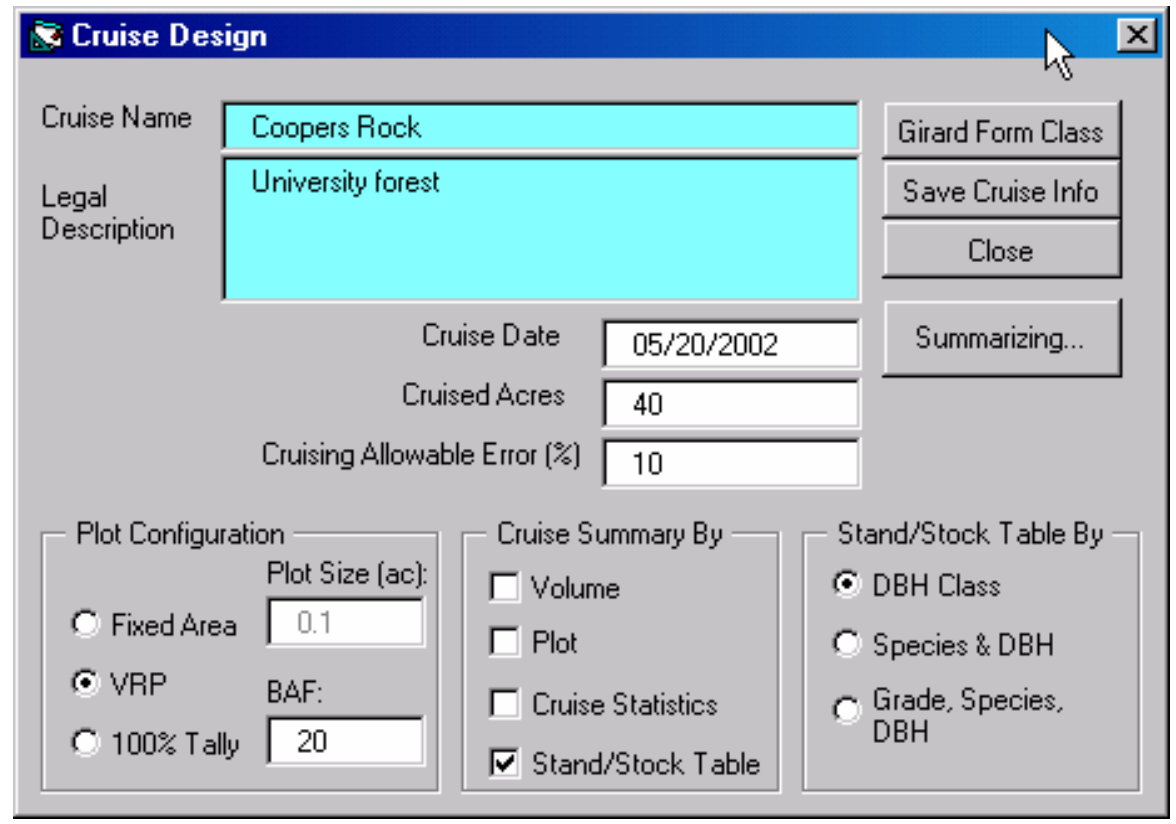

Figure A.11. Cruise design window.

In this design window, you can:

(1) Design and save cruising information for report header. Simply enter the required text boxes and then click "Save Cruise Info".

(2) Select form class for a specific species. Click "Girard Form Class", a form is displayed.

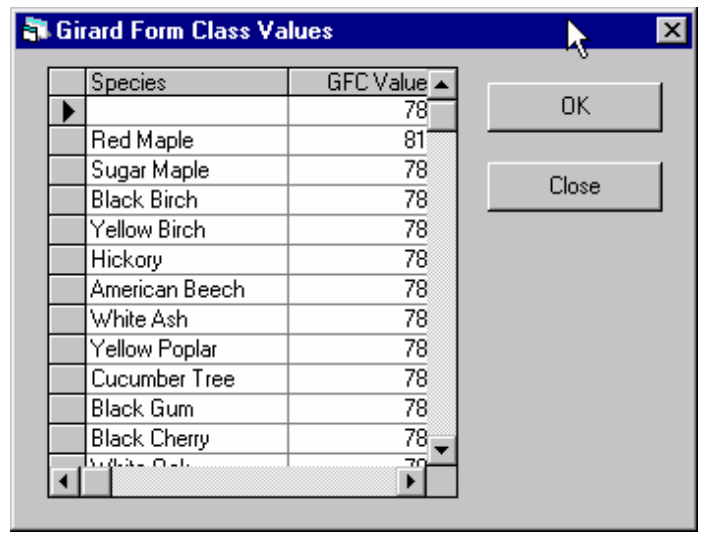

Figure A.12. Edit Girard form class by species. 
(3) Configure plot. You can use fixed area, variable radius plot, or $100 \%$ tally.

(4) Summarize cruising data by:

a. Volume

b. Plot

c. Cruise statistics

d. Stand/stock table

i. DBH class

ii. Species and DBH

iii. Grade, species, and DBH

\section{Analysis and Report}

\section{$\underline{\text { By Volume }}$}

Suppose the user checks the "VRP" and "Volume" and then click "OK", a volume summary form is displayed. Two parts of volume summary are provided: merchantable volume tract summary and merchantable volume per acre summary.

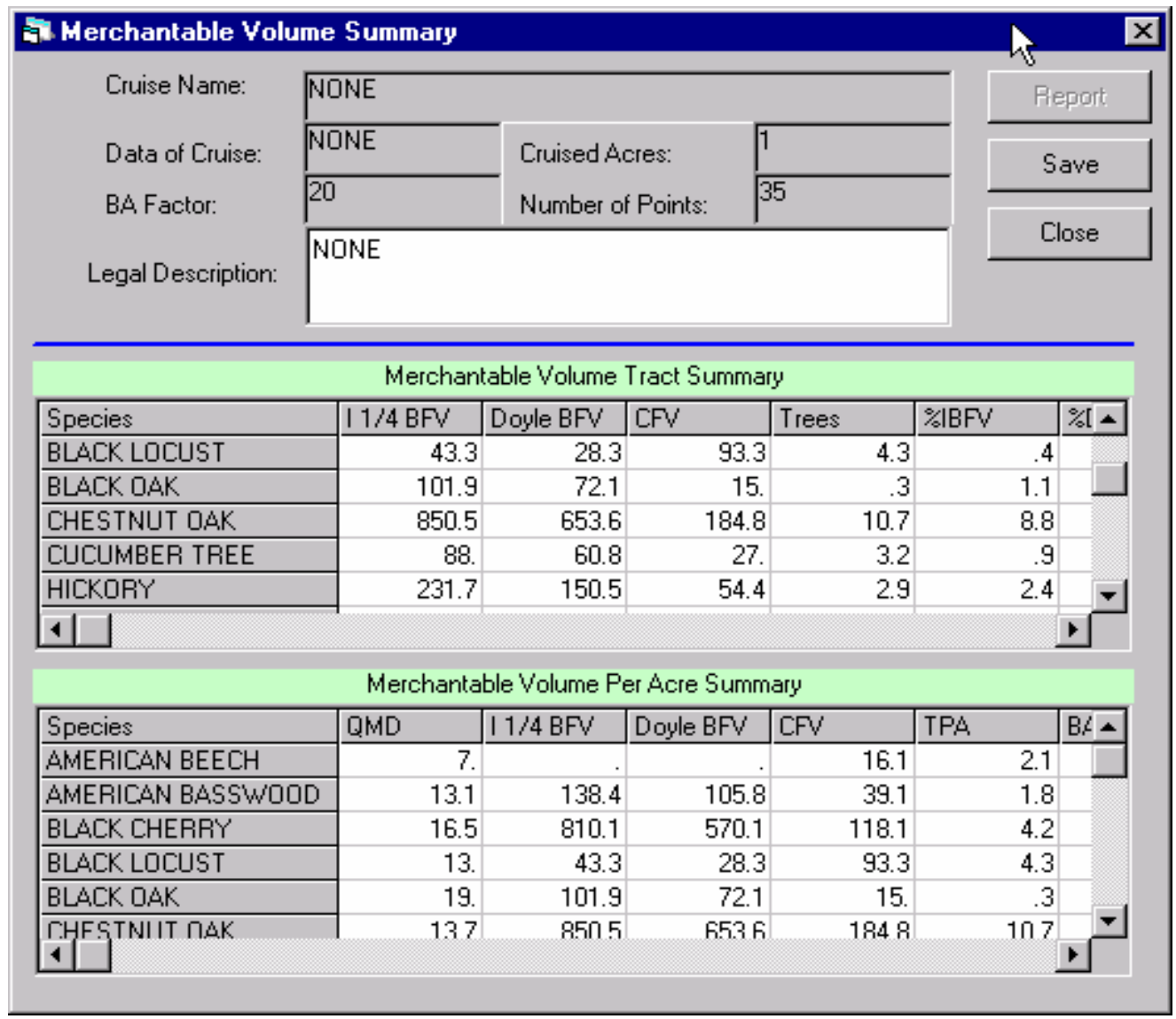

Figure A.13. Volume summary on both per acre basis and tract basis. 
Click "Save" to save the data into the database, and then click "Report", two reports will be generated in this case.

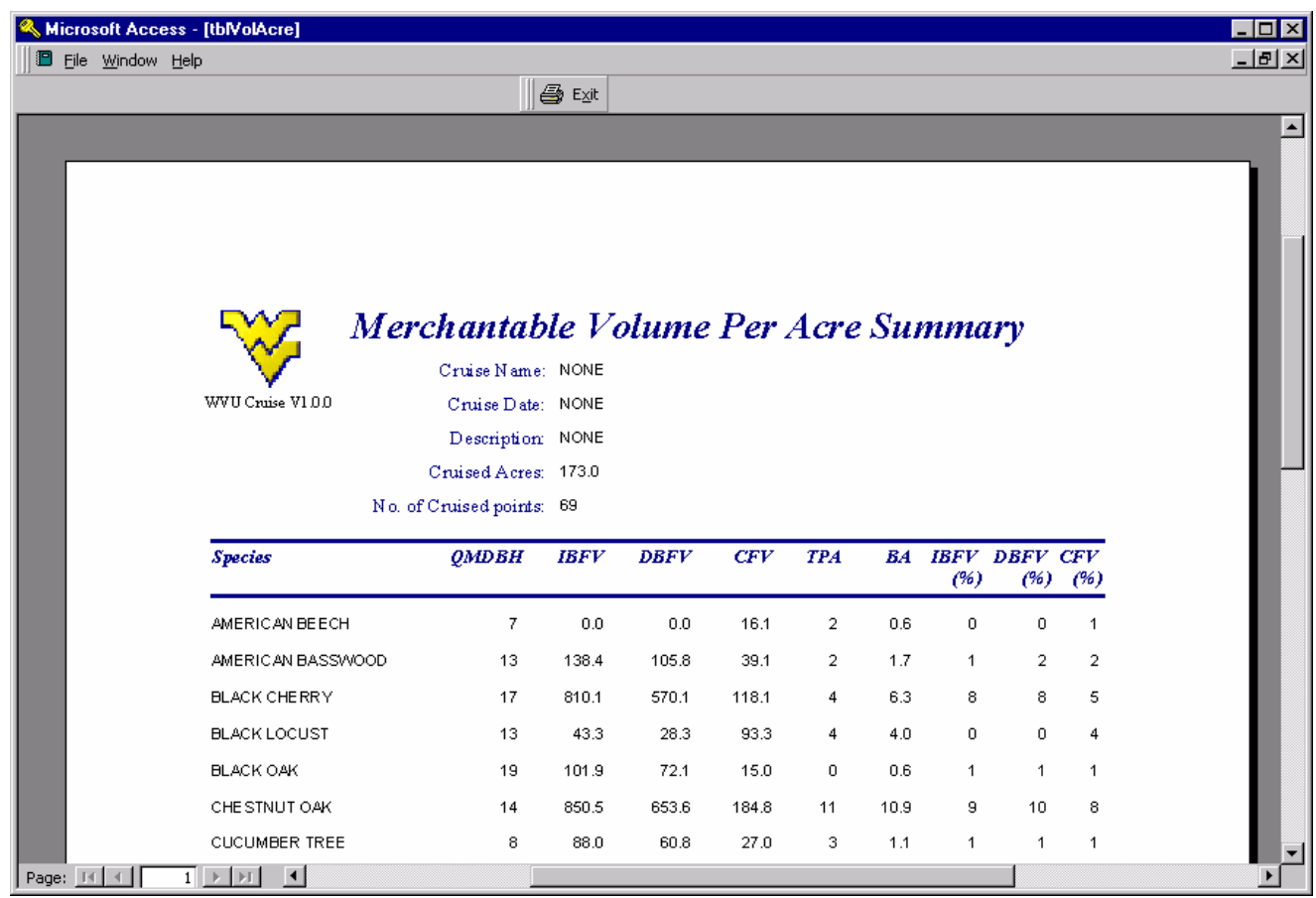

Figure A.14. Report of merchantable volume summary.

\section{By Plot}

Check "Plot" and click "OK", a summary by plot is provided. Once the data are saved, click "Report"; a report by plot will be generated.

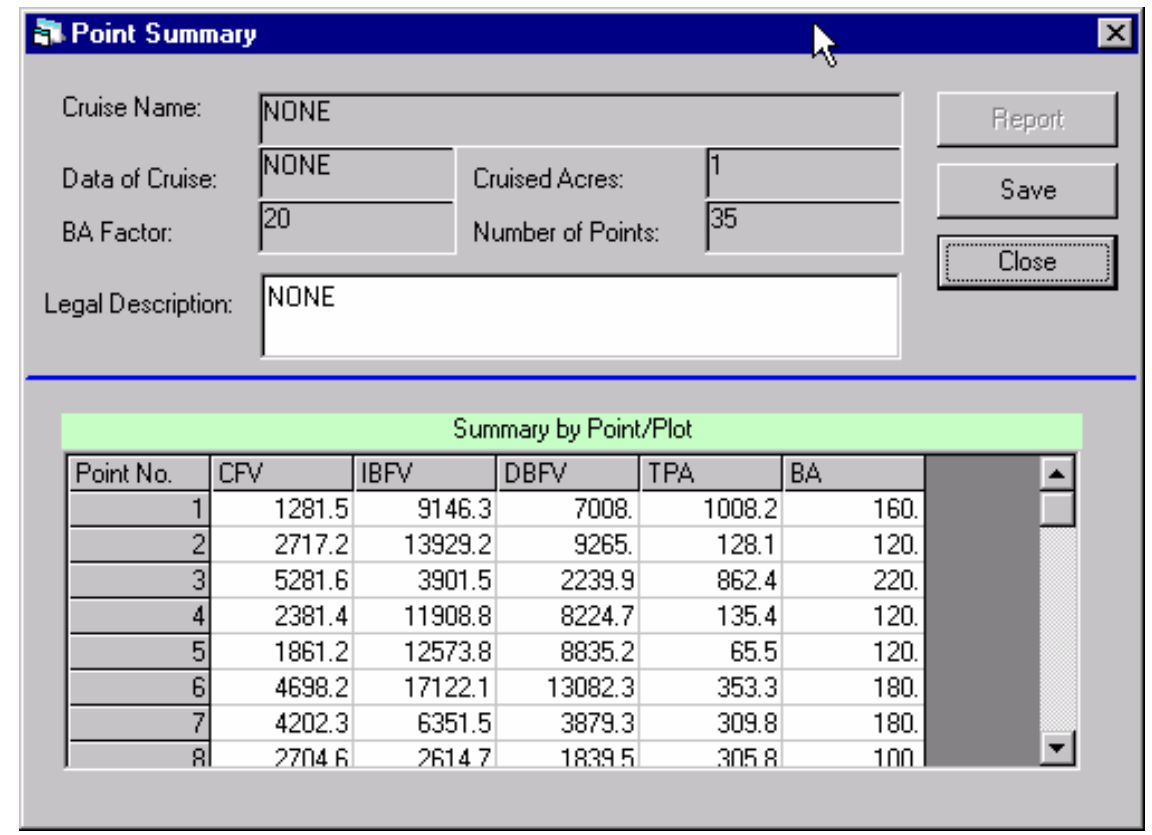

Figure A.15. Plot/point summary. 


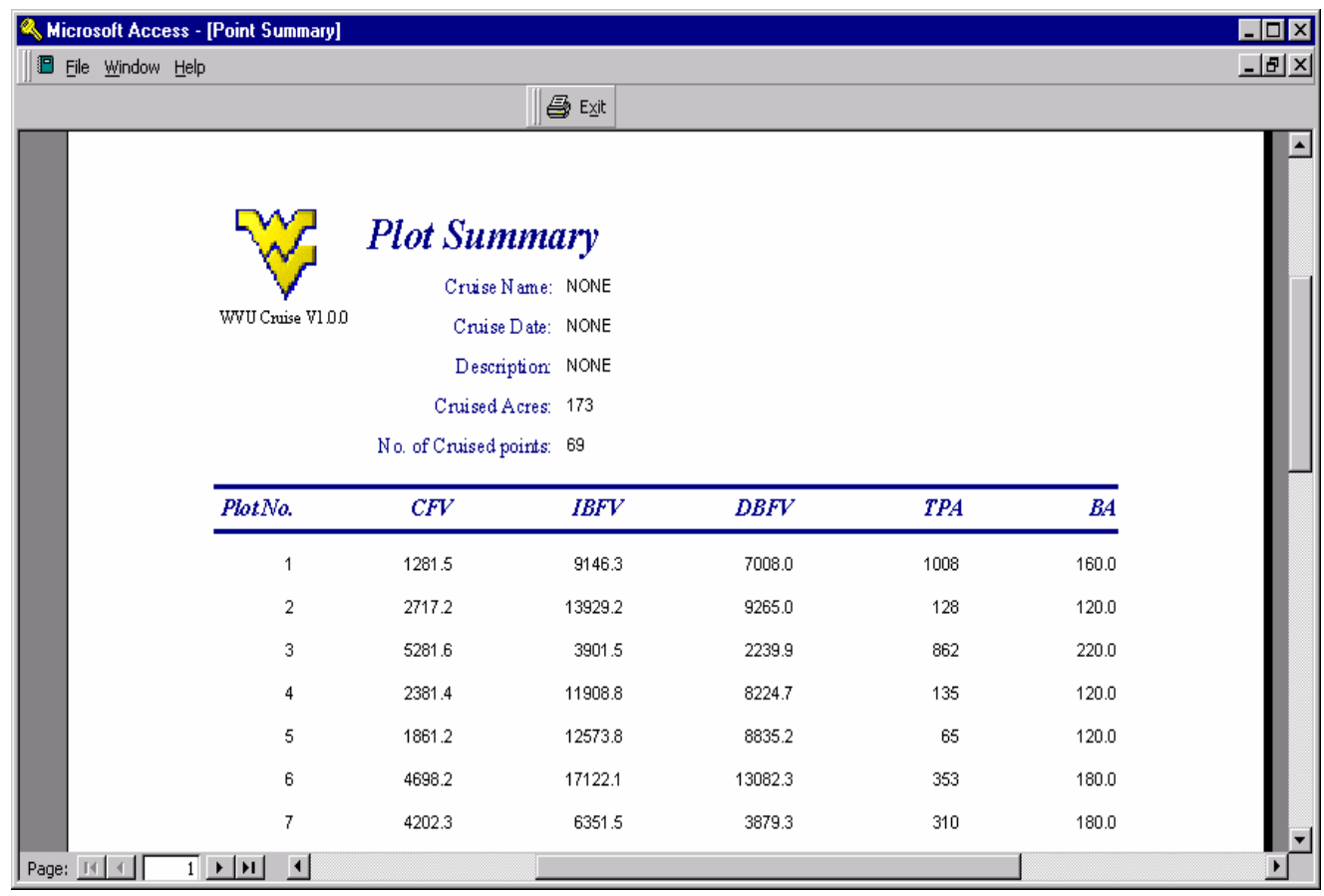

Figure A.16. Report of plot summary.

\section{By Cruise Statistics}

The cruising statistics are also provided for volume per acre in cubic foot (CFV), in International Board foot (1/4) (IBFV), in Doyle (DBFV), trees per acre (TPA), and basal area per acre (BA/A). Statistics include mean, standard deviation, standard error, variance, coefficient of variance $(\mathrm{CV})$, confidence interval at $95 \%$ level, percent of error, and sample size. The sample size will be especially useful for later cruising design.

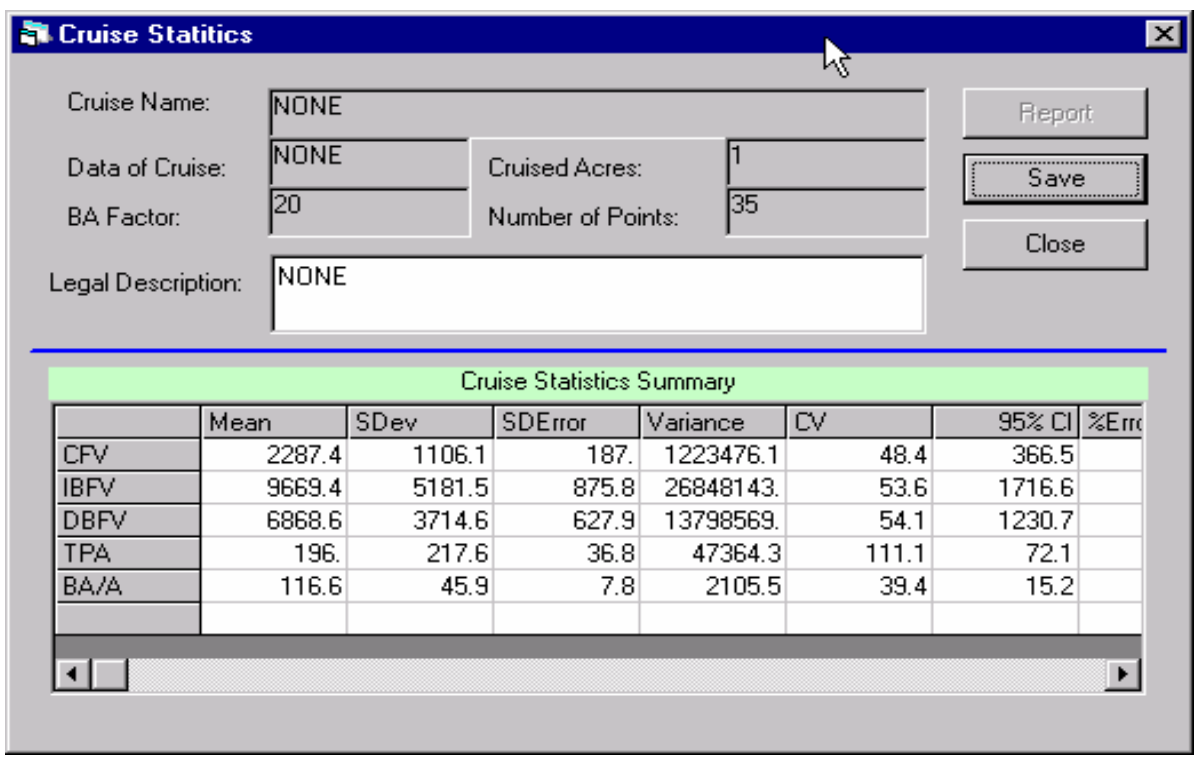

Figure A.17. Cruise statistics summary. 


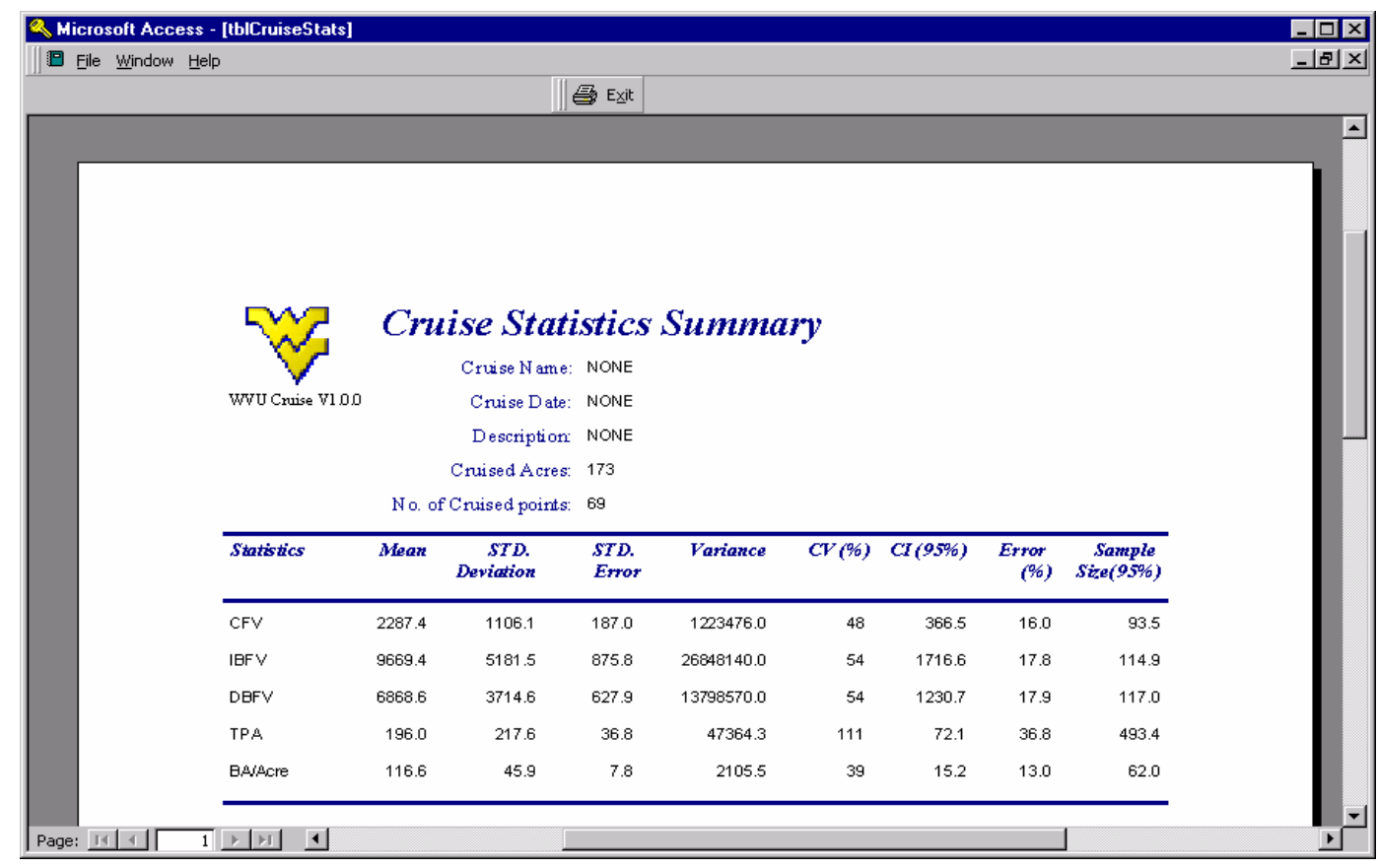

Figure A.18. Report of cruise statistics.

\section{By Stand/Stock Table}

If the user checks the "Stand/Stock" Table, a frame with items of DBH class, Species and $\mathrm{DBH}$, and Grade, species, and DBH will be enabled. Click "OK", a summary form is popped up.

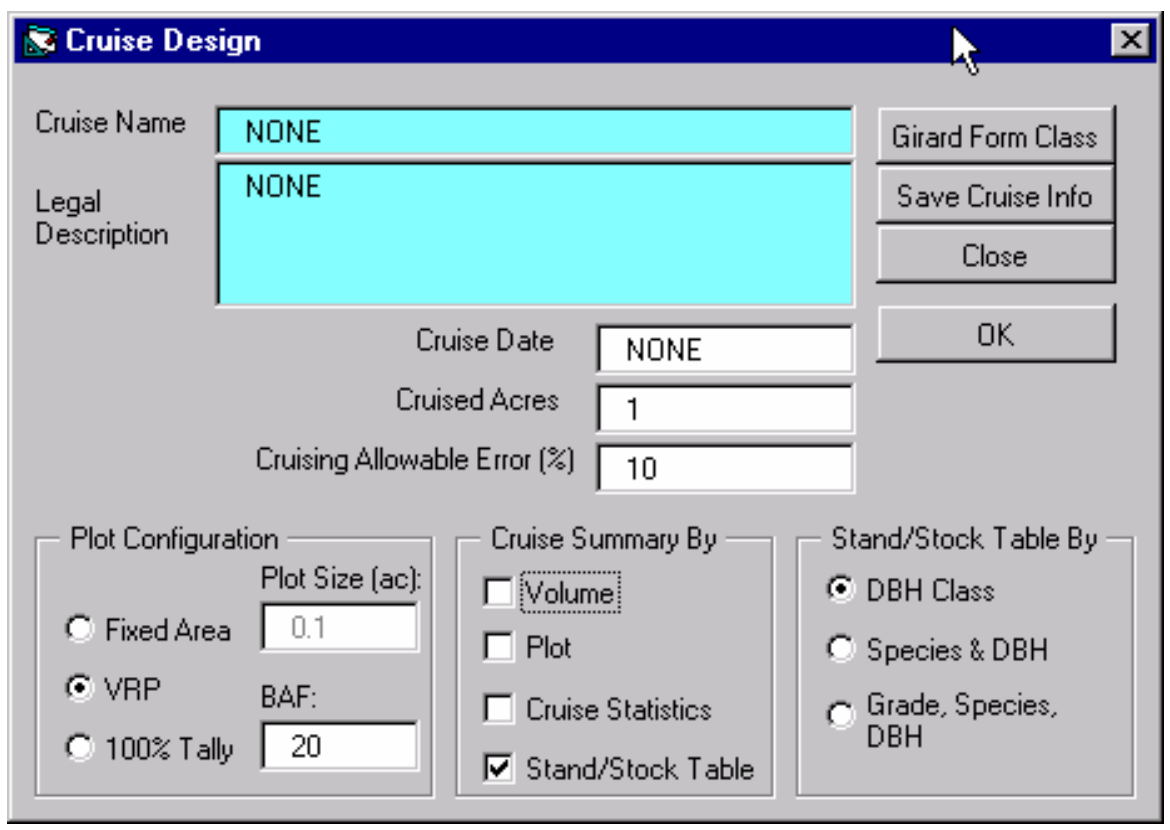

Figure A.19. Cruise design window. 


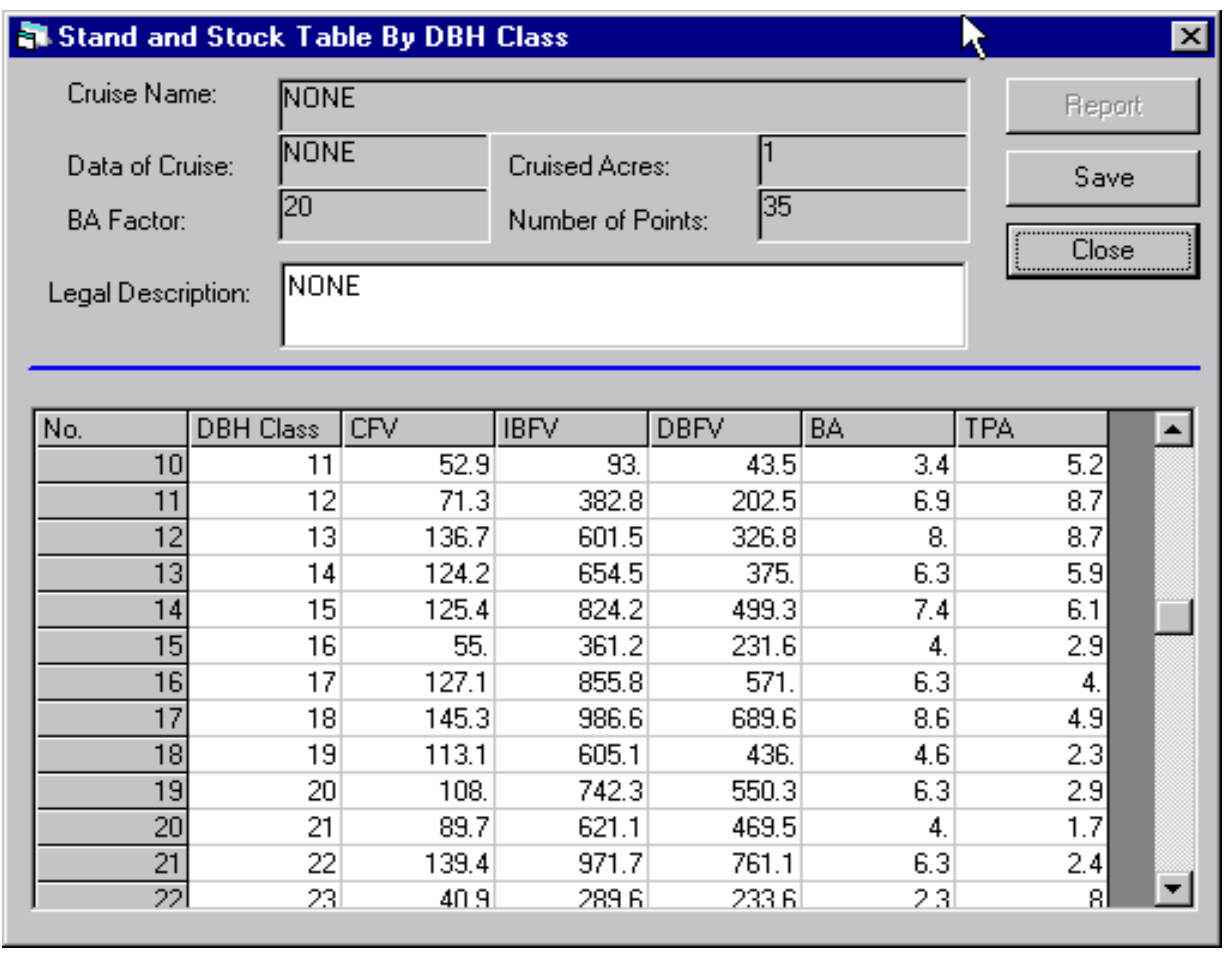

Figure A.20. Stand and stock table.

Save the data and click "Report", a report will be generated for the stand and stock table.

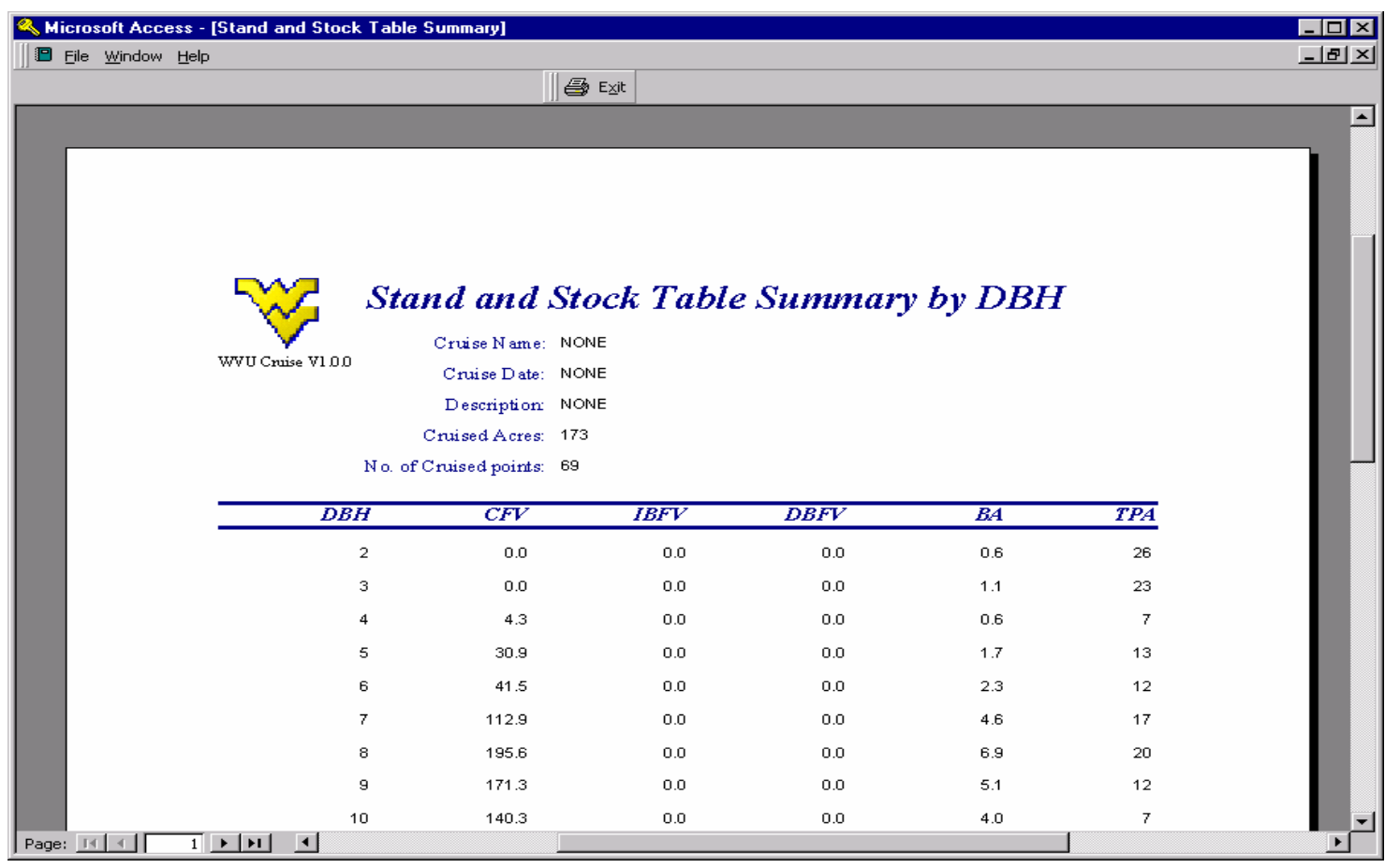

Figure A.21. Report of stand and stock table. 
Similarly, you can generate the report of stand/stock table summary by DBH class and species.

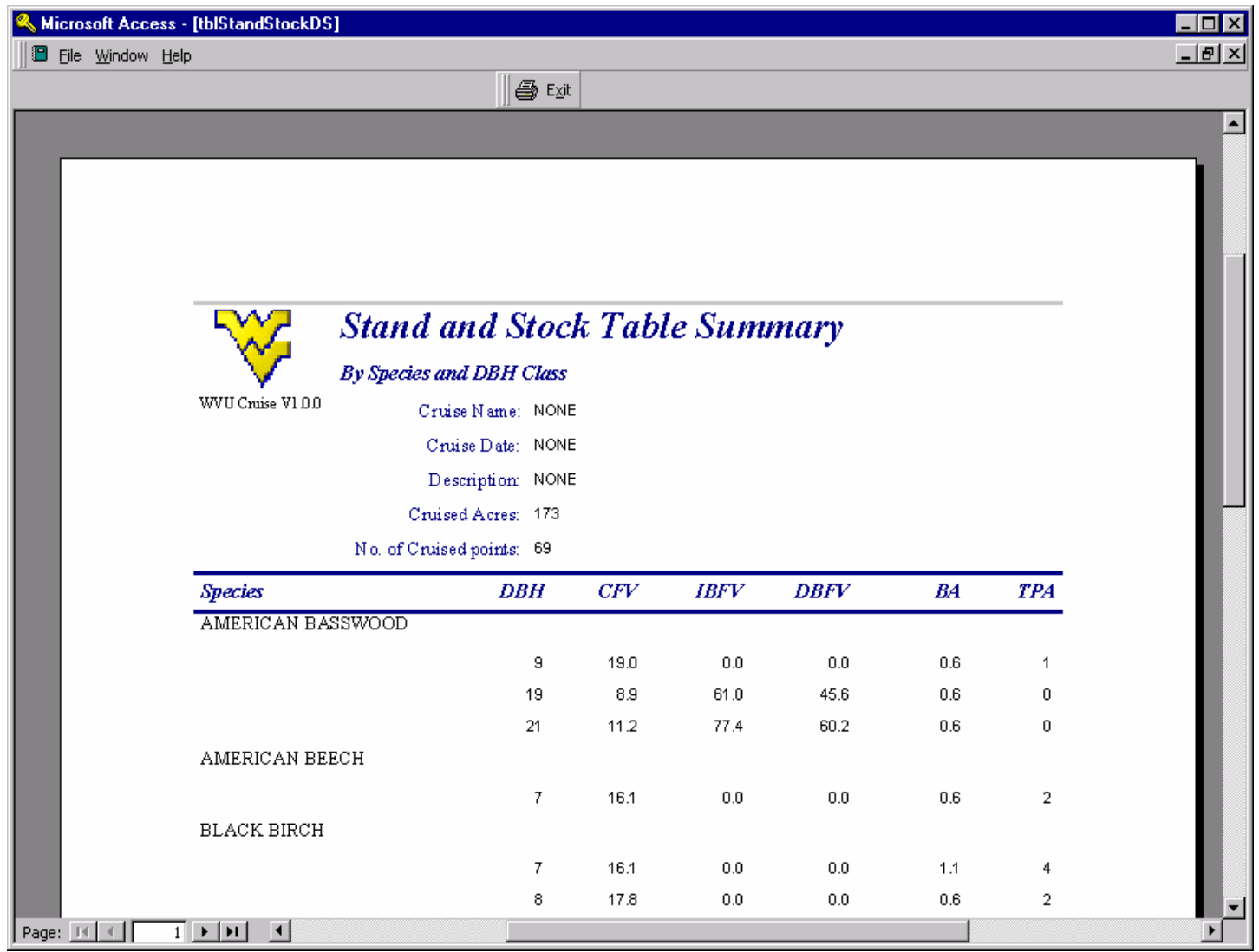

Figure A.22. Report of stand and stock table by species and DBH. 


\section{APPENDIX B: CODE LISTINGS OF SOME MAJOR FUNCTIONS}

Listing B.1. Volume calculation for a section of a log.

Public Function CalIJTermX(x As Variant, y As Variant, dbh As Variant, tht As Variant) As Variant Dim I1, I2, J1, J2, Term1, Term2, Term3, Term4, Term5, Term6

If $\mathrm{x}<=0.6034$ Then

$$
\mathrm{I} 1=1
$$

Else

$\mathrm{I} 1=0$

End If

If $\mathrm{x}<=0.1208$ Then

$$
\mathrm{I} 2=1
$$

Else

$\mathrm{I} 2=0$

End If

If $\mathrm{y}<=0.6034$ Then

$$
\mathrm{J} 1=1
$$

Else

$\mathrm{J} 1=0$

End If

If $\mathrm{y}<=0.1208$ Then $\mathrm{J} 2=1$

Else $\mathrm{J} 2=0$

End If

Term $1=0.005454154 *\left(\mathrm{dbh}^{\wedge} 2\right) *$ tht

Term $2=(2.0748 / 3) *\left(x^{\wedge} 3-y^{\wedge} 3\right)$

Term3 $=(-3.9701 / 2) *\left(x^{\wedge} 2-y^{\wedge} 2\right)$

Term4 $=(-3.9701+2.0784) *(\mathrm{x}-\mathrm{y})$

Term5 $=(-2.4816 / 3) *\left(\mathrm{I} 1 *(0.6034-\mathrm{x})^{\wedge} 3-\mathrm{J} 1 *(0.6034-\mathrm{y}) \wedge 3\right)$

Term6 $=(25.1129 / 3) *\left(\mathrm{I} 2 *(0.1208-\mathrm{x}) \wedge 3-\mathrm{J} 2 *(0.1208-\mathrm{y})^{\wedge} 3\right)$

CalIJTermX $=$ Term $1 *($ Term $2+$ Term 3 - Term4 - Term5 - Term6)

End Function 


\section{Listing B.2. Cull percent calculation.}

Public Function CalCullPCT(dbh As Variant, tht As Variant, mht As Variant, topht As Variant, bomht As Variant, seccull As Variant) As Variant

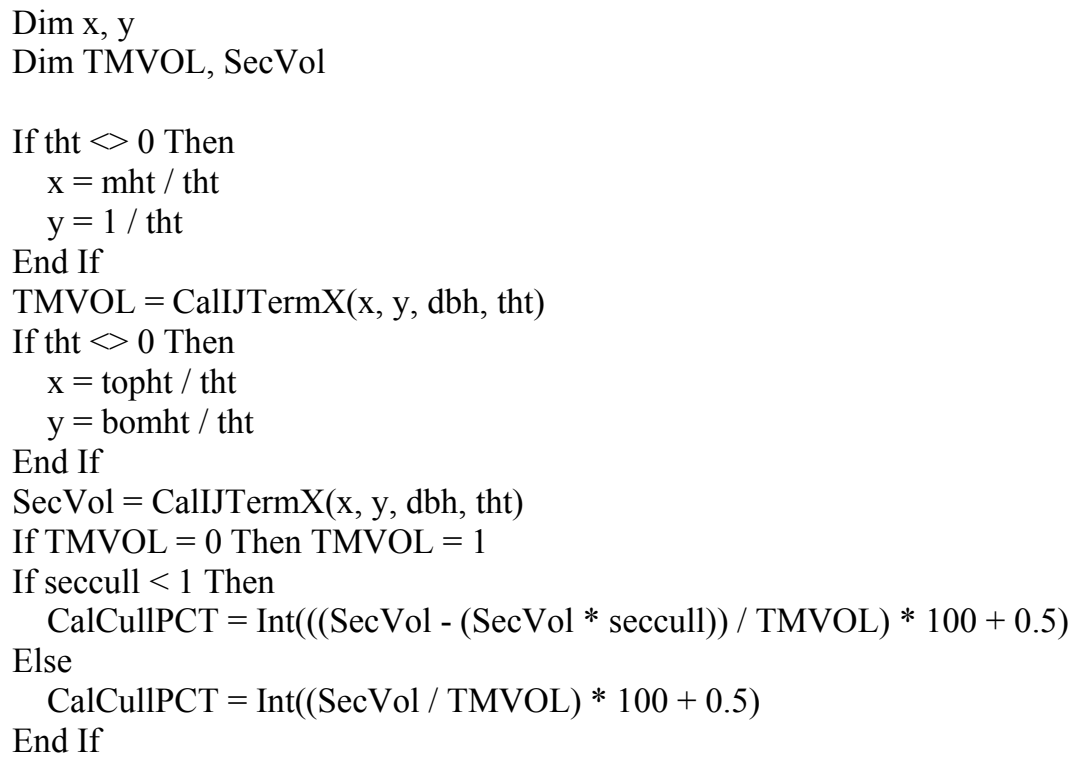

End Function 


\section{Listing B.3. Data transfer from HPC to desktop PC.}

Private Sub cmdFromHPC_Click()

Dim intStatus As Long

Dim sPath, sTableList As String

Dim nPCLoads, nPCLogs As Integer

Dim blCopyHPC, blEmptyHPC

Dim StartCopying

If Right(App.Path, 1) <> "|" Then

sPath = App.Path + "|"

End If

blCopyHPC $=$ MsgBox("This will transfer all plot, tree, and transect data on the HPC!" \& Chr(13) \& "

Are you sure you want to do that?", vbYesNo + vbExclamation, "Copying tables to HPC")

$$
\text { If blCopyHPC }=\text { vbYes Then }
$$

' Copy the tables from the $\mathrm{H} / \mathrm{PC}$ to $\mathrm{PC}$.

sPath = sPath + "dbSFCruzFromHPC.mdb"

sTableList = "tblPlot..tblTree..tblTransect.."

intStatus = DEVICETODESKTOP(sPath, sTableList, False, True, "dbCECruise.cdb")

'For updating Main Database with Handheld Data

Set dbCESFCruz $=$ OpenDatabase $($ sPath $)$

Set rsCEPlot $=$ dbCESFCruz.OpenRecordset("tblPlot")

Set rsCETree $=$ dbCESFCruz.OpenRecordset("tblTree")

Set rsCETransect $=$ dbCESFCruz.OpenRecordset("tblTransect")

' Check whether the table was copied successfully.

If (intStatus $<>0$ ) Then

MsgBox "An error occurred transferring the table: " \& intStatus

End If

'Appending Plot,Tree, and Transect data

Call AppendPlotData

Call AppendTreeData

Call AppendTransectData

End if

End Sub 
Listing B.4. Transfer plot data from HPC to desktop PC.

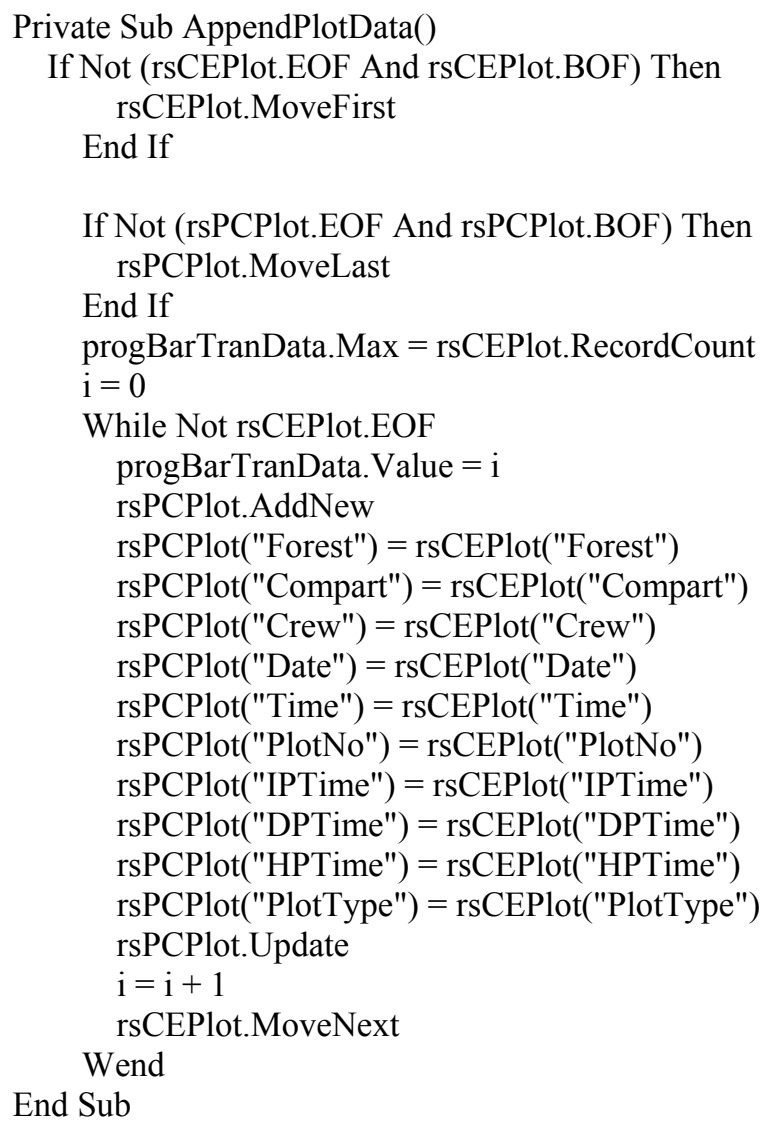




\section{Listing B.5. Volume calculation for individual tree.}

Function TreeVolume(GFC as integer, $\mathrm{L}$ as single, $\mathrm{D}$ as single, $\mathrm{APC}$ as single, $\mathrm{LR}$ as string) as single

'calculate adjustment factor for varying form class for board-foot volume

'(rule: adjust volume by $3 \%$ for each form class value above/below 78 )

If $\mathrm{GFC}=78$ Then

$$
\mathrm{AF}=1
$$

Else

$$
\mathrm{AF}=1+(\mathrm{GFC}-78) * \mathrm{APC}
$$

End if

If $\mathrm{LR}=$ "BF_INT" then "log rule international $1 / 4$ "

If $\operatorname{Int}(\mathrm{D}+0.5)>9$ And $\mathrm{L}>0$ Then

TreeVolume $=\mathrm{AF}^{*}\left(\left(1.52968 * \mathrm{~L}^{\wedge} 2+9.58615 * \mathrm{~L}-13.35212\right)+\right.$

$$
\left(1.7962-0.27465 * \mathrm{~L}^{\wedge} 2-2.59995 * \mathrm{~L}\right) * \mathrm{~d}+
$$

End if

$$
\left.\left(0.04482-0.00961 * \mathrm{~L}^{\wedge} 2+0.45997 * \mathrm{~L}\right) * \mathrm{~d}^{\wedge} 2\right)
$$

Elseif LR="BF_D" 'calculate board-foot volume in Doyle rule

TreeVolume $=\mathrm{AF}^{*}\left(\left(0.55743 * \mathrm{~L}^{\wedge} 2+41.51275 * \mathrm{~L}-29.37337\right)+\right.$

$$
\begin{aligned}
& \left(2.78043-0.04516 * L^{\wedge} 2-8.77272 * L\right) * d+ \\
& \left(0.04177-0.01578 * L^{\wedge} 2+0.59042 * L\right) * d^{\wedge} \overline{2}
\end{aligned}
$$

Else ' $\log$ rule cubic foot

If $\mathrm{L}>5$ Then 'for heights up to $6 \operatorname{logs}$

TreeVolume $=\mathrm{AF}^{*}\left(2.5984-0.32222 * \mathrm{~d}+0.01383 * \mathrm{~d}^{\wedge} 2+\right.$

$$
\begin{aligned}
& 0.05906 * \mathrm{~d}^{\wedge} 2 * \mathrm{~L}+0.0001061 * \mathrm{~d}^{\wedge} 3 * \mathrm{~L}^{-}- \\
& 0.003333 * \mathrm{~d}^{*} \mathrm{~L}^{\wedge} 3-0.005602 * \mathrm{~d}^{\wedge} 2 * \mathrm{~L}^{\wedge} \overline{2}+ \\
& \left.0.00042 * \mathrm{~d}^{\wedge} 2 * \mathrm{~L}^{\wedge} 3\right)
\end{aligned}
$$

End If

$$
\begin{aligned}
& \text { If } \mathrm{L}>0 \text { And } \mathrm{L}<=5 \text { Then 'for heights up to } 5 \operatorname{logs} \\
& \text { TreeVolume }=\mathrm{AF}^{*}(-4.5465+0.3102 * \mathrm{~d}+2.427 * \mathrm{~L}+ \\
& \qquad \begin{array}{l}
0.0478 * \mathrm{~d}^{\wedge} 2 * \mathrm{~L}+0.0004282 * \mathrm{~d}^{\wedge} 3^{*} \mathrm{~L}- \\
0.07632 * \mathrm{~d}^{*} \mathrm{~L}^{\wedge} 2+0.0001858 * \mathrm{~d}^{\wedge} 2 * \mathrm{~L}^{\wedge} 3- \\
\left.0.0001197^{*} \mathrm{~d}^{\wedge} 3^{*} \mathrm{~L}^{\wedge} 2+0.00000658 * \mathrm{~d}^{\wedge} 3^{*} \overline{\mathrm{L}} \wedge 3\right)
\end{array}
\end{aligned}
$$

End If

End If

End Function 
Listing B.6. Volume summary in the format of stand and stock table.

Sub VolSummary(NofGrade as single, NodSpecies as single, NofDClass as single, nRecord as single, PlotType as string, NofPoint as single, PlotSize as single, BAF as single)

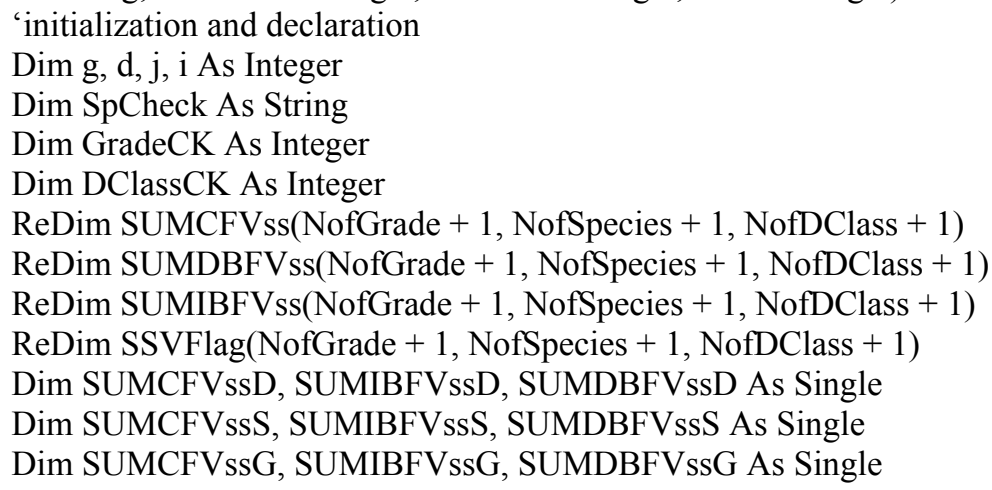

End Sub

Next $g$ 
Listing B.7. Cruise statistics for a volume estimator.

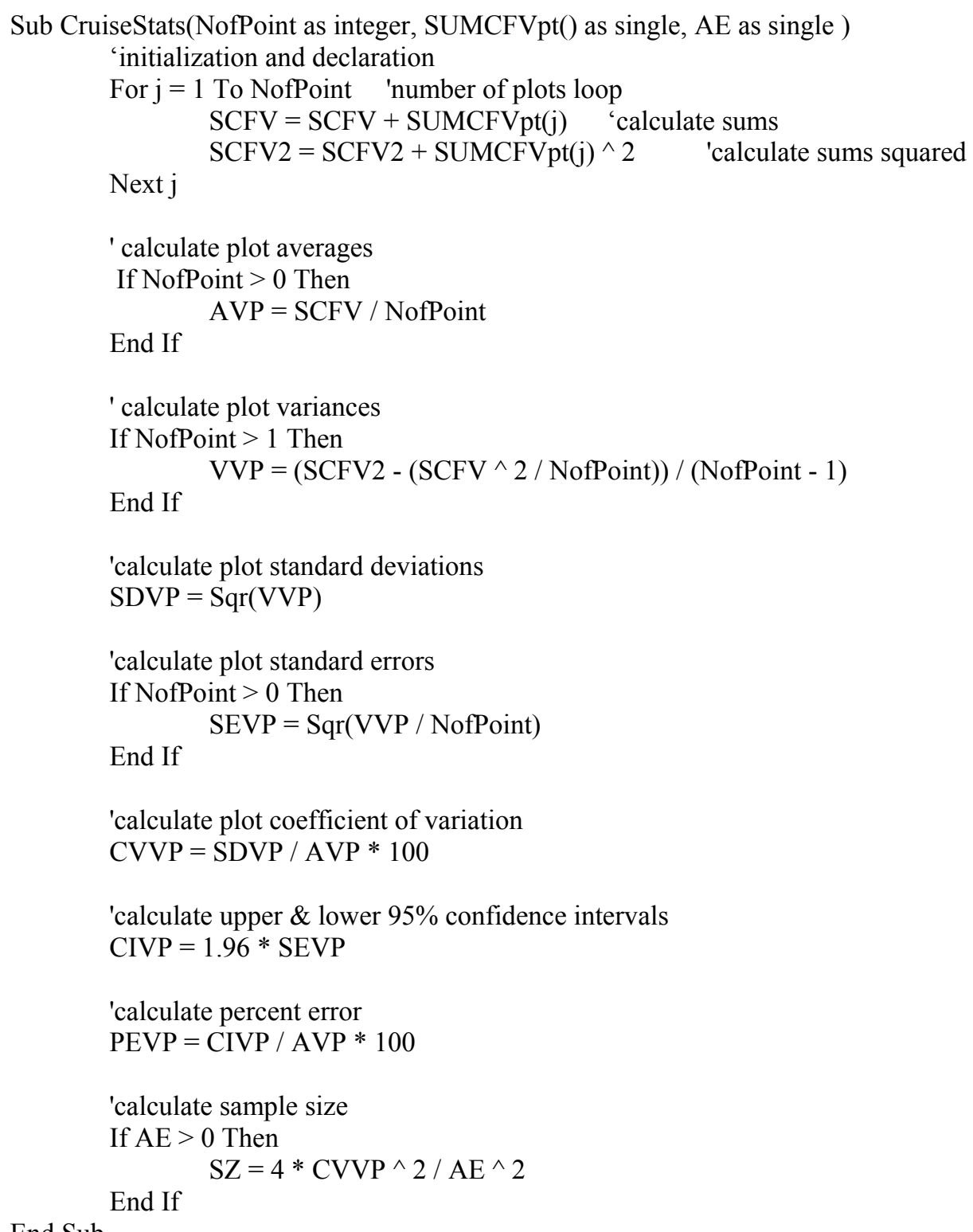

End Sub 